\title{
WestVirginiaUniversity
}

THE RESEARCH REPOSITORY @ WVU

Graduate Theses, Dissertations, and Problem Reports

2007

\section{Promoting the production of non-timber forest products}

Adam C. Riley

West Virginia University

Follow this and additional works at: https://researchrepository.wvu.edu/etd

\section{Recommended Citation}

Riley, Adam C., "Promoting the production of non-timber forest products" (2007). Graduate Theses, Dissertations, and Problem Reports. 4331.

https://researchrepository.wvu.edu/etd/4331

This Thesis is protected by copyright and/or related rights. It has been brought to you by the The Research Repository @ WVU with permission from the rights-holder(s). You are free to use this Thesis in any way that is permitted by the copyright and related rights legislation that applies to your use. For other uses you must obtain permission from the rights-holder(s) directly, unless additional rights are indicated by a Creative Commons license in the record and/ or on the work itself. This Thesis has been accepted for inclusion in WVU Graduate Theses, Dissertations, and Problem Reports collection by an authorized administrator of The Research Repository @ WVU. For more information, please contact researchrepository@mail.wvu.edu. 
Promoting the Production of Non-Timber Forest Products

\author{
Adam C. Riley \\ Thesis Submitted to the \\ Davis College of Agriculture, Forestry, and Consumer Sciences \\ at West Virginia University \\ in partial fulfillment of the requirements \\ for the degree of \\ Master of Science \\ in \\ Forestry
}
David W. McGill, Ph.D., chair
Kathryn G. Arano, Ph.D.
Joseph F. McNeel, Ph.D.
Kathryn Piatek, Ph.D.

Division of Forestry

Morgantown, West Virginia

2007

Keywords: Non-timber forest products, NTFP, special forest products, demonstration areas, entrepreneurship, case study, survey 


\title{
ABSTRACT \\ Promoting the Production of Non-Timber Forest Products in West Virginia
}

\author{
Adam C. Riley
}

Non-timber forest products (NTFPs) have long been collected for food, medicine, income, and pleasure, traditionally in rural areas. NTFPs include edible products (mushrooms, nuts, berries, etc), specialty wood products (hand carvings, walking canes, etc.), floral and decorative products (moss, vines, etc.), and medicinal products (ginseng, goldenseal, black cohosh, etc.) and reported sales contribute over $\$ 30$ million each year to the West Virginia economy.

West Virginia landowners possess some of the most biologically diverse forest in the United States. Many plants and other products can be derived from these forests for social and economic value. In order to educate, arouse curiosity, and stimulate interest, a variety of outreach methods were employed to best inform landowners about NTFPs

One method was to construct six demonstration areas (one in each of the former six Division of Forestry districts) showcasing the most commonly harvested medicinal plants. An "inoculate-your-own" shiitake mushroom workshop was also conducted at each of the sites. The second method used was to compose a booklet of ten case studies that highlighted the challenges/successes, production methods, organizational structure, and marketing methods used by landowners who started and succeeded with their own forestbased business. Finally, in an attempt to gain knowledge about the existing harvesting and interest levels among landowners, a survey was conducted that targeted four counties, two from the traditional blue-collared western region and two from the rapidly urbanizing counties in the eastern panhandle. General demographic information (age, gender, income, education, and occupation) was also collected. In addition, a landowner's willingness to pay and travel to a two-hour workshop was collected to determine future interest and workshop locations regarding NTFPs.

The survey yielded a 32\% response rate (531 valid responses; 1649 surveys mailed). Landowners who are from the western region (rural) were 2.7 times $(p=0.0105$, chi 6.55) more likely to harvest medicinal herbs than 'urban' landowners. The size of the respondent landholdings (in acres) was a significant variable in the medicinal herb, edible, and specialty wood product categories, while age was significant in all four categories. The survey also indicated that landowners who own forested land are also more willing to pay and travel to a two hour workshop than those who do not own forested land. 


\section{Acknowledgements}

Words alone cannot communicate how grateful I am for the people who have helped me along the way.

Without the innovation and the generous funding and materials supplied by the West Virginia Tree Farm Committee, none of this would have been possible. The West Virginia Division of Forestry generously supplied most of the funding for this project.

Dr. Dave McGill, my chair, has not only been an advisor to me scholarly, but someone that I look up to and admire personally. He has consistently been a mentor, motivator, and a support system for me since first accepting me into this program. Thanks also to Dr. Arano and Dr. Piatek for their assistance and encouragement with this project.

Dr. McNeel's support of all my activities has helped me immensely since first meeting him at Ryerson Station 4 years ago. I don't know where I would be without him and his faith in me.

Sean Dougherty is not only a great worker, but someone who can carry on an absurd conversation to liven up our long trips. Thanks go to Dheeraj Nelli also for helping with survey data entry and Dan Magill for proof-reading and answering my never-ending stat questions. Thanks also to Professor Stuart Moss for always having fun with me in the hallways of Percival and proof-reading our entrepreneurship questionnaire and survey.

The students at the Roane/Jackson County technical center never complained when we constructed the demonstration area down there but instead, shared stories of how to forests have played roles in a lot of their lives. They are great kids down there and I am grateful that I had the opportunity to get to know them.

Putting the demonstration areas in around the state took a lot of coordination and couldn't have been possible without the assistance of Mr. Bob Beanblossom, Ms. Barbara Breshock, Mr. John Fichtner, and Mr. Brian Wickline.

It has been a great pleasure getting to know each landowner that participated in the entrepreneurship booklet. I am grateful to all of them for enlightening conversation, welcoming me into their homes, sharing their trade, and in some cases providing me with exercise.

Finally, where would I be without the love and support from my wife, Juliana? Thank you for not only being my wife and best friend, but an answered prayer that I will treasure forever.

Trust in the LORD with all your heart and lean not on your own understanding; in all your ways acknowledge him, and he will make your paths straight. Proverbs 3: 5-6 


\section{Table of Contents}

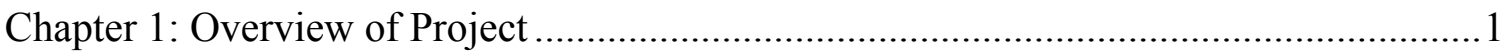

Chapter 2: Literature Review................................................................................4

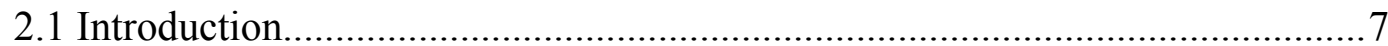

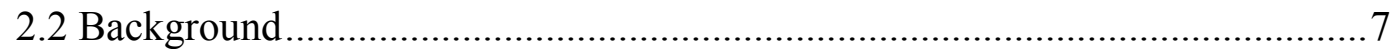

2.3 Categories of NTFPs............................................................................ 10

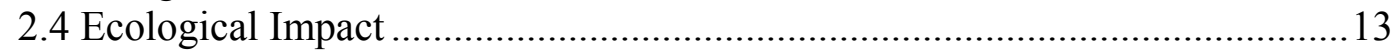

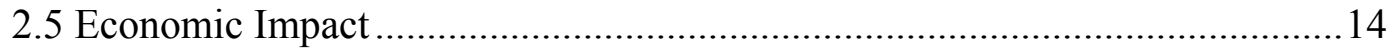

Chapter 3: Demonstration Areas ........................................................................... 15

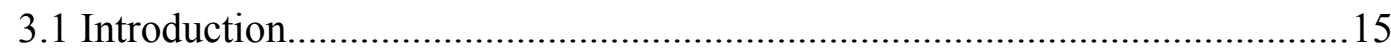

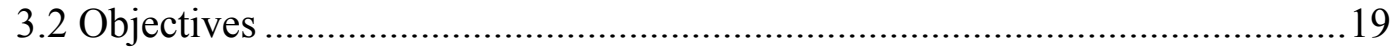

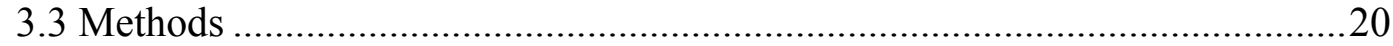

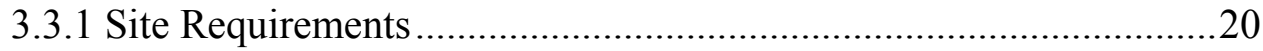

3.3.2 Controlling Shade Requirements ......................................... 21

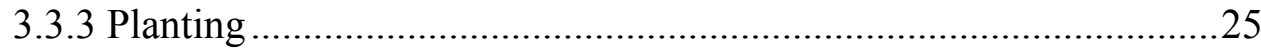

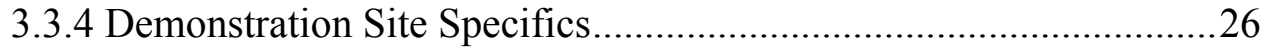

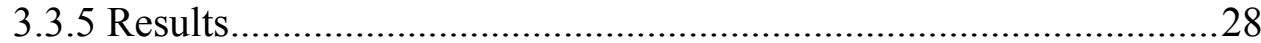

3.4 "Inoculate-Your -Own" Shiitake Mushroom Workshops ............................29

3.4.1 Introduction........................................................................29

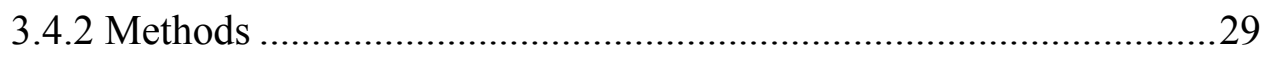

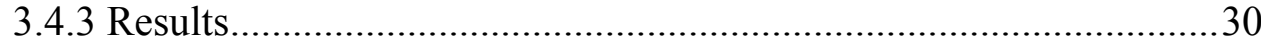

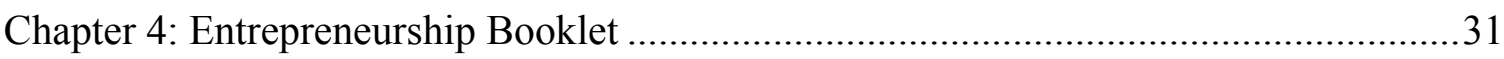

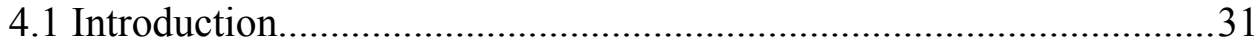

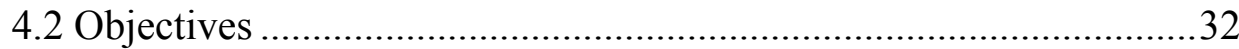

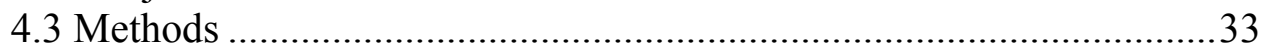

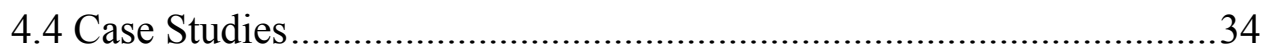

4.4.1 Appalachian Root and Herb........................................... 34

4.4.2 Crummies Creek Tree Farm ..............................................37

4.4.3 Divergent Natural Interests..............................................40

4.4.4 G \& N Ramp Farm ..................................................... 43

4.4.5 Hardscrabble Enterprises, Inc .........................................45

4.4.6 Mountain State Honey Company.....................................49

4.4.7 Mays Tree Farm...............................................................5 53

4.4.8 Peterson Paw Paws ...........................................................55

4.4.9 Richter's Maplehouse .......................................................58

4.4.10 Shady Oaks Ginseng Company ......................................6 60 


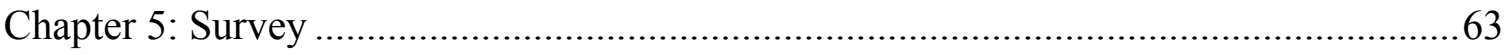

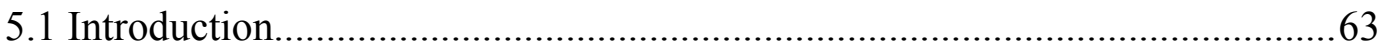

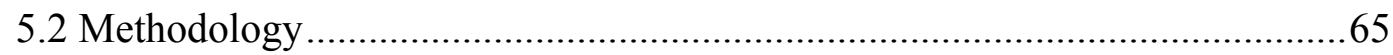

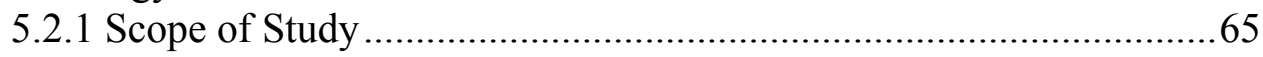

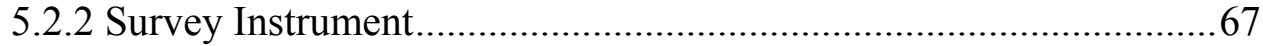

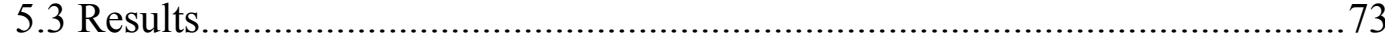

5.3.1 Survey Response...........................................................................

5.3.2 Effects of Region on Interest Level ................................................76

5.3.3 Willingness to Attend Future Workshops............................................79

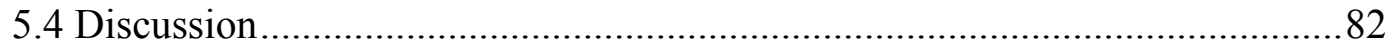

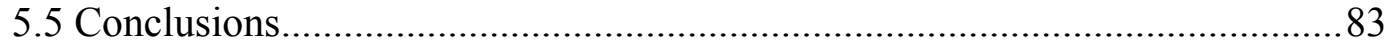

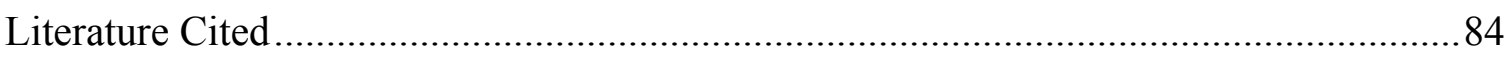

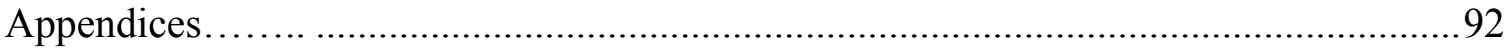




\section{List of Tables}

Table 3-1: Propagation rates of Roane/Jackson County Technical Demonstration Area .28

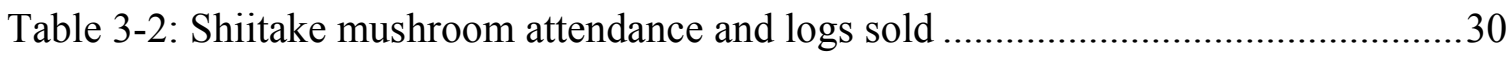

Table 5-1: Primary industry of selected counties for NTFP survey .............................65

Table 5-2: County characteristics selected for NTFP survey .....................................67

Table 5-3: Independent variables tested in logistical regression ................................. 72

Table 5-4: Categorization of the NTFP products .................................................. 73

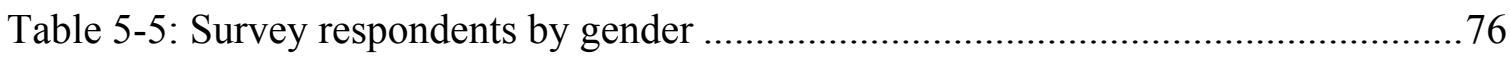

Table 5-6: Number of respondents that have owned or have thought about starting their own forest-based business ............................................................... 76

Table 5-7: Landowner property characteristics by region........................................ 78

Table 5-8: Odds ratio estimates and p-values using stepwise regression of independent variables to determine interest in NTFP categories .....................................79

Table 5-9: Landowners willingness to pay and travel to an NTFP workshop..................80

Table 5-10: Odds ratio estimates and p-values using stepwise regression of independent variables to determine willingness to pay and willingness to travel ................80 


\section{List of Figures}

Figure 3-1: Demonstration area plot layout............................................................. 21

Figure 3-2: Cable orientation for demonstration areas ..........................................22

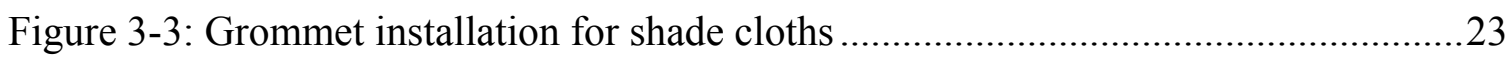

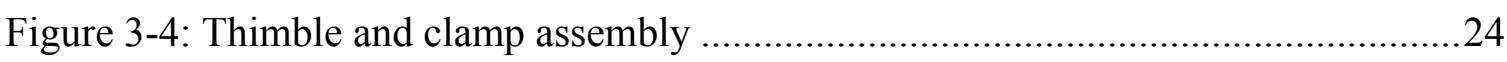

Figure 3-5: Planting arrangement for demonstration areas ......................................25

Figure 5-1: NTFP survey information by county ................................................ 68

Figure 5-2: Interest and harvest level by respondent .......................................... 71

Figure 5-3: County distribution of landowner response to NTFP survey ......................74

Figure 5-4: States from which absentee landowners responded to NTFP survey .............75

Figure 5-5: Percentages of interest in specific non-timber forest products by region....... 77

Figure 5-6: Regional landowner interest by NTFP product (harvesters excluded) ...........78

Figure 5-7: Interest levels of all responding landowners......................................... 81 


\section{List of Appendices}

Appendix 1: Former West Virginia Division of Forestry Districts ...............................99

Appendix 2: Nautical Coverage of Demonstration Areas ............................................93

Appendix 3: WVU Research Forest Demonstration Area............................................94

Appendix 4: Potomac State College Demonstration Area ............................................95

Appendix 5: Seneca State Forest Demonstration Area...............................................96

Appendix 6: Gap Mills Demonstration Area............................................................. 97

Appendix 7: Chief Logan State Park Demonstration Area ...........................................98

Appendix 8: Roane/Jackson County Technical Center Demonstration Area..................99

Appendix 9: Case Study Questionnaire ........................................................... 100

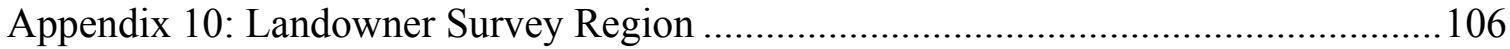

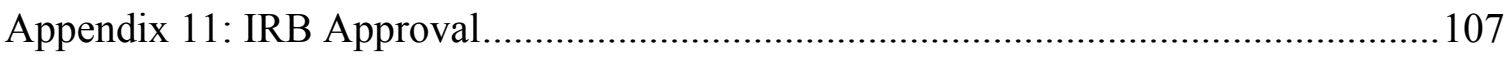

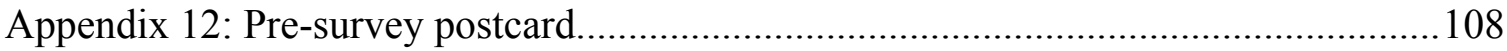

Appendix 13: NTFP Survey Cover Letter ............................................................... 109

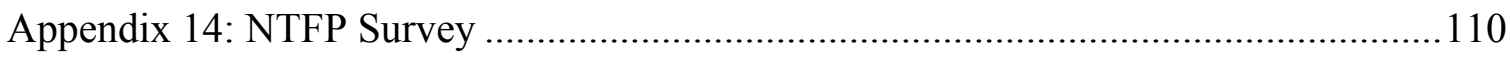

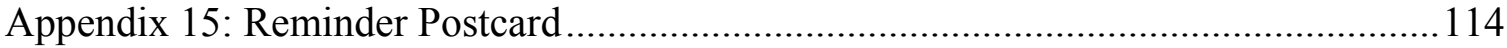

Appendix 16: Cover Letter for Follow up Survey ................................................115 


\section{Chapter 1: Overview of Project}

In Fall 2006, a collaborative project to inform West Virginia forestland owners and concerned citizens about non-timber forest products (NTFPs) was initiated between the West Virginia Division of Forestry and the West Virginia University Division of Forestry and Natural Resources. NTFPs, also called special, secondary, minor, specialty non-wood, and non-traditional forest products have long been collected for food, medicine, household income, pleasure, construction supplies, and materials for decorative and ceremonial purposes all around the world. A complete literature review, including history, definitions and categories, users, economic and environmental backgrounds is detailed in Chapter 2.

With this project, our intent was to educate West Virginia landowners about NTFPs using three methods. These methods included the use of demonstration areas placed around the state, with each displaying three of the most common NTFPs in the state along with descriptions of their respective habitat requirements. At these demonstration areas, a hands-on mushroom workshop was conducted for interested landowners (Chapter 3). Secondly, a collection of case studies of forest-based business owners was developed to provide some ideas and perspective for landowners contemplating similar enterprises (Chapter 4). Lastly, a mail survey was conducted to determine interest levels of NTFPs around West Virginia (Chapter 5) so that outreach programs might more efficiently target appropriate audiences for educational workshops. 
Initially, the project team established three goals: First, construct demonstration areas that assisted landowners in identification and habitat requirements for medicinal herbs. These six demonstration areas were strategically placed around West Virginia so that landowners could be within a one-hour drive of at least one site. The plants selected for these demonstration areas were American ginseng (Panax quinquefolius), goldenseal (Hydrastis canadensis), and black cohosh (Actea racemosa). These plants are among the most commonly harvested plants in West Virginia's forests, as well the most threatened. Though ginseng and goldenseal are not classified as endangered by the United States Fish and Wildlife Service, they are both listed on the CITES treaty, Appendix II to monitor populations for export. "Inoculate your own shiitake mushroom" workshops were also conducted at these sites to promote their use as well to educate landowners about shiitake mushrooms and how they could possible utilize their land for supplemental income. In all, 63 landowners attended the six, two-hour workshops.

The second goal of this project was completed with the development of a booklet of case studies featuring people and their enterprises that have been successful in producing NTFPs. The intent of this effort was to highlight successes and challenges in the production of various products and convey to landowners the effort needed to establish similar enterprises. The case studies provide insight into these enterprises so prospective forest-based entrepreneurs may better decide whether or not to initiate an enterprise.

The third and final goal of this project was to utilize a mail survey to gather information about interest levels of NTFPs in West Virginia. Using this survey, we asked 2,000 random 
landowners from four counties (Berkeley, Jefferson, Ritchie, and Wirt) general questions about their land (acres, years owned, last timber harvest, etc.), demographics (age, gender, income, occupation, education, etc.) as well as if they had ever or even thought about starting a forest-based business. Interest level for fourteen various NTFPs, to include ginseng, goldenseal, fruits, nuts, berries, morel mushrooms, ramps, etc. were in an easy-tointerpret figure that was used to gather interest levels of NTFPs. In addition, a landowner's willingness to pay and travel to a two-hour workshop was collected to determine future interest and workshop locations regarding NTFPs.

Through the demonstration areas, workshops, entrepreneurship booklet, and information gathered from the NTFP landowner survey, we aspired to educate West Virginia landowners that their land is worth far more than just timber stumpage value and that there are opportunities for supplemental income. 


\section{Chapter 2: Literature Review}

\section{$\underline{2.1 \text { Introduction }}$}

Non-Timber Forest Products (NTFP), also called special, secondary, minor, specialty nonwood, and non-traditional forest products (Chamberlain et al. 1998, Food and Agriculture Organization 1997, Malhotra and Poffenberger 1989), have been long collected for food, medicine, household income, pleasure, construction supplies, and materials for decorative and ceremonial purposes all around the globe (Jahnige 2002). Examples of NTFPs include fruits and berries, nuts, spices, medicinal extracts, oils, gums, resins, charcoal, cones, seeds, smokewood and flavorwood, greenery and other floral products, honey, mushrooms, specialty wood products, syrup, weaving and dying materials, aromatics, and fishing (Thomas and Schumann 1993). Throughout the United States, NTFPs are economically and environmentally important and interests in these products are growing rapidly (Hammett and Chamberlain 1998). In many areas, rural populations have traditionally depended on local forest resources to provide additional income through collection and sales of NTFPs. Where employment opportunities from traditional industries are declining, workers looking for alternative income sources often turn to collection of these products from nearby forests (Hammett and Chamberlain 1998). Specifically in West Virginia, where rural communities that depend on the timber and coal industries often have fluctuating periods of employment, NTFPs play a significant role in alternate income and interest in these products is expanding tremendously (Bailey 1999).

Appalachia is host to some of the areas of greatest living biodiversity in North America (Weinberg and Shackleford 1977). "No other region in North America hosts so much 
living diversity, than Appalachia," notes Constantz (1994). The mountainous, deciduous forests of West Virginia contain one of the greatest varieties of forest products, timber and otherwise, in the United States, enabling the region to be a major source of NTFPs (Nature Conservancy 1977). In West Virginia, forests comprise 78 percent (12 million acres) of the state's 15.4 million acres of land. Hammett and Chamberlain (1998) note that NTFPs have economic and social values that surpass even timber products in some areas of southwestern Virginia and are vital to many forest based communities. Increasing pressure is placed on forests to produce various products as communities seek ways to economically benefit from their natural resources (Padoch 1992, Peters et al. 1989).

Despite being ranked $41^{\text {st }}$ in size (acres) among all 50 states, West Virginia ranks as the third most heavily forested state in the nation from the standpoint of percent forest cover, and ranks second in total hardwood sawtimber volume in the nation, following only Pennsylvania, with 22.3 billion cubic feet of hardwood growing stock (Widmann 2003). West Virginia's wood products contributes more than $\$ 4$ billion annually to the state's economy, and in 2006 provided nearly 30,000 jobs statewide, had payrolls amounting to $\$ 703$ million, and generated $\$ 45.4$ million in taxes (Childs 2005). In 2000, over 88 percent of timberland in West Virginia was owned by private parties, including individuals, corporate businesses, farmers, and the forest industry (Childs 2005).

Magill et al. (2004) estimated that less than 15 percent of the over 250,000 non-industrial private forest (NIPF) landowners in West Virginia have received little, if any, forestry assistance from 1990 to 2000 . Forestry assistance to NIPFs is provided either by 
consulting foresters or by the West Virginia Division of Forestry (WVDOF). The DOF offers assistance with forest management planning, tree planting, forest road development, recreational development, wildlife habitat enhancement and timber sales assistance (West Virginia Division of Forestry 2007).

West Virginia's forests contribute to the state's economy in many ways other than the harvesting and processing of timber. Landowners are now discovering that NTFPs create opportunities for generating supplemental income. Additional expertise and technical assistance outside the realm of forestry is often required, but is even less available to rural landowners. Magill et al. (2004) states that producing these products are of interest to West Virginia landowners, especially those who are also interested in traditional timber production, wildlife management, and recreational opportunities. In addition, market value and demand for NTFPs have grown considerably over the last decade while declining revenues from timber in some areas has led foresters to consider the values of a wide variety of commodities other than timber (Savage 1995). McLain and Jones (2002) stress that managing forests in ways that expand the availability of NTFP species may substitute in part for jobs lost in the wood-products industry. Von Hagen et al. (1996) suggest that NTFPs may be a good economic opportunity for rural people and that agroforestry systems, which incorporate NTFPs, can be highly beneficial for generating additional income. In the Pacific Northwest, NTFPs are considered to be the most viable option for strengthening those rural communities suffering from the decline in timber harvests from government lands (Hammett and Chamberlain 1998). Astute landowners, willing to make the effort, may improve their forest-based incomes by gathering and marketing NTFPs 
(Chamberlain and Predny 2003). However, even with diverse income sources, collectors often are in a low-income bracket or live below the poverty level (Browder 1992).

\section{$\underline{2.2 \text { Background }}$}

NTFPs fall under a variety of definitions. The United Nations Food and Agricultural Organization (FAO) defines them using categories, broken down into foods, such as wild edible mushrooms, fruits, nuts, and berries; medicinal plants and fungi; floral greenery and horticultural stocks; fiber and dye plants, lichens, and fungi; and oils, resins, and other chemical extracts from plants, lichens, and fungi (Thomas and Schumann 1993). Chamberlain et al. (1998) define NTFPs as "plants and parts of plants" that are harvested from within and on the edges of natural and disturbed forests. The Pennsylvania Department of Conservation and Natural Resources (DCNR 2005) identify NTFPs as "plants or plant parts" that have perceived economic or consumption value sufficient to encourage their collection and removal from forests. Fox (1994) describes NTFPs as "non-timber biological materials" extracted from forests for human use.

NTFP uses in the United States are neither new nor merely old-fashioned remnants of some distant culture (Emery 2002). Native Americans traditionally used plants for a variety of reasons, to include food, shelter and religious ceremonies. Chamberlain et al. (1998) state that Native Americans used bark for housing, branches and stems for utensils and tools, and wood for containers and other products. The first European settlers brought with them their own NTFP knowledge and practices as well as items essential to sustain their lives: a supply of food, tools, and seeds to start crops, and when these resources were 
depleted, they took to local resources and learned from the Native Americans about the local forests for their vital needs (Emery 2002). Munson (1989) mentions that the relationship was sometimes multi-directional, stating that the early Native Americans consumed processed maple sap only as syrup. European settlers, who learned to harvest and process maple from Native Americans, introduced the iron kettle for boiling. A common practice learned from Native Americans was the mixing of certain medicinal plants, such as ginseng and sassafras that were believed to contain health promoting properties, to produce a 'folk medicine'. This was done throughout the present day northeastern United States and persisted almost exclusively in the remote, mountainous regions until the early 1900s (Cavender 2003).

Knowledge gained from early Native Americans forms the foundation of the herbal medicinal industry today in the United States (Chamberlain et al.. 1998). Foster and Duke (2000) list the medicinal properties for over 500 plant species common to the Eastern and Central United States that up to 5,000 generations of Native Americans discovered. Some of the plants important to the native tribes included sassafras (Sassafras albidum), marshmallow (Althaea officinalis), and wild indigo (Baptisia tinctoria); (Coon 1979). Sassafras tea quickly gained popularity as a tonic and was an important species for early European settlers. It is widely believed that it was one of the first exports from the New World to Europe and assisted in financing the Plymouth colonies (Coon 1979, Foster and Duke (1990). American ginseng (Panax quinquefolius) was found growing in northeast North America and was quickly sent to China for comparison against their prized panacea root, Asian ginseng (Panax ginseng). The roots were found to have similar medicinal properties and the first export from New England was arranged in 1720 (Foster 1995). 
By the 1800 's many settlers in the Northeast continued to rely on NTFPs while exploration and the NTFP industry started changing (Chamberlain et al.. 1998, Emery 2002). Due to a port blockade during the Civil War, the Confederate government was in dire need of medicine when they pulled a field surgeon from his duties to explore the forest for medicinal plants that might be used instead of the traditional European imports. The surgeon reported more than 400 substitutes, including Cornus florida (dogwood, a quinine substitute), Liriodendron tulipifera (tulip poplar, for fevers) and Liquidambar styraciflua (sweetgum, for diarrhea) (Percher 1970).

In the 1900s, the discovery of synthetic material that could be substituted for natural products led to an almost total rejection of medicinal plant remedies and produced many medicinal frauds. This led to government intervention that resulted in legislation requiring that drugs be proven safe, labeled correctly, and tested for efficacy (Chamberlain et al. 1998).

NTFPs, edible mushrooms in particular, became popular in the Pacific Northwest during the 1990s after many loggers were displaced or laid off due to the decline of timber harvesting on national forests in that region. Because of this surge of activity, the USDA Forest Service and other agencies started studying the market potential for NTFPs. Medicinal researchers also investigated uses for NTFPs, to include taxol (an extractive from the tree Pacific yew (Taxus brevifolia)) that has been approved by the Food and Drug Administration (FDA) to fight ovarian cancer and some forms of breast cancer (Chamberlain et al. 1998). 


\section{$\underline{2.3 \text { Categories of NTFPs }}$}

An evaluation of market opportunities for NTFPs in Minnesota established six major categories of NTFPs: cones, decorative greenery, floral and ornamentals, herbs and medicinals, decorative woods, and smokewoods/flavorwoods (Mater 1993). The NTFP industry in the Northern Rockies recognizes five categories: floral greens, Christmas ornamentals, wild edible mushrooms, other edibles and medicinals, and Pacific Yew (Schlosser et al. 1995). The United States Forest Service adheres to five general categories: floral and decorative, medicinal, herbal, edible, and specialty wood products (Dix 1996). The most recent classification, Chamberlain et al. (2000) of the National Agroforestry Center in Blacksburg, Virginia, classifies NTFPs into four distinct categories: edibles, specialty wood products, floral greens, and medicinal and dietary supplements.

Because Chamberlain's research is the most applicable to our region, his classifications will be illustrated. Examples of edible forest products, mushrooms in particular, are perhaps the most well-known and documented forest product. Other recognizable products in this category include maple syrup, fruits like paw paw (Asimina triloba), persimmon (Diospyros virginiana), grapes (Vitis spp), various nuts such as acorns (Quercus spp), chestnuts (Castanea spp), walnuts (Juglans spp), and blueberries and blackberries. Fiddlehead ferns, wild leeks (Allium tricoccum), and wild harvested watercress are a few herbaceous plants that may appear in fine restaurants (Chamberlain et al. 1998, Facemire 2007). 
Specialty wood products are considered non-timber if they are produced from trees or parts of trees but not sawn wood (Chamberlain et al. 2000). Products common in the Appalachian region include handicrafts, carvings, turnings, utensils, containers (baskets), and special furniture pieces.

Floral greens are mainly used in decorative arrangements. The end uses for many forest harvested floral greens include fresh/dried flowers, aromatic oils, greenery, basket filler, wreaths, reindeer moss, and roping.

Medicinal and dietary supplements have a long history and may constitute the highest valued segment of the industry (Chamberlain et al. 2000). Such supplements come from plants like American ginseng, goldenseal (Hydrastis canadensis), black cohosh (Actaea racemosa), bloodroot (Sanguinaria canadensis), St. John's Wort (Hypericum perforatum), and various species of Echinacea (Echinacea spp). Several tree species can also be of medicinal value, to include, but not limited to: white oak (Quercus alba), slippery elm (Ulmus rubra), ginkgo (Ginkgo biloba), sassafras, flowering dogwood, sweetgum, and willow (Salix spp). Chamberlain et al. (1998) notes that plants that meet strict FDA standards are marketed as medicinal products. Examples of these products include Pacific yew, fox glove (Digitalis purpurea) and lobeline (Lobelia inflata). Products that do not meet the strict FDA standards are marked as dietary supplements in the United States. These products are legally considered food items and product labels can make no claim about their medicinal benefits. The most common of these are American ginseng, goldenseal, St. John's wort, gingko, and black cohosh. 
NTFPs typically fall into two types of production classifications: corporate enterprisebased or traditional household-based. Corporate enterprise-based systems usually are only worthwhile for large-scale removal of a highly valuable NTFP (Browder 1992). A prime example of this type of extraction is taxol, a phytomedical compound extracted from Pacific Yew bark, which is approved by the FDA as a cancer treatment (Savage 1995). Traditional household-based extraction of forest products includes the harvesting of forest plants or plant parts for personal use.

The Pennsylvania DCNR (2005) classifies NTFP harvesters into five general categories:

I. Incidental collectors are those who collect a small quantity of a material for immediate consumption, usually on site. An example of this would be a camper who collects a handful of leeks to flavor the evening meal.

II. Recreational collectors collect materials for home use and consider the collecting experience to be a recreational outing. Having a family picnic with the intention of also picking blueberries to take home for canning or pies exemplifies this group.

III. Ceremonial collectors are those who gather NTFP to use in religious ceremonies or those to whom the harvesting of an NTFP in their traditional manner is part of religious or cultural custom. Huckleberry (Vaccinum spp) is a sacred food among Native Americans and its gathering has long been the focal point for renewing kinship and cross tribal social ties (Emery 2002).

IV. Subsistence collectors are those who rely on NTFP to provide a significant part of their, food, medicine, or shelter. 
V. Commercial collectors are those who collect, sell, or trade in NTFP either to provide supplemental income or as a principal form of employment or business.

\section{$\underline{2.4 \text { Ecological Impacts }}$}

The impacts of harvesting these non-timber forest products are difficult to determine because many of these products are either gathered for personal use or the data are not readily available on supply and demand. In fact, it is estimated that more than 100 herbaceous forest perennials native to the United States are at risk of extinction (Robbins 1999). These forest resources could soon be lost if over-harvesting continues (Chamberlain et al. 1998). Although not listed as endangered, wild populations of American ginseng and goldenseal have diminished not only from West Virginia's forests, but also throughout their natural range from Canada to Georgia and westward toward Wisconsin. International trade of many NTFPs is now regulated through the Convention on International Trade in Endangered Species of Wild Fauna and Flora (CITES; See Appendix II), which includes species not necessarily threatened with extinction, but in which trade must be controlled in order to avoid over-harvesting with their survival (CITES 2006).

Several signs of over-harvesting have become apparent within the past decade. Since 2002, harvesting of ramps, or wild leek, has been banned in the Great Smoky Mountains National Park until sustainable populations can be achieved once again (Rock et al. 2003). The Monongahela National Forest in eastern West Virginia no longer issues collection permits for moss. Permits will then again be issued when sustainable population levels can be achieved (Tompkins 2004). 
Non-timber forest products are an integral part of sustainable forest management (Hammet and Chamberlain 1998). Management plans that consider these products lead to a more holistic depiction of the ecosystem that is to be managed. However, Chamberlain et al. (2002) researched 32 eastern national forests and found that only seven had NTFPs in their management plans. Kays (1998) states that income will also be more "sustainable" as the products generated will be marketable in shorter cycles than the conventional timber crop.

Humans are not the only factor affecting herbaceous plant populations. Another factor that affects understory plants is deer browsing. McGraw and Furedi (2005) estimate that the state's ginseng populations, as well as other valuable understory herbs are likely to become extinct in the coming century because of the deer population density in West Virginia.

\section{$\underline{2.5 \text { Economic Impact }}$}

West Virginia's forest product diversity can allow landowners to possibly generate revenue year round. According to the West Virginia Trappers Association (2007), wild ginseng sold for as high as $\$ 510 /$ dry pound and goldenseal root as much as $\$ 23 /$ dry pound (West Virginia's Fur Trappers Association 2007). Fruits, nuts, and berries directly contributed $\$ 11.4$ million annually to the state's economy in 2002. In 2002, harvested tree transplants used in the nursery and tree production business contributed $\$ 8.6$ million in 2002 (Childs 2005). The floral green industry is a million-dollar a year business for one southern West Virginia moss collector (Smith 2005). 


\section{Chapter 3: Demonstration Areas}

\section{1: Introduction}

Non-timber forest products were harvested long before timber was marketable. For generations people have depended on forests for food, shelter, medicine, and recreation. West Virginia has the ideal habitat for most shade tolerant medicinal plants and various edible forest products (mushrooms, berries, etc.). According to Adams (2002) the interest in propagating and marketing non-timber products such as ginseng, black cohosh, and goldenseal is rising among resource professionals and forest landowners. With the increase in interest has come a decrease in plant populations due to over-harvesting and to deer browsing. For various medicinal plants, such as ginseng and goldenseal (both of which are protected by government treaty) the populations have been diminishing and had government intervention not occurred, these species could possibly be extinct (CITES 2005).

One way to promote the protection and cultivation of threatened plants is through education. A common educational tool used for Extension programs are outdoor demonstration areas (Harmon and Jones 1997). People young and old seem to prefer to learn in this manner (Riesenberg and Gor 1989). Demonstration areas have proven to be effective and may better involve the public and lead to a deeper understanding of sustainability (Saunders et al. 2005). Because of the lack of technical assistance that nonindustrial private forest landowners in West Virginia receive (Fraser and Magill 2000), education about non-timber forest products and their relationship to timber harvesting and the specific site requirements to produce these products is needed. If a landowner is 
interested in making additional income from his/her forest, they must understand methods to harvest non-timber forest products from the same area as timber (Mater 1997). To help facilitate an educational program on non-timber forest products, easily accessible demonstration areas should be established throughout the state.

Most (58\%) of the forestland in the United States is privately owned (Downing and Finley 2005). Private forestland ownership is changing. New owners include retirees, professionals, and white-collar workers (Birch 1996). Shifting ownership patterns coupled with increased societal demands for forest products emphasize the need to deliver relevant information and service to an ever increasing and changing forest owner population. Reaching these landowners can be challenging. Demonstration areas of medicinal plants by Purdue University, University of Kentucky, and the University of Missouri have all been installed and are still used in educational outreach (Adams 2002) by these institutions.

Forest management expertise is available to landowners with at least 10 acres through the West Virginia Division of Forestry, which makes them eligible for cost-share programs that will support management on their private lands. But traditional forest management activities are usually secondary in importance to other products and values on private lands and landowners frequently need assistance to achieve these non-traditional objectives. Non-timber forest products are often part of these objectives. These NTFPs require additional expertise outside of the realm of conventional forestry and technical assistance for NTFPs is even less available to rural landowners. The outdoor field demonstration is a 
popular learning tool for Extension programs; however evaluations of educational effectiveness are surprisingly rare (Harmon and Jones 1997). Because money is limited in Extension education, it should be spent providing programs that have been demonstrated to be effective (Andrews 1983).

The demonstration areas that were constructed for this project showcase the varying degrees of shade, simulated by polypropylene cloth, to illustrate how shade (overstory composition) affects plant growth and available soil moisture. Inside the artificial shade plots, plants will be showcased to aid in proper identification of specific forest plants that thrive in shaded areas.

The plants chosen for these demonstration areas are American ginseng, goldenseal and black cohosh. These plants were selected not only because of the economic value to the state, but because of their diminishing populations.

American ginseng is a plant that has been long sought after by entrepreneurs in North America, specifically the eastern United States. It was first 'discovered' near Montreal, Canada in 1716 by a Jesuit Missionary who sent word to the orient that he found a plant that resembles their prized ginseng. Since then, wild ginseng has been exported to the Orient for a high price. French fur traders were quickly buying as many wild ginseng roots as possible for $25 \notin /$ pound and selling it in China for over $\$ 5 /$ pound, and by 1752 , were selling over $\$ 100,000$ in ginseng (Emery 2002). By the late 1800's, growers started cultivating ginseng under shade panels and under natural forest canopy, with this 
cultivation method have some success (Emery 2002). In more modern times, the average price per pound for ginseng root in West Virginia usually tops at \$350/pound (Scott et al.. 1995), but rose to over \$500/pound in 2006 (West Virginia Trapper Association 2007).

Carroll and Apsley (2004a) describe the four ways in which ginseng is grown or found in the Appalachian region. They are:

I. Wild ginseng occurs naturally in the forest, commonly on north or east facing aspects with a gentle slope under a deciduous canopy.

II. Wild-Simulated ginseng occurs by intentional planting efforts with ginseng seed or rootlets in an ideal site.

III. Woods-Cultivated ginseng occurs under any forest canopy that provides adequate shade in a raised planting bed.

IV. Field Cultivated ginseng occurs under artificial shade (commonly polypropylene weaved cloth but sometimes wood panels) in a raised bed in an open setting. Park (2003) estimates that Asian ginseng (Panax ginseng) has been cultivated in China for nearly 1,500 years.

Goldenseal is another plant with economic value that is commonly harvested in West Virginia's forests. Bailey's (1999) research in southern West Virginia found that many diggers harvest goldenseal before the ginseng season starts to help identify where ginseng plants might be. According to the West Virginia Trapper Association (2007), goldenseal root brought $\$ 23 /$ pound while the leaves (herb) sold for $\$ 3.25 /$ pound. In Pennsylvania, goldenseal root reached \$40/pound in 1999 (Burkhart and Jacobson 2006). 
Black cohosh is also a commonly harvested medicinal herb and is suffering from habitat degradation due to logging activity and developmental properties. Because of its medicinal properties, specifically reducing levels of a hormone associated with hot flashes, it is becoming one of the most important medicinal herbs of the $21^{\text {st }}$ century (Carroll 2005, Foster and Duke 2000). Site requirements for goldenseal are the same as that of American ginseng, preferring north and/or east facing aspects, moderate slope with adequate drainage and heavy overstory composition. Black cohosh can also strive in these moist situations, as well as in forested areas that allow for more light to the forest floor.

Demonstration areas were established in each of the former six West Virginia Division of Forestry districts. Each site is set up with four 10 -foot by 10 -foot plots, each with varying degrees of shade provided by black woven polypropylene shade cloth (ranging from $0 \%$ to $80 \%)$. Thirty transplant rootlets for each ginseng, goldenseal, and black cohosh were planted per plot, for a total of 120 rootlets per site. In addition to the plants being presented at the demonstration sites, shiitake mushroom (Lentinula edodes) workshops, a hands-on, "inoculate-your-own" activity were conducted to educate interested landowners on inoculation of shiitake spawn in host logs for small scale mushroom production.

\section{2: Objectives}

There were two main objectives for this project. First, to establish the six demonstration areas (one in each of the former WVDOF Districts) (Appendix 1). This was accomplished by communication with WVDOF personnel, as well as one private landowner. This 
strategic placement of demonstration sites covers over $96 \%$ of West Virginia within 60 nautical miles (Appendix 2).

The second objective was to carry out technical sessions/field workshops for private landowners. The workshops were an "inoculate-your-own” shiitake mushroom workshop, where participants learned inoculating procedures for shiitake mushrooms, as well as successful tips for care during the incubation stage of the fungus. Shiitake mushrooms are an example of a different NTFP, belonging to the edible products classification.

\section{3: Methods}

\subsection{1: Site Requirements}

Typically, ginseng, goldenseal, and black cohosh require very specific sites in which to grow. These sites should be of a north or east facing aspect (typically more shade and available moisture), gentle slopes (these areas tend to have deeper soils, more leaf litter accumulation, and more moisture holding capacity), and under a deciduous canopy (for leaf litter (mulch), and shade requirements (Beyfuss 1997 \& 1998, Carroll and Apsley

2004b, Hankins 2000). To effectively illustrate shade requirements for each medicinal herb and easy accessibility to each demonstration site, the shade structures were constructed in open areas, to include established gardens (District 2), leveled roadsides with adequate drainage (District 3, 6), open edge of a hay field (District 4, 5), and beside an established educational trail (District 1). Since these medicinal plants grow well on a variety of soils, all loamy soils were considered sufficient for planting (Apsley and Carroll 2004, Beyfuss 2002). Three of the six sites had loamy soils as indicated by each site's 
county soil survey (USDA Soil Conservation Service 1965, 1982, 1998, 2006) and neighboring forests contained diagnostic plants, to include Jack-in-the-pulpit (Arisaema triphyllum), bloodroot, black cohosh, and various ferns that indicated good site quality (Beyfuss 1997, Carvell and Perkey 1997, Carroll and Apsley 2004b). The District 2 site (Potomac State College, Mineral County) is sectioned off from an existing garden and contained rich fertile potting soil (Jones 2006). Only Jackson County (District 6) contained a high concentration of clay soil (USDA Soil Conservation Service 2006). Loamy fill dirt was purchased from a local distributor and hauled to the site.

\subsection{2: Controlling Shade Requirements}

At each of the six sites, four individual plots were established, each measuring 10-ft by $10-$ $\mathrm{ft}$. Three levels of shade treatment were applied using polypropylene cloth, ranging in shade from $0 \%$ (sun plot) to $30 \%, 50 \%$, and $80 \%$. Each demonstration area covers 10 feet by 49 feet (total area $=490 \mathrm{ft}^{2}$ ) and each individual shade structure is supported by four, 10-foot long black locust (Robinia pseudoacacia) posts (Figure 3-1).

\section{Figure 3-1: Demonstration Area Plot Layout}

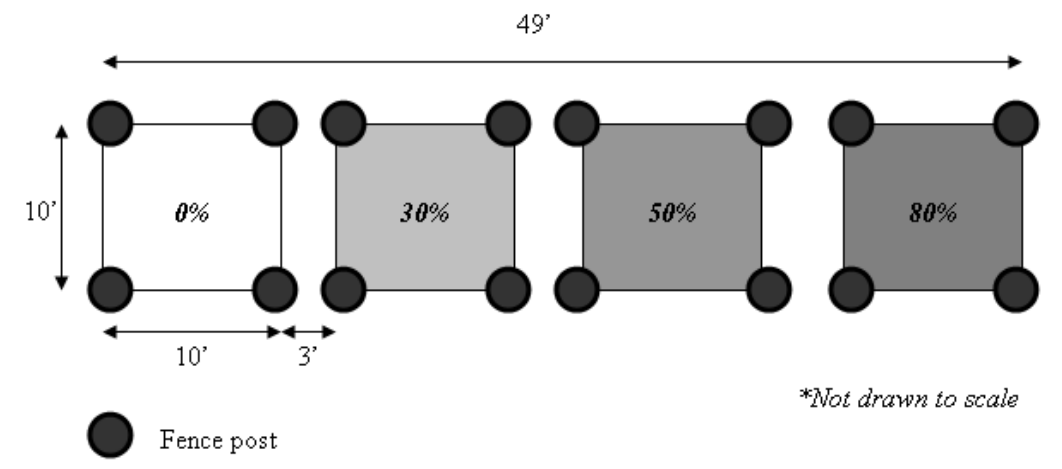


Postholes were dug using a hand-held motorized 8-inch auger and each locust post was buried in the ground 2.5 feet. The posts were secured in the ground by tamping dirt and rocks that were excavated from the posthole. The remaining 7.5 feet of post above ground served two purposes; (1) support for the shade cloth and (2) support for the deer fence. At the 7-foot mark of the two inside faces for each post, screw hooks were installed to support the $1 / 8$-inch cables that secured the shade cloth. After all eight screw hooks were installed, cables that measured 14-feet 4-inches (extra cable was required so that thimbles and clamps could be used to secure cables to screw hooks) were installed diagonally from one corner post to the opposite corner post to provide additional support for the shade cloths (Figure 3-2).

Figure 3-2: Cable Orientation for Demonstration Areas

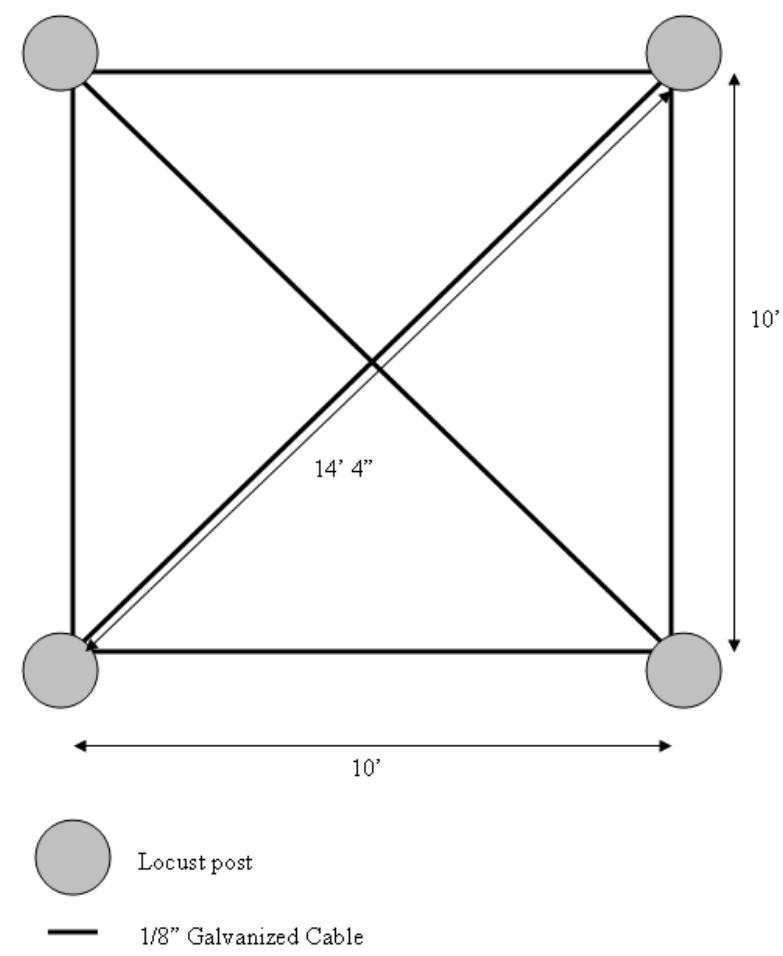


Polypropylene shade cloths were measured to 16 feet in length (standard width of each shade cloth was 10 -feet). The additional 6 feet of shade cloth was placed on either the south or west side of site, depending on the direction of the plot. Shade cloths were measured and 3/8-inch grommets were installed at the corners, and at 3-foot 4-inch interval along both the length and width of the cloth to evenly distribute the weight (Figure 3-3). For additional grommet support, tear and weather resistant tarp was cut and used as supplemental material around each grommet hole.

\section{Figure 3-3: Grommet Installation for Shade Cloths}

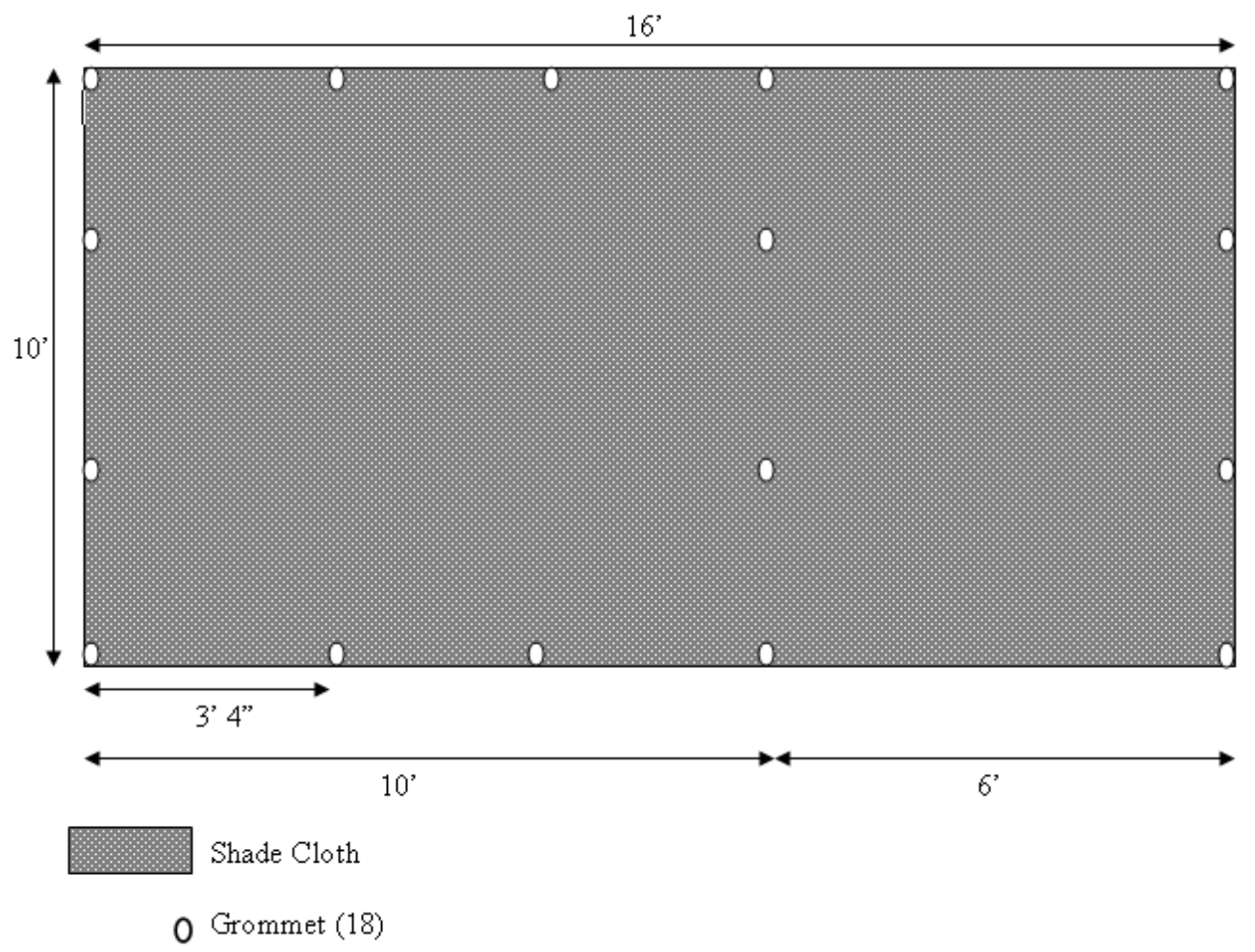

The cables that ran length-wise were measured to 17 feet ( 16 feet for the length, 1 extra foot to allow for thimbling and clamping). The cables that ran width-wise were measured to 11 feet (10 feet for width, 1 extra foot to allow for thimbling and clamping). After 
weaving the cables through the grommets, each end was thimbled and clamped (Figure 34) and attached to the screw hooks.

\section{Figure 3-4: Thimble and Clamp Assembly}

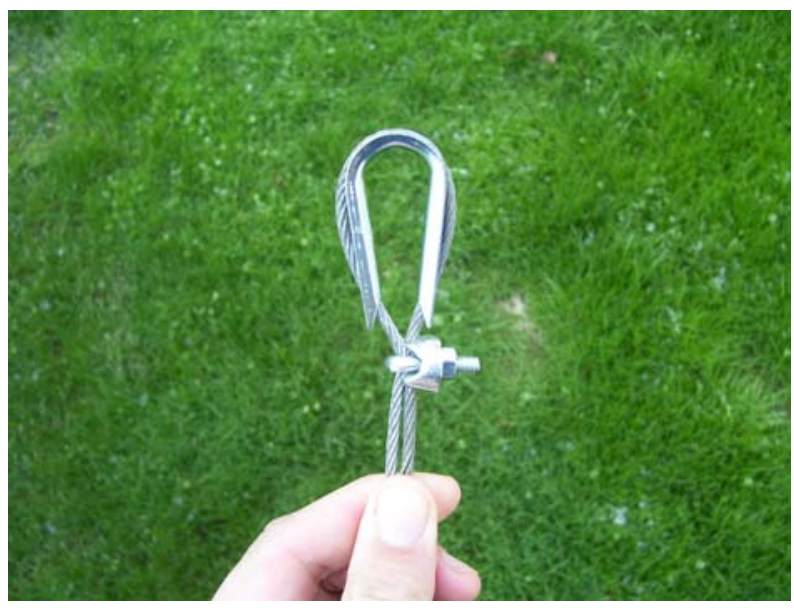

The additional 6-feet of shade cloth that draped down the south end was secured with another 1/8-inch cable weaved through four grommets of equal spacing and secured by screw hooks located 1.5 feet off the ground. The shade cloth was then stapled from the 1foot mark up to the 7-foot mark to secure the shade to the post to evade wind damage to the grommets. Deer fence was installed around each shade plot, retaining a 3-foot walkway in between each plot.

Interpretive signage constructed of corrugated cardboard (18" x 24" dimensions) was also installed at each demonstration area, to inform landowners the various types of NTFPs and the planting arrangement and design for the artificial shade structures. 


\subsection{3: Planting}

The plants used in the demonstration areas were three-year old American ginseng (Panax quinquefolium), goldenseal (Hydrastis canadensis), and black cohosh (Acteae racemosa).

In November 2006, after removing existing vegetation by hand-pulling, the soil bed was tilled using an 8-horsepower rototiller to a depth of four inches (Beyfuss 1998, Hankins 2000). Large rocks and sticks were removed and placed at the bottom of the slopes to catch debris or soil that could potentially be blown or eroded off (Carroll and Apsley 2004b).

Thirty plants of each species were planted in each 10-ft by 10-ft plot (Figure 2-5). The planting pattern provided each plant with one square foot of growing area. The plants were planted at a depth of one inch (Burdette 2005, Campbell and Beyfuss 2001). Goldenseal was planted in row one, from left to right, with ginseng in row two and black cohosh in third row. This procedure was repeated three times (Figure 3-5) for each shade plot (nine total rows).

Figure 3-5: Planting Arrangement for Demonstration Areas

\begin{tabular}{|c|c|c|c|c|c|c|c|c|}
\hline$G s$ & $A g$ & $B_{c}$ & $\mathrm{Gs}$ & $\mathrm{Ag}$ & $\mathrm{Bc}$ & $\mathrm{Gs}$ & $\mathrm{Ag}$ & $\mathrm{Bc}$ \\
\hline$G s$ & $A g$ & $B c$ & $\mathrm{Gs}$ & $\mathrm{Ag}$ & Bic & $\mathrm{Gs}$ & $\mathrm{Ag}$ & $\mathrm{Bc}$ \\
\hline$G s$ & $A g$ & $B c$ & $\mathrm{Gs}$ & $\mathrm{Ag}$ & $\mathbf{B c}$ & $\mathrm{Gs}$ & $\mathrm{Ag}$ & $\mathrm{Bc}$ \\
\hline$G s$ & $A g$ & $B c$ & $\mathrm{Gs}$ & $\mathrm{Ag}$ & Bic & $\mathrm{Gs}$ & $\mathrm{Ag}$ & $\mathrm{Bc}$ \\
\hline$G s$ & $\mathrm{Ag}$ & $B c$ & $\mathrm{Gs}$ & $\mathrm{Ag}$ & $\mathrm{Bc}$ & $\mathrm{Gs}$ & $\mathrm{Bg}$ & $\mathrm{Bc}$ \\
\hline$G s$ & $A g$ & $B c$ & $\mathrm{Gs}$ & $\mathrm{Ag}$ & $\mathbf{B c}$ & $\mathrm{Gs}$ & $\mathrm{Ag}$ & $\mathrm{Bc}$ \\
\hline$G s$ & $A g$ & Bic & $\mathrm{Gs}$ & $\mathrm{Ag}$ & $\mathrm{Bc}$ & $\mathrm{Gs}$ & $A g$ & $\mathrm{Bc}$ \\
\hline$G s$ & $A g$ & $B c$ & $\mathrm{Gs}$ & $\mathrm{Ag}$ & $\mathrm{Bc}$ & $\mathrm{Gs}$ & $\mathrm{Ag}$ & $\mathrm{Bc}$ \\
\hline$G s$ & $A g$ & $B c$ & $\mathrm{Gs}$ & $\mathrm{Ag}$ & $\mathrm{Bc}$ & $\mathrm{Gs}$ & $\mathrm{Ag}$ & $\mathrm{Bc}$ \\
\hline$G s$ & $A E$ & $B_{c}$ & $\mathrm{Gs}$ & $\mathrm{Ag}$ & $\mathbf{B c}$ & $\mathrm{Gs}$ & $\mathrm{Ag}$ & $\mathrm{Bc}$ \\
\hline
\end{tabular}




\subsection{4: Demonstration Site Specifics}

\subsubsection{1: West Virginia University Research Forest}

The District 1 site is located on the West Virginia University Research Forest near Coopers Rock State Forest in Monongalia and Preston Counties (Appendix 3).

The site has a gentle northern slope $(<5 \%)$, with a mixed mesophytic forest down slope, including yellow-poplar (Liriodendron tulipifera) and northern red oak (Quercus rubra). The soil type is DeKalb loam, very stony, 3\% to 15\% slope (USDA 1982).

\subsubsection{2: Potomac State College}

The District 2 site is located on the Potomac State College's Agricultural Farm in Keyser, Mineral County (Appendix 4). The site was previously used at a garden, contains highly fertile soil and is completely fenced in to prevent deer damage. The ground has been leveled off for commercial growing of various tree and plant species (Jones 2006).

\subsubsection{3: Seneca State Forest}

The District 3 site is located at Seneca State Forest in Pocahontas County (Appendix 5). The site is gently south-western sloping $(<5 \%)$ and located near a vacant house that belongs to the State Forest. Eighteen-feet to the south of the plots is a row of 15-foot Eastern hemlock (Tsuga canadensis). The hemlocks do not currently provide any additional shade for the site. The soil type for this site is Berks channery silt loam, very stony, $3 \%$ to $15 \%$ slope (USDA 1998 ). 


\subsubsection{4: Gap Mills}

The District 4 site is the only demonstration site located on private land. The land belongs to Stacy Clarkson of Gap Mills, Monroe County (Appendix 6). The site is located at the edge of a field usually utilized for hay. The site is gently western sloping $(<5 \%)$. The neighboring stand is a roadside rest area and is occupied by white oak (Quercus alba), red oak (Quercus rubra), and black gum (Nyssa sylvatica). The soil type for this demonstration area is Dunmore silt loam, 3\% to 8\% slope (USDA 1965).

\subsubsection{5: Chief Logan State Park}

The District 5 site is located at Chief Logan State Forest, Logan County (Appendix 7). The site has a gentle southerly slope $(<5 \%)$ and a maple/hickory forest type is adjacent to site's eastern side. The site is located on a clearing placed perpendicular to the stream that flows along the bottom of a neighboring dam at the bottom of the eastern slope.

\subsubsection{6: Roane/Jackson County Technical Center}

The District 6 site is located at the Roane/Jackson County Technical Center thirteen miles east of Ripley in Jackson County (Appendix 8). The existing soil at the site was not suitable for ginseng, goldenseal, or black cohosh. Topsoil was purchased from a local source (Upshur-Gilpin complex) (USDA 1961) that was present (not a desired soil type for ginseng, goldenseal or black cohosh) (Beyfuss 1997 \& 1998, Carroll and Apsley 2004b). Each plot's soil for this site was placed in a 10-ft by $10-\mathrm{ft}$ framed box constructed from 2inch by 4-inch framing lumber. 


\subsection{5: Results}

Only one of the six demonstration sites was constructed in time to determine propagation rates from the transplant rootlets. The Roane/Jackson County Technical Center's site was built and planted in the fall of 2005 so that plants could be counted the following spring. This demonstration area also served as a template for materials and time for the other five demonstration areas. The remaining areas were built in the summer of 2006 and planted in the fall of 2006, resulting in the plants propagating too late for this document's records.

The Roane/Jackson County Technical Center demonstration site recorded $62 \%$ growth of new plants transplanted (Table 3-1). Factors in this propagation rate include drier conditions in the less shaded plots, lower soil moisture, deer eating around protected edges, and damaged rootlets.

Table 3-1: Propagation rates for Roane/Jackson County Technical Center demonstration area. Thirty of each plant was planted in each shade plot.

\begin{tabular}{|l|c|c|c|c|}
\hline \multicolumn{5}{c}{ Shade Supplied } \\
\hline \multicolumn{1}{|c|}{ NTFP } & $0 \%$ & $30 \%$ & $50 \%$ & $80 \%$ \\
\hline Ginseng & 2 & 11 & 18 & 20 \\
\hline Goldenseal & 9 & 21 & 26 & 24 \\
\hline Black cohosh & 16 & 19 & 29 & 27 \\
\hline
\end{tabular}




\section{$\underline{3.4 \text { "Inoculate-Your-Own" Shiitake Mushroom Workshop }}$}

\subsection{1: Introduction}

Shiitake mushrooms (Lentinula edodes) are the third most commonly produced mushroom in the world. It is a saprophytic fungus that feed off of a wide array of hosts, most commonly oak, white (Quercus alba) in particular. Through the six workshops (one at each demonstration area), our goal is to stimulate interest in shiitake mushroom production for either personal or commercial use. Landowners can do this by proper silvicultural techniques, such as 'thinning from below' or harvesting tops of harvested timber, that can be incorporated to promote a healthier stand of timber. A $\$ 15$ per log fee was applied for the workshop help offset gas and equipment rental charges. In addition, Paul Goland, of Hardscrabble Enterprises Incorporated in Franklin, WV, was present for one the workshops to assist landowners with questions about shiitake mushroom inoculation and related products.

\subsection{2: Methods}

Shiitake mushroom production can be performed by many similar methods, to include thimble spawn, sawdust spawn, and dowel spawn. All of which require a corded drill, specialized drill bits, eye protection, sawhorses, and mushroom spawn. Sawdust spawn can also require a spawn applicator to inject the spawn and hot wax to protect the mushroom spawn from dryness. Two of the most common inoculation methods, thimble and sawdust, were presented at the workshops. Following the demonstrations, landowners were allowed to choose their log and inoculate via thimble spawn. Upon completion of 
inoculation, landowners were able to go home with their log or purchase additional shiitake logs.

Advertising for the workshops was accomplished by many different means. West Virginia University Extension agents from the counties that housed each demonstration area, as well as neighboring counties, were contacted for their assistance in outreach (posting and forwarding a promotional flyer). Three local newspapers also ran the flyers for free, and two extension agents mentioned the workshops in their weekly column. In addition, a mailing list from West Virginia Woodland Owners Association was used. Landowners that resided within 50 miles of each demonstration area were mailed a postcard with their nearest workshop date, time, and location. A member from the state's Master Gardner program was also contacted, who distributed the flyer.

\section{$\underline{3.4 .3 \text { Results }}$}

In all, sixty-three landowners attended the workshops (Table 3-2).

Table 3-2: Shiitake mushroom workshop attendance and logs sold.

\begin{tabular}{lcc}
\hline \multicolumn{1}{c}{ Demonstration Site } & \# Landowners Attended & \# Logs Sold \\
\hline WVU Research Forest & 22 & 37 \\
Potomac State College & 2 & 2 \\
Seneca State Forest & 14 & 21 \\
Gap Mills & 6 & 11 \\
Chief Logan State Park & 4 & 4 \\
Roane/Jackson Co. Tech & 15 & 12 \\
\hline
\end{tabular}




\section{Chapter 4: Entrepreneurship Booklet}

\section{$\underline{4.1 \text { Introduction }}$}

A booklet of ten case studies featuring people that have been successful in producing NTFPs was developed in a collaborative effort between the West Virginia Division of Forestry and the West Virginia University Division of Forestry and Natural Resources. The intent of this entrepreneurship booklet is to highlight successes and challenges in the production of various products and convey to landowners the effort needed to establish similar enterprises. The case studies provide insight into these enterprises so prospective forest-based entrepreneurs may better decide whether or not to initiate an enterprise. The ten case studies selected for this booklet include landowners who produce and market NTFPs. These enterprises include: Christmas tree farm, fish, ginseng (and other medicinal and supplemental plants and herbs), honey, maple syrup (and other by-products), moss, paw paws, ramps (wild leek), and shiitake mushrooms.

Non-industrial private forest landowners often face the issue of whether or not to start a non-traditional forest based business to take advantage of renewable resources on their properties. Their reasons for doing this frequently include the opportunity to earn additional revenue from their forested acreage (Kays and Drohan 2004, Campbell 2004). Kays and Drohan (2004) advise potential entrepreneurs to carefully consider the idea of starting their own business because many endeavors are less than successful, or fail altogether, because the landowner lacked adequate information needed to make an informed decision or failed to take a long-term view of the enterprise. Starting a forestbased business involves a strong stewardship ethic, entrepreneurial risk-taking and 
flexibility (Campbell 2004). Starting a new enterprise can be risky both from a financial and a personal viewpoint.

Typically, the easiest ways for a landowner to gather new information regarding a forestbased business is by (1) gathering information from a variety of publications, (2) making personal observations, (3) contacting and visiting existing businesses, suppliers, etc., and (4) surveying potential buyers and sellers (Kays and Drohan 2004). Kays (1998) advises people to complete a series of evaluations to determine whether or not the business is profitable before investing time, money, and energy into a potential new venture. The personal evaluation deals with reasons to start the business. The second evaluation consists of a market evaluation, where landowners are encouraged to contact present growers and buyers in their areas to learn more about the specific requirements of the business (how much material, what quality, what characteristics, etc.).

\section{$\underline{4.2 \text { Project Objectives }}$}

The objective of developing and presenting these case studies is to provide a resource for potential entrepreneurs who are interested in starting a forest-based enterprise. This resource will highlight challenges and successes, activities, production levels, and organizational structure that established entrepreneurs have shared. Other information gathered from these entrepreneurs include number of employees, the relationships to these employees (family business), history of the business, how the owner developed an interest in the market, general marketing questions (how they advertise, group/organization affiliations, percent of their business that is repeat business), as well as interesting facts 
about themselves and/or their business. Another objective is for general educational purposes. Interested individuals who benefit from this book can obtain helpful hints about starting and operating a specific forest-based business as well as contact information for established business owners.

\section{$\underline{4.3 \text { Methods }}$}

A database of forest-based businesses was developed through internet searches, phone book searches, and discussions with West Virginia Division of Forestry personnel. Once the database was compiled, owners of the forest-based enterprises were contacted and asked about other similar operations that would be willing to participate, which were also entered into the database.

Case study enterprises were selected based on uniqueness of the enterprise or business and eagerness of the owner to share information. A questionnaire was developed and reviewed by committee members and other West Virginia University Division of Forestry and Natural Resources faculty (Appendix 9). The questionnaire inquired about such business aspects as enterprise activities, production levels, organizational structure (number of employees, subcontractors, relationship of employees to owners, etc.) and the challenges most frequently encountered in their daily business.

Ten enterprises were selected to be included in the booklet and provided a questionnaire. Upon completion of the questionnaire and in some instances, a site visit, a descriptive narrative (case study) was composed and reviewed by staff and faculty members of West 
Virginia University Division of Forestry and Natural Resources, as well as West Virginia's Division of Forestry personnel.

\section{$\underline{4.4 \text { Case Studies }}$}

\subsubsection{Appalachian Root and Herb Company, Rainelle WV}

Hollywood movies such as "Jurassic Park," "Planet of the Apes," "The Haunting," "The Blair Witch Project," "Mr. and Mrs. Smith" and "The Pirates of the Caribbean" movies all made it to the big screen, but first had to stop in the tiny town of Rainelle, West Virginia to pick up supplies. Rainelle is the home of the Appalachian Herb and Root Company, the company that supplied these films with natural greenery for their cinematic props.

The Appalachian Root and Herb Company has been a family-owned business for over 33 years. The owner, Tim Thomas, started in the business helping his dad and uncle pick ginseng and other wild-crafted roots, herbs, and other forest naturals. Eventually, mosses became the dominant product. "Our core business is moss. We buy the moss (and other products) from contractors/pickers and clean, dry, package and ship the final product."

Most of the sheet moss used by the floral industry currently comes out of Tennessee and West Virginia, with the Appalachian Root and Herb Company being "the largest producer east of the Mississippi (River). We literally harvest from thousands of acres, largely on properties managed by large timber companies." Once the products are harvested, they are 
cleaned, dried, prepared, and stored on the 5-acre lot in Rainelle until purchase or shipment.

"We are a 'value-added' manufacturer. We take natural non-timber forest products and process them into a final product for consumer use or an intermediate product for another manufacturer to finish into consumer-ready goods." This includes goods for the local flower shops, as well as the moss packaged in plastic on racks at Wal-Mart stores.

Success in the floral trade business generally requires emphasizing diversity and avoiding overdependence on season products. ${ }^{1}$ This means that a company should have many different types of products and not rely on one product that can only be gathered during a short season. To assure a consistent stream of revenues, the Appalachian Root and Herb Company also handle grapevine products such as wreaths and garlands; branches for decoration, small tree trunks for the manufacture of decorative artificial trees (ficus, etc). Thomas states that he also sells a substantial amount of camphor vine (dutchman's pipe) to the decorative and movie set design trade.

Before a person decides to invest in harvesting and selling floral products, the USDA Forest Service recommends that the individual do a trial run to determine just how much time and expense is involved in the harvesting, drying, processing, packaging, and distribution of the products. Second, a lot of people make the mistake of pricing their product based only on what retailers are currently paying for similar products. To avoid this, one should set the price low enough to protect future profit margins of wholesalers as 
well as retailers. Being able to sell to wholesalers is important because, for wholesale products, the most successful entrepreneurs will make their profits by selling large volumes at lower prices rather than by selling small volumes at higher retail prices. This strategy requires a commitment to building a business slowly rather than trying to get rich quick. ${ }^{1}$

"Our core market is the wholesale/distribution trade, although we do maintain a very small retail presence on our web-site. Our entire product line is marketed for the floral and craft decorative trade. About eight-five percent of our customers are repeat business, with sheet moss, camphor vine, and grapevine products being the best sellers (in that order). In fact, we still sell to our 'very first customer' from 1973. Few businesses can say that after so many years!"

Appalachian Root and Herb Company now employ 11 permanent employees but hires up to 70 contractors/pickers during the harvesting season in the summer months. Appalachian Root and Herb Company is the third largest employer in Rainelle.

The biggest obstacle for Tim is "the lack of access to large tracts of land. The timber and mining companies have leased out vast areas of land to 'hunting clubs,' thus eliminating access for the pickers. The closure of the National Forests to the harvesting of moss and club moss is also an obstacle." The Monongahela National Forest, which covers nearly 1 million acres in West Virginia, banned 'mossing' in 2001 until it could study the impact of

\footnotetext{
${ }^{1}$ Income Opportunities in Special Forest Products: Self-help Suggestions for Rural Entrepreneurs. Agriculture Information Bulletin 666. May 1993 pg 75
} 
moss harvesting. Even with the (Monongahela) National Forest closed to pickers, we produce about 150,000 pounds of dry moss per year, the wet equivalent of another 20,000 pounds of dry moss; in addition to 300 dozen grapevine wreaths, several miles of grapevine garland, and several miles of camphor vine.”

With many helping hands and a sharp sense in business management, Tim has successfully taken his father and uncle's business of yesterday and turned it into a million dollar business today. Strong markets for forest-grown naturals and the renewable nature of these products will surely maintain this productive enterprise for many years to come.

\subsubsection{Crummies Creek Tree Farm, Arnoldsburq, WV}

Russ Richardson was able to see the forest through the trees when he purchased Crummies Creek Tree Farm 18 years ago. "During our first summer, it took nearly a month of regular visits to the property to slow the extreme harvesting of medicinal plants from our woodland. As we became more familiar with the property we noticed that the woodland contained a much more diverse forest understory than is typical for central WV."

Russ realized that his newly acquired land had excellent potential for medicinal herbs. "Prior to completing the timber inventory for our forest stewardship plan, an earlier assessment of understory vegetation had identified several areas where commercial populations of several important medicinal plants were present including black cohosh, goldenseal, and American ginseng." Bloodroot was also inventoried in that first year, but because of poaching, it and goldenseal were pretty much extirpated. "It took nearly five 
years, but by 1994 all poaching of black cohosh had ceased and ginseng harvesting was reduced as well."

Russ now maintains that since that time, black cohosh has rebounded significantly and goldenseal transplant beds have been set up all over the tree farm to reestablish the plant on a more widespread basis. The black cohosh has indeed bounced back from that dreadful start for Russ. "Starting in the late 1990s we've sold black cohosh seed and we have frequently sold live black cohosh roots for transplanting. In 2006, we began to harvest a greater amount of mature black cohosh from the woodlands and we're considering organic certification of our medicinal plant producing woodlands."

Medicinal plants have always been of interest to Russ. Almost every aspect of his tree farm operation is either unique or groundbreaking for the area. "I try to interact with everyone I can and do not make any aspect of our ongoing medicinal plant efforts secret. I also use my own woodland for demonstration purposes.” Crummies Creek has hosted numerous workshops and other educational outreach programs over the years. A few of these were titled: Invasives: Forest Health and Forest Productivity, and Recognizing Sites and Management Opportunities for Special Forest Products, and Recognizing Significant Populations and Management Opportunities for Non-timber Forest Products.

Russ agrees that while producing products from the medicinal and dietary sector of nontimber forest products is rewarding, there are some challenges. "Poaching is a continuous and ongoing threat, but the general indifference of policy makers and rural economists to 
the science and business of these enterprises is a continuous source of frustration." Russ is referring to the regulations imposed by the U.S. Fish and Wildlife Service on the export of wild or wild simulated ginseng; this agency is the official governing body of the Convention on International Trade in Endangered Species of Wild Fauna and Flora (CITES) treaty.

Russ also relies on his woodlands for other various non-timber forest products (NTFPs), including several species of ferns and some plants that can be used in landscaping. "We are also growing log moss for packaging in our live root business." His production levels of all his various NTFPs have been increasing steadily since his intensive management in 1989 , but at this stage he is more interested in the investment side of the process than the income end. "In the past, black cohosh seeds provided most of our NTFP income but now live black cohosh roots have taken over, and soon that will be eclipsed by wild simulated ginseng." Russ estimates that over $80 \%$ of his business is repeat business.

Russ has been instrumental in his recognition and treatment methods of several species of exotic invasive plants that could potentially be lethal to understory ecosystems that harness a lot of NTFP opportunities. "Almost every aspect about our business is either unique or groundbreaking for the area. The techniques we developed have a very good chance of replication in many West Virginia locations.” Given Russ' unique location and enthusiasm for growing diverse forest products, his efforts in managing his property for both timber and NTFPs continue to inspire scientists, forestry professionals and other woodland owners. 


\subsubsection{Divergent Natural Interests, Elk View, WV}

"The only thing I regret about the fish business is that it is hard for me to find time to spend fishing!” says Fred Hays, owner of Divergent Natural Interests (DNI) in Elkview. He began the business in 1995 on his 150-acre farm and has increased production each year to meet the needs of his customers.

Fred currently sells grass carp (for weed control), largemouth bass, bluegill, hybrid bluegill, red-ear sunfish, channel catfish, koi carp (ornamental and for algae control), goldfish, miscellaneous pond critters (mystery snails, crayfish, tadpoles, etc.), and aquatic plants (lotus, water lilies, pickerel rush, etc). "We currently serve landowners, farmers, schools, homeowners associations, government agencies, and resorts."

Fred is an educator of Holistic Management; a worldwide non-profit organization that is dedicated to promoting land resource management that restores land to health and profitability. "My commitment to nature and diversity led to the establishment of my business. The key concept involves the sustainable use of resources to develop diverse products. In regards to aquaculture, I began raising fish for local customer on a relatively small scale. At the same time, I also raised rabbits, worms, compost, and mushrooms and each product had a beneficial role in the development of the other. As customers sought solutions to pond management issues, the aquaculture business quickly expanded to my present-day pond stocking operation."

\footnotetext{
${ }^{2}<$ http://www.holisticmanagement.org/>
} 
Managing his land holistically has enabled Fred to live his management practices and not just run a business. "In addition to the aquaculture enterprise, our tree farm is well managed with wild simulated ginseng, six hundred shiitake mushroom logs, and a variety of berries. A few acres of grassland are being intensively managed through a rotational grazing matrix to produce locally marketed grass-fed beef and a few laying hens provide fresh eggs." Fred also owns a one-man sawmill that converts cull trees to functional lumber. When weather keeps him from getting to these outdoor activities, Fred produces custom hunting knives that he sells at local hunting and fishing events. "As a certified Holistic Management Educator, I also provide consultation on sustainable enterprises. Through this venue, I studied under world-renowned Alan Savory, and have been involved in discussions concerning conservation issues with peers from all over the world. Many of my articles on sustainable practices have been published in conservation newsletters and In Practice magazine. In addition, there have been a number of articles featuring my efforts in local papers as well as People, Places, and Plants and Smithsonian magazines. Author David Taylor included several pages about me in his recently published book, Ginseng: The Divine Root."

Fred admits that 50 to $70 \%$ of his business is repeat business and insists that he does not actively promote his business. The remainder of his business is from new customers who have heard from satisfied customers or was recommended by West Virginia Division of Forestry personnel. He also remains dedicated to the community and established organizations to assist landowners who may have questions. "I am a Capitol Conservation District Supervisor and Holistic Management Educator as well as a member of the WV 
Aquaculture Association, Tree Farm Association, and WV Ginseng Growers Association (WVGGA). I closely interact with other community organizations such as watershed associations, woodland owners, and extension, among others conducting training sessions."

Fred was very instrumental in the instigation of the West Virginia Ginseng Growers Association (WVGGA). "I helped establish the WVGGA and remain a board member and primary contact for individuals interested in growing ginseng. We provide information tailored for the West Virginia region, bulk root auctions, and a bulk-seed program that acquires ginseng seed at greatly reduced prices for members. I helped start a number of other organizations for rural residents including the Kanawha County Farm Bureau, Blue Creek Watershed Association, and Center for Sustainable Resources, Inc."

"Since the business is holistically managed, it is not just a business, but a lifestyle - and it's labor intensive! Although I enjoy being active, there is little 'time off,"' Fred states while discussing challenges he encounters in his business. "There are also bureaucratic issues to work through, but you'll have that when you develop a business that doesn't 'fit the mold' or is innovative."

DNI has been supplying pond-stocking fish to satisfied customers throughout West Virginia for over ten years and provides pond management consultating and healthy fish at affordable prices. Bass, bluegill, and catfish are the most popular game fish for stocking. DNI is the first West Virginia vendor to sell grass carp (or white amurs) for weed control. 
Fred loves his job. "It is rewarding when customers call just to thank me for the amazing results from grass carp clearing up their weed problem or to tell me about their grandchildren catching trophy sized bass that were stocked two years ago." With such a zest for helping people with this unique enterprise, West Virginia will continue to benefit from these services for many years to come.

\subsubsection{G\&N Ramp Farm, Richwood, WV}

West Virginia is famous for many things, but did you know that it is home to the only "ramp farm" in the world? Ramps, or "wild leeks," are a close and edible relative of the onion, and in 1990 Glen and Norene Facemire of Richwood started growing and selling products made from these edible delicacies. "We started by taking what we had on our land and making a few products like ramp salt, dehydrated ramps, and pickled ramps. As time went on, we made ramp jelly, ramp potato biscuit mix, ramp gravy, and ramp mustard.” They also sell ramp postcards.

“The ramp is a 'cool' herb!" Glen joked, referring to the plant's ideal growing habitat—the rich, moist deciduous woods all over West Virginia. Ramps grow in 22 other states as far west as Minnesota and Missouri and as far south as Tennessee, North Carolina, and upland Georgia. Ramps are also native to Canada, and studies have shown that the plant's popularity has lead to diminishing numbers due to overharvesting. "Canada is pretty much dug out - the market is picking up and I'm selling more up there." 
Glen and Norene now manage their 50 -acre farm as a Web-based business. "We opened a retail store for three years in Richwood, but closed it down to concentrate on the Web business." Glen admits that $90 \%$ of his business is repeat business. "We have shipped to all 50 states." He has sold his ramps to the famous James Beard House in New York City and the Kentucky Derby. "While my son was in Seattle, he ate a fancy restaurant atop of the space needle, where ramps were an $\$ 8$ side dish!” But G \& N Ramp farm products go far beyond U.S. borders. "I have been selling to this big resort in Dorset, England for years. They always order a large amount every year."

The "king of stink" has a rich history. As one of the first plants to appear in the spring, ramps were traditionally consumed as the season's first "green." In early U.S. history, they provided necessary vitamins and minerals following long winter months in which the menu mainly consisted of dried fruits, nuts, beans, and dried beef or salt pork. Native American tribes near Lake Michigan knew where ramps grew well and called the place “Shikako" meaning, "skunk place", later renamed "Chicago" after English settlement.

Glen is thrilled about helping others grow ramps. "If a person wanted to get into a secondary business, I'd highly recommend planting ramps." Glen and Norene have been "farming" ramps since 1990. "You don't really farm, there is no fertilization and no watering, but there is managing" admits Glen. "The number one thing for a good ramp patch is leafy mulch buildup." This leafy build up provides the ramps with essential minerals needed for sprouting, thermal protection, and maintaining soil moisture. "The ramp business has a good future for someone who wants to work it." 
Glen adds that the only real obstacle to managing ramps is that they are very seasonal.

"The leaves are only up for a couple of weeks before the forest canopy closes, then they die back to make room for the flower stalk."

Glen has turned his hobby into a unique passion. They have written three books; Ramps: From the Seed to the Weed, Ramps A Cookin', and Growing Your Own Ramps. The Facemires have helped various educational institutions learn about ramp 'farming', harvesting, and management.

Ramps are a unique delicacy. Whether you love them or can't stand them, ramps have a long and important history in West Virginia and the Facemires continue to cultivate this valuable piece of natural heritage.

His books may be purchased on his web page, in addition to other merchandise to include: fresh ramps (when in season), ramp seeds, dehydrated ramp bulbs, and postcards.

\subsubsection{Hardscrabble Enterprises, Franklin, WV}

Shiitake (pronounced "shee-tah-kay") are said to be the favorite mushroom in Japan. They are also a sought-after product in China, Korea and parts of Indonesia, and for good reason — shiitake mushrooms are low in calories, sodium, and fat, and yet are a highly nutritious containing calcium, vitamins D and B-complex, iron, phosphorus, and potassium. This wonderful food item compliments garden vegetables well and is easy to 
grow. Just ask Paul Goland of Hardscrabble Enterprises, Inc, who has been growing shiitake mushrooms on his 223-acre Cherry Cove farm in Pendleton County for 27 years.

Paul first learned about the shiitake mushroom from an organic gardening magazine article. "It described the shiitake as an exotic blend of filet mignon and lobster flavored with garlic. Since those tastes appealed to me, I ordered some spawn, cut some logs and started growing mushrooms." Paul decided to purchase four $\$ 18$ kits soon after reading that article and has been growing these specialty mushrooms ever since. And Paul's not alone. According to the USDA's National Agricultural Statistics Service (NASS), 176 growers produced roughly 8 million pounds of shiitake mushrooms in the United States during 2005-2006. ${ }^{3}$ In fact, the shiitake mushroom is the third most widely produced mushroom in the world, just behind the common button and oyster mushrooms,.

In Asia, shiitake mushrooms have been cultivated and used for centuries. Highly prized as both gourmet fare and folk medicine, they are called "the ginseng of mushrooms" and "plant of immortality" because of their culinary and medicinal properties. Some of these properties include antiviral, antifungal, and anticarcinogenic properties. For example, the consumption of shiitake mushrooms significantly lowers blood cholesterol levels and is reported to lower high blood pressure in laboratory animals. Shiitake mushrooms contain all eight essential amino acids in better proportions than soybeans, meat, milk, or eggs ${ }^{4}$.

\footnotetext{
${ }^{3}$ Agricultural Statistics Board (NASS, USDA) Mushrooms, August 2006 (pg 10)

${ }^{4}$ Koske, Thomas J. 1998. Producing Shiitake - The Fancy Forest Mushroom. Clemson University Cooperative Extension Service
} 
With an energetic spirit, Paul teaches dozens of workshops every year and is very enthusiastic about sharing mushroom information with anyone interested in producing mushrooms for personal or commercial use. "The first time I grew them I did everything wrong" he admits. "It took me two years to get the first mushroom. Now, if someone does everything right, they can get their first crop in 6 to 18 months."

To grow shiitake mushrooms, Paul advises that there are several important steps in producing quality shiitake mushrooms. First, one should order good-quality culture (also called spawn or inoculum), so that it can be on hand when needed. The spawn that you purchase is nothing more than a pure strain of mycelia, the fine strands of fungus that make up the "body" of the shiitake and that is grown either in sawdust or in hardwood dowels. "The spawn is prepared in a laboratory under sterile conditions. It should be kept refrigerated until a day or two before use. "The spawn has a short shelf life and must be used within two weeks of receiving it; otherwise it is likely to dry out and die."

In the second step of shiitake production, a prospective grower should obtain high-quality hardwood logs. "White oak is the favorite choice, but other kinds of oak, sugar maple, sweet gum, black gum, or ironwood can be used." Logs should be cut from young, healthy disease-free trees. "Don't use dead or damaged trees, as other fungus species may have already invaded the wood and shiitake doesn't compete well against other fungi." The pieces suitable for producing shiitake should be three to six inches in diameter and cut into three to four foot sections. Call a firewood dealer if you do not have any suitable tree species, they can often provide the small logs you need for a negotiated price. 
The third step in growing shiitakes involves inoculating the logs. Essentially, inoculation consists of drilling holes in the logs and inserting spawn. Generally, a 5/16" drill bit will be used for dowel spawn and a 7/16" drill bit for sawdust and thimble spawn. Drill offsetting rows of holes (usually three rows per log, each hole about 6 to 8 inches apart) and insert spore plugs; dowel spawn will be tapped in with a hammer. For sawdust spawn, melted wax is brushed over the inoculation hole to seal and to prevent its drying out. Thimble spawn does not require wax because each 'thimble' comes with a little Styrofoam cap, which serves to seal off the plug once installed. "This reason alone makes the thimble method a big plus compared to sawdust or dowel.” Enough thimble spawn for ten logs costs $\$ 17$ (plus $\$ 6$ shipping and handling). The best place to store shiitakes is in deep shade, and they can be stacked by many different methods. "I prefer a 'pick-thru' rack; it is highly space efficient and easy to make." For a person just starting out, leaning a couple logs under a shade tree will work.

Logs must set in place for 5 or 6 months as the fungus grows and consumes the wood of the logs. After this period called the "spawn run," logs should be soaked in cold water for 24 hours, then removed and put back in the stack or rack. Mushrooms will emerge from the logs in 8 to 10 days and will continue to fruit for about three days. This soaking process can be carried out every 6 to 10 weeks for three or more years.

Paul advises people to actively search out markets for their mushroom products. "Only about $15 \%$ of my business is repeat business. My number one market is fairs and festivals. I like the interaction with customers." His best seller is pre-inoculated, ready-to-soak logs, 
which usually sell for $\$ 12$ to $\$ 18$ a $\log$ (depending on the log's diameter). "There is a guy who sells smaller inoculated logs out of Arkansas by mail, but I'm not a fan of that because I would lose contact with my customers," Paul adds. Paul has diversified products including sauces and soup mixes made from dried shiitake mushrooms.

The biggest obstacle that Paul faces is the biological aspect of growing mushrooms with some slight problems from slugs and fungus thrips. "You don't have to worry about deer, ground hogs, or other varmints eating the mushrooms; however I have found out that horses love 'em." Slugs eat leaves, fungus, and decaying vegetable material, but Paul has found that diatomaceous earth, a fine powder also known as silicon dioxide consisting of fossilized diatoms (microscopic water algae), can prevent these pests from occurring. Just apply a light dusting around areas where pests are found or hide such as in garden rows or under the leaves.

Paul has successfully taken his business from a sheer experiment to a large scale operation and is happy to assist whoever would like to start a similar venture. Paul supplies spawn and other growing supplies needed to start your growing your own shiitake mushrooms.

\subsubsection{Mountain State Honey Company, Hambleton, WV}

Trees in West Virginia's forests are well-know for the scenic beauty and high-quality wood they provide. No so evident is the fact that they also are the source of one of nature's finest commodities - honey. Sourwood, basswood, yellow-poplar, sumac, and black locust are just a few of many tree and shrub species that bees visit as spring turns to 
summer and nectar flows from sweet-scented flowers. Paul and Alisa Poling have made good use of this abundant forest resource by producing honey labeled by their Mountain State Honey Company.

Originally established as a partnership in 1989, the Polings became sole proprietors of Mountain State Honey Company in 1996 when their business partner retired. "In the early 1990's, we pollinated apples in the eastern panhandle of West Virginia and parts of Virginia" Paul explained. "We started with one hive that we used to pollinate the garden and apple orchard."

Paul developed an interest in beekeeping because they are interesting insects. In fact, monotony is not something one should expect out of beekeeping. "The different types of honey that bees produce are interesting. Each year is different from the last and no two years are the same."

Creative marketing of the many products that bees produce is crucial to the success of a bee-keeping enterprise. A typical colony of bees can produce 80 to 120 pounds of surplus (harvestable) honey and 10 to 18 pounds of pollen every year. Besides selling honey and other bee products - such as beeswax, pollen, royal jelly, or queen bees - beekeepers can also provide pollination services (hive rentals) to farmers and orchard owners. "We now pollinate melons, squash, blueberries, apples, pumpkins and almonds. We do not produce honey from the crops we pollinate, but we do produce honey mainly from the forests here

\footnotetext{
${ }^{5}$ ATTRA Beekeeping Publication, available at: <www.attra.ncat.org $>$
} 
in West Virginia. We market [the honey] according to the predominate source that they were derived from. Each type of honey has its own color and flavor."

As with all businesses, proper planning for a bee-keeping enterprise is essential. The safety of family members and neighbors is the most important consideration. A prospective 'keeper' should be aware of neighbors who may be allergic to bee stings. It is wise to start small, learn efficient management methods, and increase the beekeeping operation as time, experience, and finances allow. The National Sustainable Agriculture Information Service ${ }^{1}$ advises prospective keepers that whether the bees are kept as pollinators for crops or for the income from their products, producers need to be aware of their states' apiary laws concerning inspection, registration, and permits, as well as labeling and marketing standards. The West Virginia Department of Agriculture addresses this issue in a free publication available to West Virginia landowners titled "Guide to Beekeeping in West Virginia ${ }^{6} . "$ In compliance with the Code of West Virginia, Chapter 19 Article 13, apiaries must fill out the registration form (form is available in Guide to Beekeeping Book). The book also details a wide variety of information one should educate themselves about before starting a bee-keeping business.

The best time to start raising bees is the spring or early summer. As a minimum, you will need the basic components of the hive, a source of bees, protective gear (include, but not limited to a veil, suit, leather gloves, and boots), ancillary gear (smoker and a hive tool),

\footnotetext{
${ }^{6}$ Guide to Beekeeping in West Virginia, available at: $<$ www.wvagriculture.org $>$
} 
and equipment for handling the honey crop. ${ }^{7}$ It is important that beginners purchase their equipment early so that it will be ready to use when the bees arrive.

"Parasitic mites are a challenge to keep under control" is an obstacle that Paul and Alisa admit. "These mites are not a natural parasite of our honey bees. They were found in the US in 1985 in Florida and have spread to every state except Hawaii. As miticides [Apistan (R] have been developed, the mites have adapted and become resistant to them." The West Virginia Department of Agriculture Beekeeper Assistance Program changed the supplied miticide from Apistan ${ }^{\circledR}$ to Check-Mite $+\circledR$ after the discovery of the resistance to all beekeepers participating in the program. Although it is a great way to save some money, it is strongly recommended not to buy used equipment; secondhand equipment may be contaminated with mites or diseases. Beekeepers are encouraged to monitor and test their hives often in the fall to determine if the mites (varroa mites, in particular) have developed a resistance to Check-Mite+ ${ }^{\circledR}$.

Parasitic mites and the foulbrood diseases (a bacteria that affects the bees when they are in the larval and pupa stages) pose a threat to all hives. The Guide to Beekeeping in West Virginia booklet, published by the WV Department of Agriculture, also describes the Noninsured Crop Disaster Assistance Program (NAP) "provides financial assistance to eligible farmers (including beekeepers) whose crops (such as honey) have been affected by adverse weather conditions and other natural disasters. An eligible natural disaster is

\footnotetext{
${ }^{7}$ Beekeeping Tips, Mississippi State Department of Entomology, $<$ www.msstate.edu/Entomology/Beekeeping/Beekeeping001.html
} 
defined as any of the following: drought, excessive moisture, hurricane, earthquake, flooding, excessive heat, or insect infestation."

\subsubsection{Mays Tree Farm, Petersbura, WV}

Christmas can be a year-round business for many folks, just ask May's Tree Farm just outside of Petersburg. They started growing Christmas trees there in 1967 and have since expanded their business to seedlings, transplants, and ball \& burlap trees. In 1975, they developed a nursery segment to grow their own planting stock to supply other Christmas tree growers with high quality products.

Mays Tree Farm offers a wide variety of Christmas trees, to include: (1) Douglas fir, which accounts for most of their wholesale production, (2) concolor fir, the most aromatic of the Christmas trees, (3) Canaan fir, a very decorative Christmas tree with good needle retention, (4) Colorado blue spruce, a great replantable Christmas tree, (5) Fraser fir, offered almost exclusively at May's, and (6) scotch pine. Norway spruce is also available, although it does not make a very good Christmas tree because of poor needle retention. It can however, be planted on a broad range of sites, to include very wet sites.

"We sell between 6,000 and 12,000 wholesale cut Christmas trees annually. Seedling and transplants range from 60,000 to 100,000 annually," says David May. “About $90 \%$ of our sales are with repeat customers." In August, May's Tree Farm customers receive a letter alerting them to the upcoming Christmas sales to allow them to be the first in reserving the tree species they want by mail, fax, or phone. Though they offer many varieties, "our best 
sellers are Douglas-fir and concolor fir cut Christmas trees, as well as Canaan fir and concolor fir transplants." After September $1^{\text {st }}$, they start accepting orders from new customers. The trees are cut usually around mid-November and kept under a shade cloth to assure freshness.

The May's have Christmas trees growing on over 120 acres in Grant County. They take great pride in their hard efforts to bring a quality product to their customers. In addition to just growing a superior product, they do the little things that make a customer's experience a memorable one. For instance, they remove lower limbs (pruned by hand) so the customer doesn't have to hassle with them while putting the tree in a stand and placing presents under tree. They also fertilize, and apply herbicides to keep competing herbs and grasses down to reduce competition, and fungicides and insecticides to keep the tree's vigor.

Business ventures relying on natural resources eventually confront some aspect of nature that hinders production; there's no exception with Christmas trees. David says that two main problems they have faced in recent years are rhabdocline needlecast and whitetail deer. "The rhabdocline fungus on Douglas fir is a problem now, but wasn't a problem 5 years ago. This disease attacks new needles in the spring when the foliage is actively growing, when it is time to harvest the trees the infected needles fall off the tree leaving an abnormally open tree. This disease spreads rapidly. 
For the whitetail deer problem, The May's have tried numerous methods during the past 25 years in order to keep deer browsing to a minimum. David suggests that many repellants do work, but can be costly if you have to apply them to a large area annually. Their greatest success has been with their recently-installed high voltage, ten strand, eight-foot fence, but they advise that these fences can be very expensive depending on the type of specialized features you order.

Mays Tree Farm is one of the top producing Christmas tree farms in the Eastern United States and has sold and shipped trees to 35 states. They are happy to share their experiences with other landowners who are interested in starting a similar enterprise. They can be reached at:

\subsubsection{Peterson Paw Paws, Harpers Ferry, WV}

It was love at first bite for Neal Peterson when it came to paw paws. His enthrallment in this tropical fruit relative has persisted for over 30 years. While studying for his Master's Degree at West Virginia University in the fall of 1975, Neal was walking along a flood plain along the Monongahela River in WVU's Arboretum when he decided to pick up and try one of these tasty fruits. To his amazement, the fruit was absolutely delicious. Since that day, Neal has made his life's work revolve around that glorious day.

The paw paw tree (Asimina triloba (L.)) is a native tree and has a range that covers 25 states, reaching from southern Ontario (Canada) to northern Florida and as far west as Texas, Oklahoma, and Kansas. It is the largest native fruit tree in the United States and is 
the only temperate member of the tropical Annonaceae (the custard apple) family in North America. The tree's fruit is commonly called a paw paw, but is also known as the Poor Man's Banana. The fruit is tasty to some, resembling the flavor and shape of a banana. It possesses a sweet, rich taste and is surprisingly nutritious. Paw paw's nutritional value exceeds that of apples, peaches and grapes in vitamins, minerals, amino acids and calories. In fact, Lewis \& Clark's expedition on their return trip in the fall of 1810 subsided on paw paws when in western Missouri their rations ran low and no game was to be found.

Neal's interests in paw paws soon turn to an obsession. Neal's work at West Virginia University revolved around plant genetics, so when he took that first bite into a paw paw, it started a new excitement in his life. "Why don't we find paw paw fruit in grocery stores?" and "How come something that tastes this good has never been domesticated?" were questions he found asking himself. As a student of genetics he knew that the first task in plant breeding was to assemble the best parent trees that were out there. Neal then hid himself in the libraries of WVU and tracked down these trees, largely in part due to a National Contest that was held for the "Best Paw Paw" in 1916. With the information that he attained from that contest, Neal headed out to find the best stock of paw paws available.

Since then, Neal founded, owns, and operates Peterson Paw Paws and employees a total of 4 employees, all of which work on a week-by-week basis in the beginning of April. His business is located outside of Harpers Ferry (Berkeley County). Neal has the distinct honor of patenting trees, grafting tops of one tree to stocks of others to create a better overall tree. His three most desired varieties are the Shenandoah, Susquehanna, and the Rappahannock. He opts for the in-ground nursery style as opposed to the less intensive 
containerized system. "Our saplings are field grown, one-year grafts on three-year old seedling rootstock. They are vigorous and healthy and average three feet in height. Occasionally we have larger paw paws, 4 to 5 feet, for sale and available in pots. Our standard sapling is field-grown rather than container-grown because we think we are able to produce a stronger root system and sturdier overall tree this way."

Neal has enjoyed great success selling his trees. His 2007 stock has sold out, as well as his 2006, 2005, and 2004 stocks, selling about 800 trees per year. His Shenandoah variety is his best seller, and is most popular in the Washington D.C. farmer's markets, while both the Susquehanna and the Rappahannock varieties are popular among telephone and mail orders. Although the native range of paw paws covers 25 states, Peterson Paw Paws feels confident that their varieties will grow well in all the lower continental lower 48 states and puts their guarantee on it.

Weather can be an unpredictable opponent to tree farms. Neal admits "in 1999, I planted 3000 of my paw paw seedlings in Pendleton County and lost all of them by the year 2000 because of the drought." Raising rootstock is an additional problem. "For years I raised my own rootstock from seed which was a large project in its own right. I have sampled rootstock from many wholesale nursery growers and almost all is inferior. Finally, last year I found a source of quality rootstock.”

Neal is passionate about promoting the domestication of paw paws; in fact he founded the Pawpaw Foundation as a 503c1 organization to promote interest in paw paw and is also the co-editor of the Pawpaw Foundation's semi-annual newsletter. He has worked closely 
with university scientists investigating paw paws and declares that his three varieties are the best paw paws in existence.

\subsubsection{Richters Maplehouse, Pickens, WV}

Before spring is in the air, you can bet that Mike Richter is in the woods. Mike owns and operates Richter's Maplehouse, near Pickens, West Virginia. With "taps" on over 4,000 maple trees and 27 miles of sap line, he produces one of West Virginia's most "sweetest" distilled commodity—maple syrup.

Nestled in the hills of Randolph County, Mike's maple grove is ideal for producing maple syrup. As a child growing up near Pittsburgh, Pennsylvania, "a friend and I made syrup as a hobby." In addition to syrup, Mike also produces maple sugar, maple candy, as well as maple cream and pancake mixes.

For 25 years (1981 to 1996), Mike relied on his forest to generate supplemental income.

Since 1997, he has made the maplehouse a full-time trade. Mike encourages his neighbors to take advantage of the cash crop growing in their own backyards. He has purchased sap from other landowners and has mentored many that were interested in learning more about the business.

Mike is a pioneer in terms of West Virginia commercial "sugaring," the collection and production of maple syrup. He is now one of only three maple syrup producers in our state and acknowledges that the state could handle more. "There is a great demand for maple 
syrup, which could sustain more than me," Mike explains. Mike believes that the one thing that deters many people from starting a commercial syrup business is that it is labor intensive. Mike has made the process easier by investing in state-of-the-art equipment, including the 27 miles of tubing which allows the sap to flow downhill directly into large storage tanks. He also purchased a reverse osmosis machine that quickly separates a large amount of water from the sugary sap. But to maintain a bit of sugaring heritage, Mike also has antique sugaring equipment, including a 150-gallon wood-burning sap evaporator and sap collecting buckets that hang from trees.

Syrup season usually begins in early February as sap begins to rise in the trees, stimulated by the daily freeze-and-thaw cycle, Ideally, this happens when temperatures are below freezing at night and rise into the 40 's during the day. Sugar maple (Acer saccharum) is the preferred tree for tapping, although most maples with the exception of box elder (Acer negundo) can be used. Trees that are going to be tapped must be at least 12 inches. "We usually put one tap into a tree with a diameter of 16 to 24 inches, and 2 taps in trees larger than that." It takes, on average, 40 gallons of sap to make 1 gallon of syrup.

While many Americans may think of Vermont or New York of being the most prominent producers of maple syrup, Quebec, Canada produces over $80 \%$ of the world's maple syrup. But Mike has no problem selling the sweet syrup and makes most of his sales through mail and over the internet. He produces four different grades of syrup, which comprises $99 \%$ of his business. His syrup grades range from light to dark, with the medium amber being his best seller. He has many satisfied customers and quotes that 80 percent of his business is 
repeat business. His website brings in many new customers, as does the West Virginia Maple Syrup Festival which he helped establish in 1984. The annual event is held in nearby Pickens every March.

Mike has published many articles on sugaring in newspapers and magazines, and has a promotional video. He also frequently wins awards for his prize maple syrup from festivals and fairs. He is willing to assist anyone who has any questions about syrup production and is looking for an apprentice for hopes that he can retire. "The syrup business is a very good opportunity for someone who would like to earn a living from the land. It can be done and I am proof."

\subsubsection{Shady Oaks Ginseng Company, Poca, WV}

Diversifying products grown in the forest can help a family or business enterprise assure a more stable stream of revenues. Helping people diversify the plants they grow in the woods is what Shady Oaks Ginseng Company does best. The company was founded in 1998 by Chris and Leslie Burdette on their 32-acre tract outside of Poca in Putnam County, and has evolved into producing a rich array of medicinal plants and other products for gardeners, farmers and herb producers throughout the region.

Shady Oaks Gingseng Company specializes in high quality, wild-simulated ginseng and goldenseal roots. All the rootlets they sell are grown under the natural shade of their rich woods. "My wife was the one who originally had the idea for ginseng production" admits Chris. "We started out with ginseng and goldenseal with intentions of waiting 7-10 years 
until harvest. After a couple of years, we began selling transplant rootlets, and that led us into growing other native plants for transplanting."

In addition to growing goldenseal and one-, two-, and three-year old ginseng rootlets, they also offer stratified (specially prepared for ready sprouting) ginseng seed, bloodroot, black cohosh, blue cohosh, wild geranium, three types of trillium, columbine, twinleaf, maidenhair fern, jack-in-the-pulpit, Solomon's seal, and the most recent additionsbluecrop, duke and northland blueberry varieties.

Chris advises people who are interested in growing these plants to take some time to get experience growing ginseng and also to diversify into some other types of herbs and expand their markets. "The ginseng business can be profitable but it can also be very tricky so don't quit your day job and start planting ginseng. If you don't want to take the time to grow your ginseng from seed your best bet would be to buy some 3 -year-old rootlets and transplant them into your own beds. You could be producing your own seeds the following year and have full seed production in your second year." Chris also encourages new growers in the state to become a member of the West Virginia Ginseng Growers Association (WVGGA) and learn from other growers.

"We have always had a desire to be able to get away from being on the road working all the time, so when this opportunity presented itself, we decided to give it a try." 
Diversifying your forest products is similar to a business portfolio; you should avoid putting all your eggs into one basket. "In 2002, we started growing blueberries, raspberries, and blackberries for summer berry production. [Most recently], we started growing shiitake and oyster mushrooms. I am sure some people can make a living off of one product but we have found that we have to diversify and make something off several items and then expand those into a viable business."

"We have found the biggest problem is having enough time to develop our farm into a money making endeavor. We currently run another company and would like to convert to farming full time. Local marketing [is also another problem]. Most of our ginseng, goldenseal, and other native plant sales are for live plants to those who want to start their own plants on their farms. There are a few local sales, but most of our ginseng and goldenseal rootlet business comes from out of state via our website."

Chris and Leslie take great pride in their products and are eager to assist others who are willing to try this trade. 


\section{Chapter 5: Landowner Survey}

\section{1: Introduction}

Non-Timber Forest Products (NTFPs) are often the foundation of private family enterprises and are usually produced for enjoyment or to generate supplemental income. These products are often categorized into four types: edible forest products (various berries, mushrooms, nuts, etc.), specialty wood products (canes, hand carvings, etc.), products used in the floral and decorative trade (Christmas trees, various mosses, vines, etc.), and medicinal and dietary supplements (American ginseng (Panax quinquefolius), goldenseal (Hydrastis canadensis), etc.); (Chamberlain et al. 1998). Harvesting of NTFPs in West Virginia's and other states' rural communities is often done in "informal markets" --markets where transactions are made on a cash basis and few, if any, records are kept (Chamberlain et al. 1998).

Though NTFPs have played a significant role to the income of many West Virginia residents (whether a grower, picker, harvester, distributor, or buyer) there is not much scientific, or otherwise systematically recorded data about these products' benefits, tradeoffs, risks, and constraints stemming from their harvest or their markets (Von Hagen et al. 1996, McLain and Jones 2002). Bailey (1999) found that the harvesting of these products is often motivated by financial gain, which can be intensified by numerous factors, including: the harvester's financial need, time available for harvest, and the prices offered for their respective product. The ecological status of species harvested as NTFPs is often not known. Likewise, information on harvesters is usually unavailable (Jones and Lynch 2002). American ginseng is one exception; the West Virginia Division of Forestry is 
required by law to certify and weigh this product before the root leaves the boundaries of the state and have tracked this data since 1979 (WVDOF 2007).

Ever since ginseng was first 'discovered' in Canada in 1716 (Emery 2002), its exportation to the Orient has led many to the woods of Appalachia to harvest the prized root. In West Virginia, which is completely encompassed in ginseng's natural range, the harvest and sale of this plant is often regarded as the 'cultural fabric of rural communities' (Hufford 1997, Bailey 1999). Bailey (1999) also states that in a 1995 telephone survey, $42 \%(n=922)$ of ginseng harvesters surveyed also harvested goldenseal in the weeks and months heading into ginseng season. Both of these highly valued species are listed and protected in international trade by the Convention on International Trade in Endangered Species (CITES) Treaty, Appendix II, which requires monitoring in the wild to ensure that harvest levels cause no detriment to the species' survival.

Despite increasing use and recognition of NTFPs, they continue to be thought of as "rural" resources collected from rural areas and important to rural people (Guijt et al. 1995). Jones and Lynch (2002) state that NTFP harvesting in the United States is often rooted in traditions that have persisted in spite of declining resource bases, loss of rural knowledge, and the domination of timber production. Without understanding cultural use patterns, it is difficult to identify who harvests these natural products and what motivates them to do so.

In order to substantiate the importance of NTFPs to West Virginia landowners, a survey was conducted to identify the interest level and educational needs of these landowners with 
respect to NTFPs. Specifically, our objective was to examine landowner interest, or receptiveness, in NTFPs, and the effect of urbanization of farm and forestland on the interest in production or harvesting of NTFPs.

\section{2: Methodology}

\subsection{1: Scope of study}

Four counties were selected for this survey based on population and proximity to urban centers. To examine NTFP interest levels among landowners in areas of different urbanization intensities, counties were selected to represent a "rural" region, and an "urban" region. The rural counties selected were Ritchie and Wirt counties in northwestern West Virginia and the urban counties were Berkeley and Jefferson counties in eastern West Virginia. Distinct differences between the two regions involve the level of urbanization; in the eastern panhandle development is spreading rapidly on flat agricultural land of Berkeley and Jefferson Counties, in contrast to the traditional timber-based rural setting of the western Ohio River valley (Ritchie and Wirt Counties) (Appendix 10). To better illustrate this point, the primary industries in the selected counties are listed in Table $5-1$.

Table 5-1: Primary industry by selected county for NTFP survey. *

\begin{tabular}{|c|c|c|c|c|}
\hline \multirow{2}{*}{ Industry Rank } & \multicolumn{4}{|c|}{ County } \\
\hline & Berkeley & Jefferson & Ritchie & Wirt \\
\hline 1 & Retail & Retail & Manufacturing & Farming \\
\hline 2 & Health Care & Arts/Entertainment & Mining & Retail \\
\hline 3 & Construction & Food Services & Farming & Health Care \\
\hline
\end{tabular}

*All data obtained from the West Virginia County Data Files (2006). 
According to Rosenberger et al. (2002), land in the eastern panhandle of West Virginia is undergoing significant changes in land use and ownership resulting from a combination of largely widespread uncontrolled forces. Productive agricultural land is being converted to residential, commercial or industrial uses. For example, a substantial amount of land in and around counties located near large metropolitan centers, particularly in the eastern panhandle region, is being used for second or retirement homes, campground and weekend recreational use, or has been purchased for profitable investments by residents of the District of Columbia, Baltimore, and other cities. Most of these developments seek flat, well-drained land for their activities (Rosenberger et al. 2002).

Rural areas are defined by the USDA National Agricultural Library (2005) as having a population less than 2,500 people per square mile. Although all counties in West Virginia fall under this classification, both rural counties in this survey have considerably lower population densities than the counties in the eastern panhandle. Furthermore, Shi et al. (1997) demonstrated the significant effects of distance from urban areas on the price of farmland in West Virginia. From this we infer that Berkeley and Jefferson have more urban influence than Ritchie and Wirt counties based on their respective proximities to major urban areas. Therefore, Ritchie and Wirt Counties are classified as more rural than Berkeley and Jefferson Counties (Table 5-2). 
Table 5-2: County characteristics selected for survey. *

\begin{tabular}{lcccc}
\hline Field & Ritchie & Wirt & Berkeley & Jefferson \\
\hline Population (2005 estimate) & 10,540 & 5,896 & 93,394 & 49,206 \\
Land Area (sq mile) & 453 & 232 & 321 & 209 \\
Persons per square mile & 22.8 & 25.2 & 236.5 & 200.9 \\
Median Household Income (2003) & $\$ 29,774$ & $\$ 32,012$ & $\$ 43,301$ & $\$ 48,567$ \\
\hline
\end{tabular}

*All data obtained from US Census Bureau Webpage (2007).

\subsection{2: Survey instrument}

Mail surveys, because of their low cost and ease of dissemination (Cui 2003) were mailed out to landowners from January 2007 to March 2007 to collect landowner information for the study.

The survey database, obtained in 2005 from the WV Tax Office originally consisted of 93,753 entries between Berkeley, Jefferson, Ritchie, and Wirt Counties. The data was sorted by acreage and any land parcel that was less than ten acres required for this survey was eliminated. Duplicate entries (landowners with multiple tracts of land) were also deleted. Through this process, the number of eligible survey entries from all four counties dropped $93.3 \%$, from 93,753 to 6,289 .

The county data sets were then combined by region (Western=Ritchie and Wirt; Eastern=Jefferson and Berkeley) and each landowner was assigned a random number, generated by Microsoft Excel using the random number function $(=\operatorname{rand}())$. These random numbers were then sorted in ascending order, and the lowest 2000 numbers $(1,000$ from each region), and the corresponding landowners associated with those numbers, were 
selected for the survey. Landowners were then sorted alphabetically by last name by region and then assigned a four digit control number, specified as "WVU \#" to track respondents for follow-up mailings. For ease of cataloging, the eastern region's WVU number started with " 1 " and the western's " 2 ". Through this random selection process, $1.31 \%$ of all landowners in Berkeley County were selected to participate in this survey, 1.42\% from Jefferson County, 5.21\% from Ritchie County, and 4.73\% from Wirt County (Figure 5-1).

Figure 5-1: NTFP Survey Information by County.

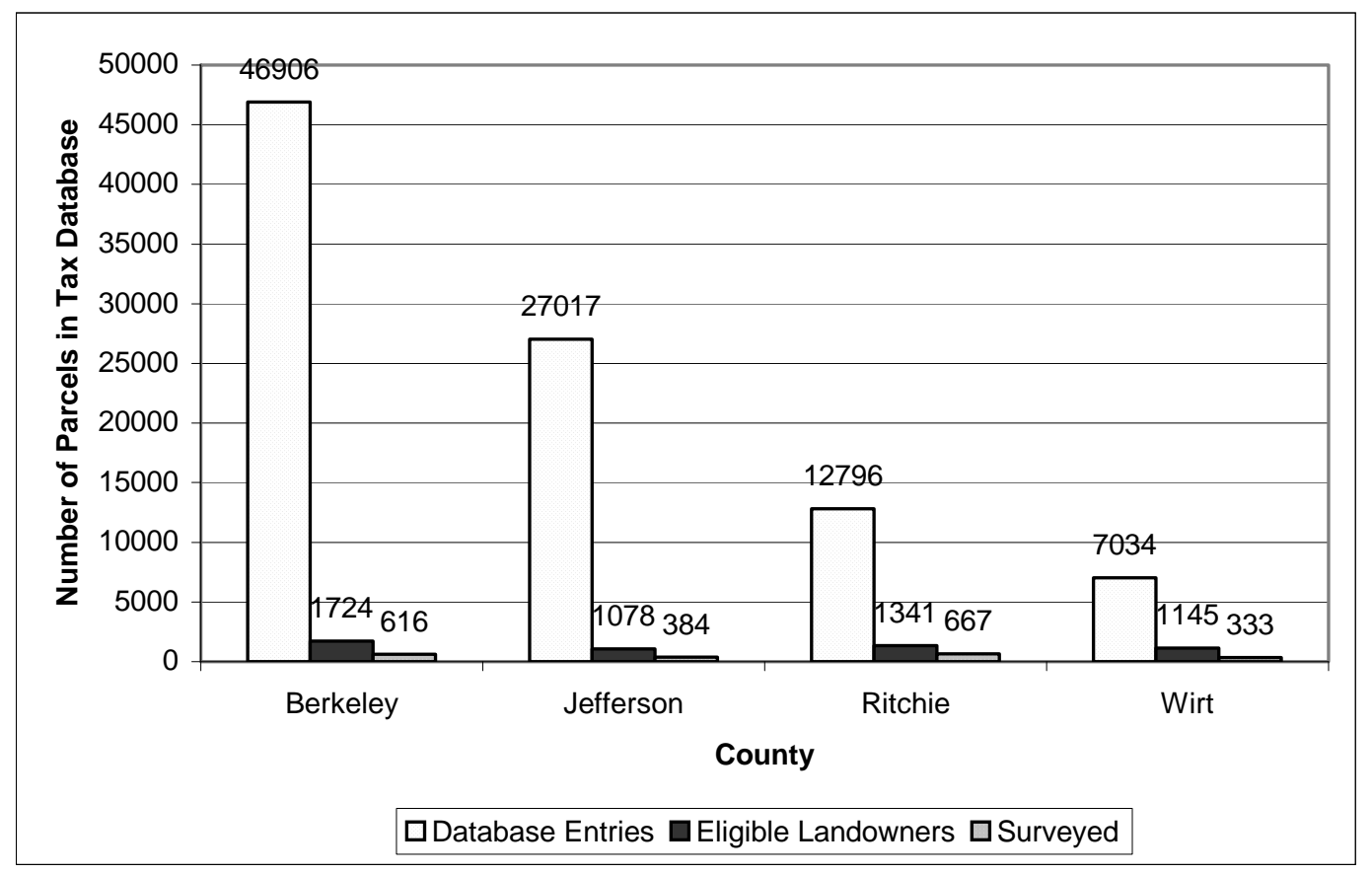

Before any mailings were sent out, all mailing articles were reviewed and approved by West Virginia University's Institutional Review Board to protect the rights and welfare of the individuals who serve as subjects for this survey (Appendix 11). The mailing itself consisted of four stages; a pre-notification postcard, the mailed questionnaire, a reminder 
postcard, and a second mailed questionnaire for those who had not responded to the first mailing. Pre-notification of the survey to the randomly selected landowners was done by a label-addressed postcard (Appendix 12) to alert them of the upcoming survey, as well as to establish its legitimacy and eliminate incorrect mailing addresses (Fox et al. 1988). These postcards were mailed from Morgantown, West Virginia on 19 January 2007. Postcards that were returned but indicated a new forwarding address for that landowner were updated in the database and new postcards were then sent to the updated address $(n=7)$.

An official cover letter with West Virginia University (WVU) stationary (Appendix 13) was enclosed with the landowner survey in an attempt to raise response rate, to educate the participants about the survey's goals, and elaborate on the survey instructions (Dillman 1983, Fox et al. 1988). A four-page survey (including cover page) was used to collect data for the study (Appendix 14). The categories of questions included questions asking whether the landowner/individual currently owned land that was greater or equal to 10 acres (in case they sold parcels or their larger landholdings), owned (or had interest in) a forest-based enterprise, and harvested (or had interest in) NTFPs. The minimum sampling acreage was used because landowners with less than 10 acres have limited management options (Gracey and Pelkki, 1996). General demographic information included age, gender, occupation, income, and education. Although research has shown there is a broad age range among harvesters, little literature discusses age as a variable in NTFP harvester research, and increasing attention is being given to the variable of gender (Jones and Lynch 2002). Gilden (1997) states that although men have traditionally dominated the harvesting 
of NTFPs, recent research suggests that commercial harvesting of NTFPs affords economic opportunities for women.

For data analysis, age was left as a continuous variable, while education, income, and occupations were categorical. Education was broken down into three levels: (1) high school diploma or less, (2) Some college up to an associates degree, (3) an undergraduate degree or further. Income was broken down into four levels: (1) less than $\$ 15,000,(2)$ $\$ 15,001$ to $45,000,(3) \$ 45,001$ to $\$ 75,000$, and (4) greater than $\$ 75,001$. Occupations were broken down into blue-collar, white-collar, retired, and other (unemployed, disabled, etc.).

Also included in the survey instrument were questions regarding the individual's interest in future NTFP workshops, including how far the landowner was willing to travel and how much they would be willing to pay for a two-hour workshop. The first round of surveys was mailed from Morgantown on 30 January 2007. Accompanying the survey was a selfaddressed stamp envelope (first class postage stamp). The use of a postage stamp, as opposed to a business stamp has also been shown to increase survey response rate (Cui 2003).

Records of returned surveys were updated daily to reflect that the surveys had been received, eliminating the participants from further mailings during the survey period. Three weeks after the initial survey was sent (20 February 2007), reminder postcards (Appendix 15) were mailed to all participants that had not yet replied to the initial survey. 
Two weeks following the mailing of the reminder postcard (5 March 2007), the participants who had not returned a survey were sent a follow-up survey, identical to the initial survey. This survey was also prefaced by an updated official cover letter with WVU's stationary (Appendix 16) requesting that they complete the survey at their earliest convenience, and acknowledging the fact they may have already sent the survey in. Only surveys that were received from 1 February 2007 to 31 March 2007 were used in the analysis.

In order to define the relationship between variables, the dependent variables examined for analysis were the fourteen NTFPs listed that asked landowners to indicate their harvest, or interest level, in each product (Figure 5-2).

Figure 5-2. Survey question that indicated the interest level for each non-timber forest product. Points were assigned to each specific interest level. If a landowner frequently harvested an NTFP, a value of 5 was assigned to that product. If occasionally (four), rarely (three), never harvested but interested (two) and never harvested and not interested (one).

\begin{tabular}{|l|c|c|c|c|c}
\hline & Frequently & Occasionally & Rarely & $\begin{array}{c}\text { Never, but } \\
\text { interested }\end{array}$ \\
Non-Timber Forest Product Type & interested & $\square$ \\
\hline Ginseng & $\square$ & $\square$ & $\square$ & $\square$ \\
\hline Goldenseal & $\square$ & $\square$ & $\square$ & $\square$ \\
\hline Specialty Wood Products (canes, handles, etc) & $\square$ & $\square$ & $\square$ & $\square$ \\
\hline Black Cohosh & $\square$ & $\square$ & $\square$ & $\square$ \\
\hline Vines (grape, camphor, etc.) & $\square$ & $\square$ & $\square$ & $\square$ \\
\hline Ramps & $\square$ & $\square$ & $\square$ & $\square$ \\
\hline Shiitake Mushrooms & $\square$ & $\square$ & $\square$ \\
\hline Morel Mushrooms & $\square$ & $\square$ & $\square$ \\
\hline Maple Syrup & $\square$ & $\square$ & $\square$ \\
\hline Boughs/Cones & $\square$ & $\square$ & $\square$ \\
\hline Fruits/Berries/Nuts & $\square$ & $\square$ & $\square$ \\
\hline Honey & $\square$ & $\square$ & $\square$ \\
\hline Fish & $\square$ & $\square$ & $\square$ \\
\hline Hunting Leases & $\square$ & $\square$ & $\square$ \\
\hline
\end{tabular}

These fourteen products were then classified into four categories (Edibles, Specialty Wood Products, Floral/Decorative, and Medicinal Herbs). Logistic regression using a stepwise 
variable selection procedure was performed separately for each of the categories with a model that initially included ten independent variables. The independent variables included five demographic questions, and six property characteristic questions (Table 5-3).

Significant independent variables identified in the stepwise regressions were then used in a model against each other separately by topic to provide the best fit of independent variables that describe landowners' interest in NTFPs.

Table 5-3: Independent variables tested in logistic regression analysis

\begin{tabular}{ccc}
\hline Category & Demographics & Property Characteristics \\
\hline & Age & Property Owned (Years) \\
& Occupation & Total Acres Owned \\
Variables & Education & Acres Forested \\
& Income & Acres Other (Pasture, etc) \\
& Gender & Last Timber Harvest (Years) \\
& & Region \\
\hline
\end{tabular}

To separately determine the interest levels by the four NTFP categories, harvest levels for each product within a category (Table 5-4) were combined and then categorized as "Very Interested". The response variable for this analysis used the single highest harvest level from among the products within the specific category for each respondent and only the highest 'harvesting level' (frequently, occasionally, and rarely) to determine harvest versus interest levels. For example, if a landowner indicated that he/she was interested (value=2) in ginseng, rarely harvested (value=3) goldenseal, and had no interest in black cohosh (value $=1$ ), then the value for rarely harvesting goldenseal (3) would be the only value counted for that category and the exampled landowner would still be considered "very interested" in medicinal NTFPs. 
Table 5-4. Categorization of the NTFP products.

\begin{tabular}{clcc}
\hline & & & \\
Edible & Specialty Wood Products & Floral/Decorative & Medicinal \\
\hline Ramps & Specialty Wood Products & Vines & Ginseng \\
Morel mushrooms & & Boughs/cones & Goldenseal \\
Shiitake mushrooms & & Black cohosh \\
Fruits/berries/nuts & & \\
Honey & & \\
Syrup & & \\
Fish & & \\
\hline
\end{tabular}

For hypothesis testing, all statistical significance levels were set at alpha $(\alpha) \leq 0.05$.

Independent variable Chi square values were used to test the null hypothesis that selection by a respondent of a specific NTFP category was independent of all landowner characteristics. Descriptive statistics were computed to highlight differences in region, property characteristics, and demographics.

Similar tests were conducted for 'willingness to travel' to a two-hour workshop, as well as a landowner's 'willingness to pay', as dependent variables. These tests were run against the same independent variables as that of the NTFP categories (Table 5-4). These tests were performed to help determine characteristics of landowners and their willingness to attend an educational workshop regarding forest-based products.

\section{3: Results}

\subsubsection{Survey Response}

Of the 2,000 surveys sent to the randomly selected West Virginia landowners, 351 prenotification postcards were returned because of bad addresses, resident deceased or unable 
to forward. The remaining 1,649 had valid addresses and 738 of these surveys (45\%) were returned. Although 738 landowners responded, 207 were excluded from the analysis because they either returned the survey blank (167), as instructed if they were not interested in participating, or sold their land that was listed in the 2004 tax record and currently own no land in West Virginia or less than 10 acres (40), thus reducing our usable responses to $531(32 \%)$. The respondents owned property in the selected counties for this survey, although some reside in different West Virginia counties or different states. This included 436 West Virginia residents from 22 different counties (Figure 5-3), and absentee West Virginia landowners residing in 20 different states and the District of Columbia (Figure 5-4).

Figure 5-3: County distribution of landowner respondents to NTFP survey.

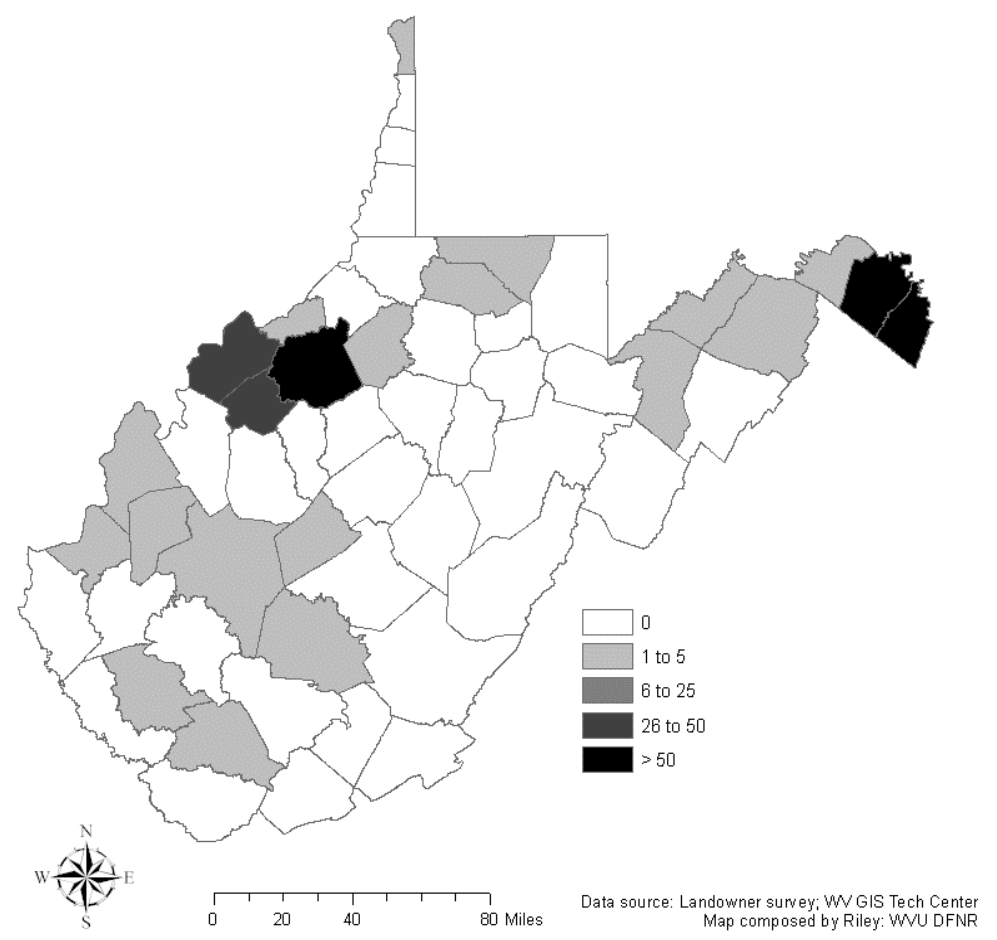


Figure 5-4: States from which Absentee Landowners Responded to the NTFP Survey

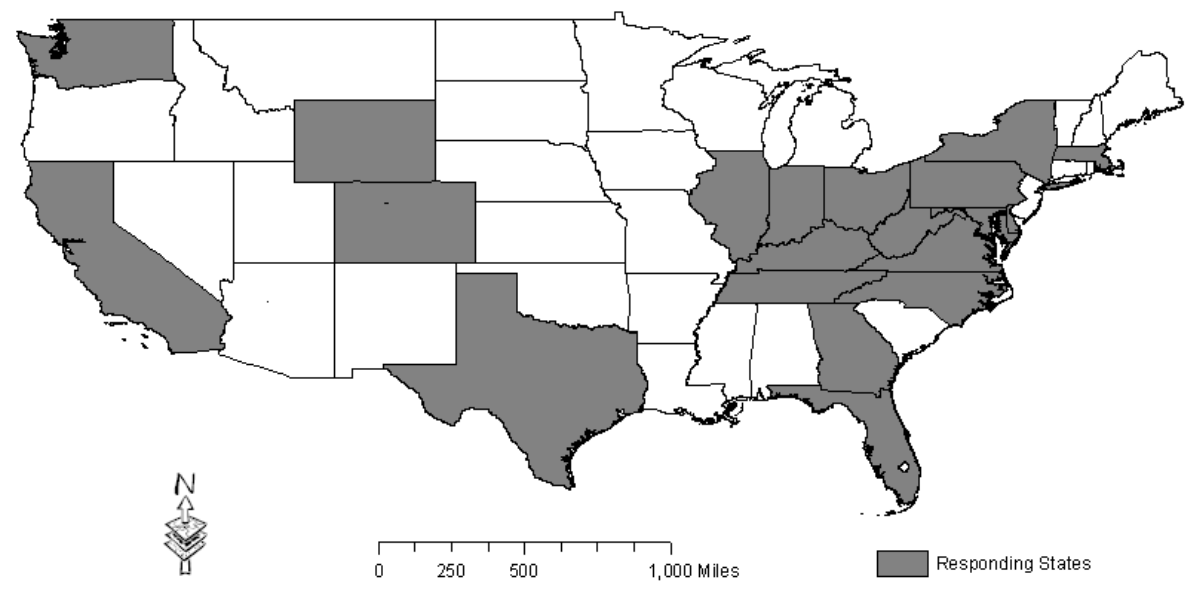

Map composed by Riley: WW Division of Forestry and Natural Resources
Data Source: WWJ GIS Tech Center

Overall, the "average" landowner that responded to this survey was 61 years old (min 28 , $\max 106)(\mathrm{n}=516)$, had "some college education", and made an income between $\$ 45,001$ and $\$ 60,000$. The average property size was 92 acres $(\min 10 ; \max 739 ; n=523)$, with 52 acres forested $(\min 0, \max 739)(\mathrm{n}=518)$ and 38 acres in other land uses like pastures, fields, etc. $(\min 0 ; \max 525 ; n=510)$. Almost $39 \%(n=209)$ of all respondents $(n=538)$ were retired $(n=209), 24 \%(n=132)$ were white-collared workers, $28 \%(n=153)$ bluecollared, $2 \%(n=10)$ were other (disabled, unemployed), and $6 \%(n=34)$ left this survey question blank.

Overall and regionally, males made up a majority of the landowners who filled out the survey (Table 5-5). 
Table 5-5: Survey respondents by gender.

\begin{tabular}{l|ccc}
\hline & Male & Female & Did not answer \\
\hline Overall $(\mathrm{n}=531)$ & $420(79 \%)$ & $99(19 \%)$ & $12(2 \%)$ \\
Eastern (Urban) $(\mathrm{n}=265)$ & $204(77 \%)$ & $53(20 \%)$ & $8(3 \%)$ \\
Western (Rural) $(\mathrm{n}=266)$ & $216(81 \%)$ & $46(17 \%)$ & $4(2 \%)$ \\
\hline
\end{tabular}

Eighteen respondents (4\%) indicated that they have owned or operated a forest-based business, and fifty-four (14\%) respondents have thought about opening a forest-based enterprise. The interests were broad and categorized by NTFP type (Table 5-6).

Table 5-6: Number of respondents that have owned or have thought about starting their own forest-based business.

\begin{tabular}{lcccc}
\hline & \multicolumn{2}{c}{ Eastern Region } & \multicolumn{2}{c}{ Western Region } \\
\hline NTFP Type & Owned & Thought about & Owned & Thought about \\
\hline Christmas Trees/Tree Farm & 4 & 13 & 1 & 7 \\
Ginseng/Medicinal Herbs & 0 & 4 & 0 & 6 \\
Mushrooms & 1 & 2 & 0 & 2 \\
Sawmill/Firewood & 2 & 0 & 4 & 2 \\
Fruits/Nuts/Berries & 0 & 6 & 0 & 4 \\
Others* & 2 & 3 & 4 & 5 \\
\hline
\end{tabular}

*Others include honey/syrup production, timber/lumber, and hunting leases

\subsection{2: Effects of Region on Interest Level}

The response rate (total $n=531)$ by region was $50 \%(n=265)$ from the Eastern/Urban region and $50 \%(\mathrm{n}=266)$ from the Western/Rural region. The urbanization, or higher rate of land turnover, of the eastern panhandle could possibly explain the higher rate of returned presurvey postcards for invalid addresses $(n=215,21.5 \%$; western region: $n=136,13.6 \%)$, as property owners have the option to sell or parcel off their land, for additional revenue. One respondent commented, "Here in Berkeley County, it is a task just to keep land out of the 
hands of developers. Nothing you can grow can compare to what the land can bring.

Water and sewer land sells for up to $\$ 70,000$ for a quarter acre."

A population proportional t-test was performed to determine whether or not the interest in specific NTFPs was statistically different among regions. No products were significant ( $\alpha$ $\leq 0.05$ ) and the western region's interest in ginseng was the only product in which there were more respondents (52\%) interested than not interested (Figure 5-5).

Figure 5-5: Percentages of interest in specific non-timber forest products by region.

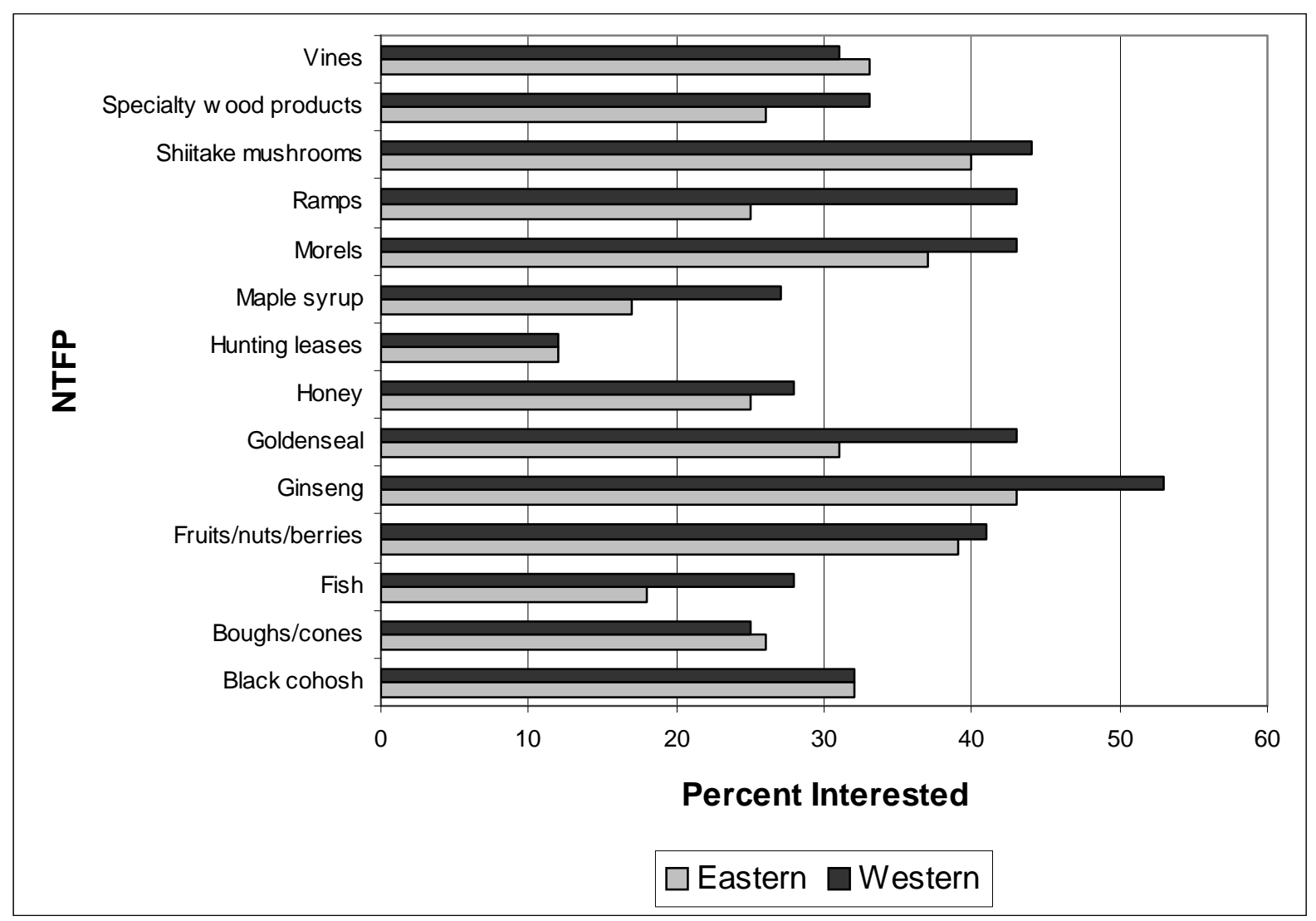

Responding landowners in the western region are shown to be more interested in all NTFP categories than landowners from the eastern region with the exception of floral and decorative category (Figure 5-6). 
Figure 5-6: Landowner interest by NTFP product by region (harvesters excluded).

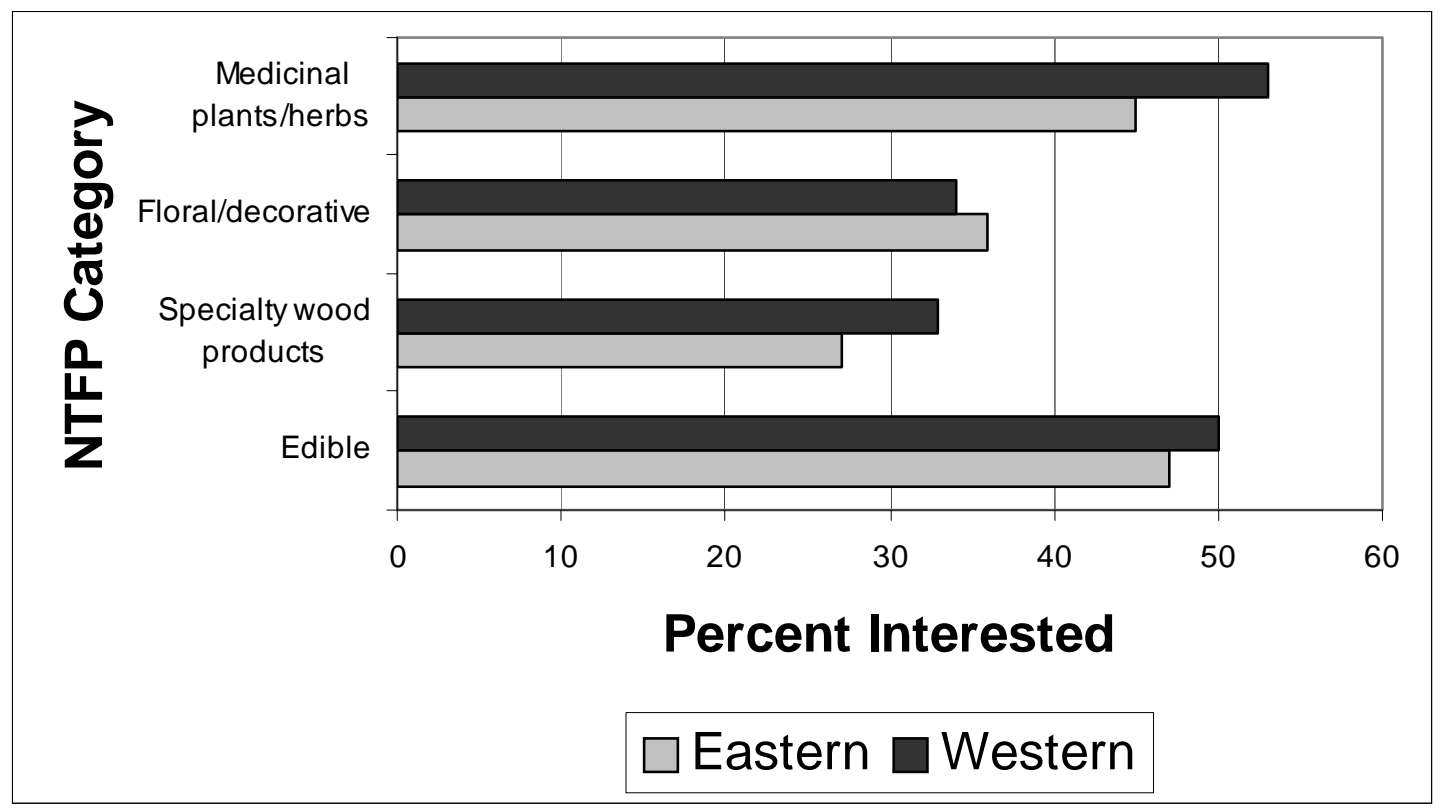

While both regions' respondents have owned their property for about the same amount of time, the average property size for the Eastern/urban region was notably smaller than that of the Western/rural region (Table 5-7).

Table 5-7: Average landowner property characteristics by region.

\begin{tabular}{ccc}
\hline Property Characteristics & Eastern/Urban & Western/Rural \\
\hline Property Owned (Years) & 24.14 & 22.5 \\
Total Acres Owned & 67.7 & 115.96 \\
Acres Forested & 24.53 & 79.49 \\
Acres Other (Pasture/Fields) & 40.03 & 35.67 \\
Last Timber Harvest (Years) & 16.69 & 15.34 \\
"Never" had Timber Harvested (\#) & 57 & 29 \\
"Unknown" Last Timber Harvest (\#) & 59 & 35 \\
\hline
\end{tabular}

Landowners who are from the western region (rural) were 2.7 times $\left(p=0.011, \chi^{2}=6.55\right)$ more likely to be more interested in medicinal herbs than 'urban' landowners (Table 5-8). 
Forested acres owned were a significant variable in the medicinal herb, edible, and specialty wood product categories, while age was significant in all categories.

Table 5-8: Odds ratio (point estimates) and p-values for each logistic procedure by all combined harvesting levels (frequently, occasionally, and rarely), and interest levels. The combined harvesting levels are called 'very interested' (VI), while landowners who showed interest but have never harvested are referred to as 'interested (I).' Both levels are compared against landowners who indicated that had 'no interest' (NI).

\begin{tabular}{llrr}
\hline Dependent Variables & \multicolumn{1}{c}{ Significant Independent Variables } & Point Est. & p-value \\
\hline \multirow{2}{*}{$\begin{array}{c}\text { Edibles } \\
(\mathrm{n}=439)\end{array}$} & Age (VI vs. NI) & 0.955 & $<0.0001$ \\
& Age (I vs. NI) & 0.954 & $<0.0001$ \\
& Education (VI vs. NI) & 0.602 & 0.0087 \\
& Acres owned, forested (VI vs. NI) & 1.007 & 0.0013 \\
& Acres owned, forested (I vs. NI) & 1.004 & 0.0498 \\
& & & \\
Spec. Wood Products & Age (I vs. NI) & 0.968 & 0.0016 \\
$(\mathrm{n}=375)$ & Acres owned, forested (VI vs. NI) & 1.006 & 0.0113 \\
& Acres owned, forested (I vs. NI) & 1.006 & 0.0003 \\
& & & \\
Floral/Decorative & & & \\
$(\mathrm{n}=327)$ & Age (VI vs. NI) & 0.970 & 0.0212 \\
& Age (I vs. NI) & 0.978 & 0.0389 \\
& Income (VI vs. NI) & 0.839 & 0.0429 \\
& Income (I vs. NI) & 1.230 & 0.0016 \\
Medicinal Herbs & & & \\
$(\mathrm{n}=418)$ & Region West vs East (VI vs. NI) & 2.694 & 0.0105 \\
& Age (VI vs. NI) & 0.971 & 0.0268 \\
& Age (I vs. NI) & 0.955 & $<0.0001$ \\
& Education (VI vs. NI) & 0.468 & 0.0049 \\
& Acres owned, forested (VI vs. NI) & 1.006 & 0.0072 \\
& Acres owned, forested (I vs. NI) & 1.005 & 0.0052 \\
& & & \\
\hline
\end{tabular}

\subsection{3: Willingness to Attend Future Workshops}

Region was not a statistically significant factor affecting neither a respondent's willingness to pay nor willingness to travel to an educational workshop on NTFPs. However, 
landowners from the Eastern panhandle responded that they would travel an average of 22.2 miles ( $\mathrm{n}=213)$ and pay $\$ 16.89(\mathrm{n}=203)$ to attend a two-hour workshop on non-timber forest products. Comparatively, landowners from the western region indicated that they would travel and average of 25.1 miles $(n=201)$ and pay $\$ 11.71(n=194)$ for the same twohour workshop (Table 5-9).

Table 5-9: Landowners willingness to pay (dollars) and travel (miles) to an NTFP workshop.

\begin{tabular}{lcccc}
\hline & \multicolumn{2}{c}{ Eastern (Urban) } & \multicolumn{2}{c}{ Western (Rural) } \\
& Willing to Pay & Willing to Travel & Willing to Pay & Willing to Travel \\
\hline Average & $\$ 16.89$ & 22.2 & $\$ 11.71$ & 25.1 \\
Minimum & $\$ 0.00$ & 0 & $\$ 0.00$ & 0 \\
Maximum & $\$ 150.00$ & 200 & $\$ 150.00$ & 400 \\
\hline
\end{tabular}

Landowners who own forested land are also more likely to be willing to pay and travel to a two-hour workshop than those who would not be willing to pay or travel (Table 5-10).

Also, landowners with a high school education (or equivalent) are 0.355 ( $\mathrm{p}=0.0007$, $\left.\chi^{2}=11.57\right)$ times less likely to pay and $0.397\left(\mathrm{p}=0.0073, \chi^{2}=7.19\right)$ times less likely to travel to a workshop than landowners who are not interested.

Table 5-10: Odds ratio estimates and p-values for each logistic procedure by landowner's willingness to travel and willingness to pay for a two-hour workshop. 'Willingness to pay' and 'willingness to travel' questions were fill-in the blank with appropriate dollars and miles (respectfully). The data was then categorized into two dependent variables, either 'willing to pay/travel' or 'not willing to pay/travel'.

\begin{tabular}{llrr}
\hline Dependent Variables & Significant Independent Variables & Point Est. & p-value \\
\hline Willingness to Pay & Education (high school or equivalent) & 0.355 & 0.0019 \\
$2 \mathrm{hr}$ Workshop & Age & .0946 & 0.0007 \\
$(\mathrm{n}=319)$ & Acres owned (forested) & 1.011 & 0.0006 \\
& & & \\
Willingness to Travel & Education (high school or equivalent) & 0.397 & 0.0073 \\
$2 \mathrm{hr}$ Workshop & Income (<= 45,001 to 60,000) & 0.528 & 0.0209 \\
$(\mathrm{n}=307)$ & Age & 0.973 & 0.0127 \\
& Acres owned (forested) & 1.006 & 0.0023 \\
\hline
\end{tabular}


The response to this survey by landowners revealed a high degree of interest in all four categories of NTFPs. Figure 5-7 shows that over 100 landowners for each NTFP category indicated some level of interest, as well as a very strong interest in edible NTFPs.

Figure 5-7: Interest levels of all responding landowners.

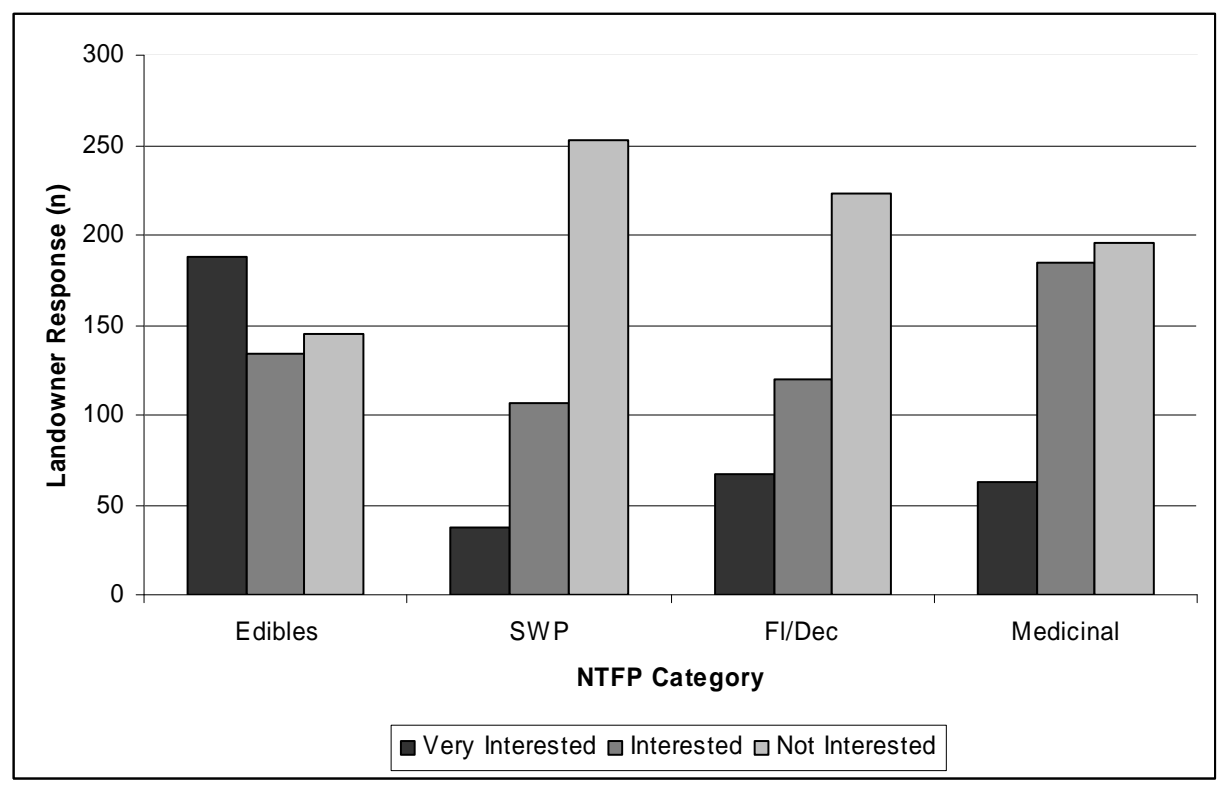

\section{4: Discussion}

Our survey revealed that respondents from both the eastern and western regions of this study actively harvest and are interested in NTFPs. Specifically, respondents from the western region are statistically more likely to harvest medicinal herbs than the eastern region (Table 5-8). Moreover, landowners from both regions show significant interest in all four categories of NTFPs (Figure 5-7). Specific demographic factors related to NTFP activity and interests are age, education (for the edible and medicinal NTFP categories), and income (for the floral and decorative NTFP category) (Table 5-8). As a result of our survey, educational outreach could be geared toward older populations that have a majority of their land forested. 
The results of this survey are unique due to the fact that there is a lack of available harvesting and NTFP interest information not only in West Virginia, but nationally (McClain and Jones 2002, Von Hagen et al. 1996). One other related survey was completed by Chamberlain and Predny (2004), who found that a high concentration of medicinal plant-based enterprises exists in the southern Appalachian forest (rural communities). The current survey supports that finding by evidence that respondents in the rural area were more likely to harvest and have an interest in medicinal plants (Figure $5-5)$.

While the current study shows that a majority of respondents have at least harvested or show interest in all four categories of NTFPs in both regions, it does not necessarily suggest that educational programs need to cover all the topics to be successful. Edible forest products, dominated by fruits, nuts, and berries, garnered the most interest of all products, while specialty wood products received the least amount of interest, particularly in the eastern region.

\section{5: Conclusions}

1. Over $64 \%$ of all respondents indicated interest in at least one of the four NTFP categories.

2. Landowners from the western (rural) region were 2.7 times more likely to have more of an interest in medicinal NTFPs (ginseng, goldenseal, etc.) than landowners from the urban region. 
3. With the exception of medicinal NTFPs, region was not a significant factor related to whether a respondent had an interest in NTFPs.

4. There are three significant demographic variables related to NTFP interest; age for all four NTFP categories, education for edible and medicinal NTFPs, and income for floral and decorative NTFPs.

5. Almost $70 \%$ of landowners from the urban region and $73.7 \%$ of rural landowners would not pay for a two-hour workshop. Urban landowners willing to attend a workshop would, however, pay \$5 more than rural landowners (\$16.89 to \$11.71). On the other hand, rural landowners are willing to drive 3 miles further than urban landowners for the same workshop (25.1 miles to 22.2 miles). 


\section{Literature Cited}

Adams, Katherine L. 2002, Ginseng, Goldenseal, and Other Native Roots. National Center for Appropriate Technology. Horticulture Technical Note. P. 1-12.

Andrews, M. 1983. Evaluation: An essential process. Journal of Extension (SeptemberOctober) pp. 8-13.

Apsley, Dave and Chip Carroll. 2004. Growing American Ginseng in Ohio: Selecting a Site. The Ohio State University Extension Fact Sheet F-58-04.

Armstrong, J.: and E.J. Luske. 1987. Return postage in mail survey: a meta-analysis. Public Opinion Quarterly 51: 233-248.

Bates, Scott. 2000. The Tanana Forest Use Survey: How households used the forest in the Tanana River Watershed from September 1999 to August 2000. Available [Online] $<$ http://www.akborealforest.org/Forest_Use_Survey_2000.pdf $>$

Birch, T.W. 1996. Private forest-landowners of the United States, (1994.). USDA Forest Service, Northeastern Forest Experiment Station, Research Bulletin NE-134.

Beyfuss, Robert L. 1997. Ginseng Soil characterization and Ecology Study. Cornell Cooperative Extension of Greene County, HCR 3, Box 906, Cairo, New York 12413.

Beyfuss, Robert L. 1998. Growing Ginseng and Goldenseal in Your Forest. Cornell Cooperative Extension of Greene County, HCR 3, Box 906, Cairo, New York 12413.

Beyfuss, Robert L. 2002. Growing Ginseng in Your Woodlot. Special Supplement on AgroForestry. The Natural Farmer. Spring 2002.

Browder, John O. 1992. Social and Economic Constraints on the Development of MarketOriented Extractive Reserves in Amazon Rain Forests. Non-Timber Forest Products from Tropical Forests. Nepstad, Daniel C. and Stephen Schwartzman. The New York Botanical Gardens. New York.

Burdette, Chris. 2005. Personal Communication. Shady Oaks Ginseng Company. October.

Burkhart, Eric and Michael G. Jacobson. 2006. Nontimber Forest Products (NTFPs) from Pennsylvania: Goldenseal (Hydrastis canadensis L.). The Pennsylvania State University College of Agricultural Science. Pub. UH 175.

Carvell, Kenneth L. and Arlyn W. Perkey. 1997. Using Diagnostic Plants to Evaluate Site Class. USDA Forest Service Publication NA-TP-03-97. Morgantown, WV. September. 
Campbell, Colin and Robert L. Beyfuss. 2001. Ginseng Research Projects: Uihlein Sugar Maple Field Station. Available [Online]

$<$ http://maple.dnr.cornell.edu/Ext/ginseng.htm $>$

Campbell, Susan M. 2004. Profiles from Working Woodlands: Exploring Forest-based Enterprises in Western Massachusetts. Massachusetts Woodlands Institute. June 2004. 74pp.

Carroll, Chip. 2005. Personal Communication. Rural Action Sustainable Forestry. September

Carroll, Chip and Dave Apsley. 2004. Growing American Ginseng in Ohio: An Introduction. The Ohio State University Extension Fact Sheet F-56-04.

Carroll, Chip and Dave Apsley. 2004. Growing American Ginseng in Ohio: Site Preparation and Planting Using the Wild-Simulated Approach. The Ohio State University Extension Fact Sheet F-57-04.

Cavender, Anthony P. 2003. Folk Medicine in Southern Appalachia [authoritative history]. Chapel Hill: University of North Carolina Press. 266 pp.

Chamberlain, J.L., R. Bush, and A.L. Hammett. 1998 "Non-Timber Forest Products: The Other Forest Products." Forest Products Journal. Vol.48 No.10. Pg.2-12

Chamberlain, J.L., R. Bush, A.L. Hammett, and P.A. Araman. 2000. Managing National Forests of the Eastern United States for Non-Timber Forest Products. Proceedings, XXI IUFRO World Congress 2000, Forests and Society: The Role of Research. 1: 407-420.

Chamberlain, J.L., R. Bush, A.L. Hammett and P.A. Araman. 2002. Eastern national forests: managing for nontimber products. Journal of Forestry. 100(1): 8-14.

Chamberlain, J.L. and Mary Predny. 2003. Non-timber forest products: alternative multiple-uses for sustainable forest management. Proceedings, First National Symposium on Sustainable Natural Resource-Based Alternative Enterprises for Private Landowners. pp. 48-63.

Childs, Randall A. 2005. West Virginia's Forest: Growing West Virginia's Future. WV Bureau of Business and Economic Research. 2-14.

CITES webpage. Available [Online] $<$ http://www.cites.org/eng/disc/how.shtml $>$ Date accessed: February 2006.

Constanz, George. 1994. Hollows, Peepers, and Highlanders - An Appalachian Mountain Ecology. Mountain Press Publishing Co. Montana. pp 267. 
Coon, N. 1979. Using Plants for Healing: An American Herbal. Rodale Press, Emmaus, Pa. 272 pp.

Cui, W.W. 2003. Reducing error in mail surveys. Practical Assessment, Research and Evalution 8(18): 8p.

Dillman, D.A. 1978. Mail and telephone surveys: The total design method. New York: Wiley and Sons.

Dillman, D.A. 1983. Mail and other self-administered questionnaires. In Rossi, P.H., Wright, J.D., and Anderson, A.B. (Eds.), Handbook of Survey Research. New York: Academice Press: 359-377.

Dillman, D.A. 1991. The design and administration of a mail survey. Annual Review of Sociology 17: 225-249.

Dix, Mary Ellen, James Freed and Louis Buck. 1996. Growing Special Forest Products in Agroforestry Systems. Inside Agroforestry. United States Forest Service. Winter.

Downy, Adam K. and James C. Finley. 2005. Private Forest Landowners: What They Want in an Educational Program. Journal of Extension. Vol.43. No.1

Emery, Marla R. 2002. Historical Overview of Nontimber Forest Product Uses in the Northeastern United States. NonTimber Forest Products in the United States. University of Kansas Press. pp3-25.

Facemire, Glen. 2007. Personal Communication. G\&N Ramp Farm. January.

Food and Agriculture Organization of the United Nations. 1997. Proceedings of Food and Agriculture Organization Expert Consultation of Global Forest Resources Assessment 2000. Finnish Forest Research Institute. Helsinki, Finland.

Foster, Steven. 1995. Forest Pharmacy Medicinal Plants in American Forests. Forest History Society. Durham, N.C. 57 pp.

Foster, Steven and J.A. Duke. 2000. A Field Guide to Medicinal Plants: Eastern and Central North America. $2^{\text {nd }}$ ed. Houghton Mifflin Co., New York. 366 pp.

Fox, Jefferson. 1994. Introduction: Society and Non-Timber Forest Products in Asia. Society and Natural Resources. Vol.8, Pg. 189-192.

Fox, R.J., M.R. Crask, and J. Kim. 1988. Mail survey response rate; a meta-analysis of selected techniques for inducing response. Public Opinion Quarterly 52: 467-491. 
Fraser, Rory F., and Daniel J. Magill. 2000. Training and assistance needs of forestland owners in West Virginia. P. 125-134 in Proc. Of Symp. On Fragmentation 2000. Annapolis, MD.

Gilden, Jennifer. 1997. “An Oregon Case Study: Families, Gender Roles, and Timber Communities in Transormation." In Public Lands Management in the West: Citizens, Interest Groups, and Values, ed. Brent S. Steel, pp. 173-184.

Gracey, Eric, and Matthew H. Pelkki. 1996. Comparing Kentucky Woodland Owners Association Members to the Non-industrial Privat Landowners Population in Kentucky In Proceedings of Symposium on Non-industrial Private Forests: Learning from the Past, Propsects for the Future. Minnesota Extension Service, U. of Minn., St. Paul, MN. 403-410.

Guijt, Irene, F. Hinchcliffe, and M Melnyk. 1995. The Hidden Harvest: The Value of Wild Resources in Agricultural Systems. London: International Institute for Environment and Development.

Harmon, Alison, H., and Stephen B. Jones. 1997. Forestry Demonstrations: What Good is a Walk in the Woods? Journal of Extension. Vol.35. No.1.

Hammet A.L. and J.L. Chamberlain. 1998. Sustainable use of non-traditional forest products: Alternative forest-based income opportunities. Pp. 141-147 In Proceedings: Conference on Natural Resources Inome Opportunities for Private lands. MD. Ext. Serv., University of Maryland, College Park, MD.

Hankins, Andy. 2000. Producing and Marketing Wild Simulated Ginseng in Forest and Agroforestry Systems. Virginia Cooperative Extension. Pub 354-312

Heberlein, T.A.; Baumgartner, R. 1978. Factors affecting response rate to mailed questionnaires; a quantitative analysis of the published literature. American Sociological Review 43: 447-462.

Hufford, M. 1997. American ginseng and the idea of the commons. Folklife Center News. Library of Congress, American Folklife Center. Winter-Spring. pp. 3-18.

H.R. 2466. 1999. Department of the Interior and related agencies appropriations act, 2000, U.S. House of Representatives bill, sent to the President October 1999.

Jahnige, Paul. 2002. The Hidden Bounty of the Urban Forest. NonTimber Forest Products in the United States. University Press of Kansas. pp 96-107.

Jones, Eric T., and K. Lynch. 2002. The Relevance of Sociocultural Variables to Nontimber forest Product Research, Policy, and Management. Nontimber Forest Products in the United States. University Press of Kansas. pp 26-51. 
Jones, Eric T., Rebecca J. McLain, and Kathryn A. Lynch. 2005. The Relationship Between Non-timber Forest Product Management and Biodiversity in the United States. Submitted to the National Commission on Science for Sustainable Forestry. pp. 61

Jones, Jeff. 2006. Personal Communication. Potomac State University. June.

Kays, Jonathan. 1998. Natural Resources Income Opportunities: Considerations for Forest Owners. P. 33-37 in Proc. Of Conf. on Natural Resources Income Opportunities for Private lands. MD. Ext. Serv., U of MD., College Park, MD.

Kays, Jonathan and J. Drohan. 2004. Guide to Choosing and Evaluating a Natural Resources-Based Enterprise (NRAES-151). Ithaca, NY: Natural Resource Agricultural Engineering Service (NRAES). 99pp.

Magill, Daniel J. 2000. Assessing West Virginia NIPF owner characteristics and preferred assistance topics. Unpublished M.Sc. Thesis, West Virginia University, Morgantown, WV. 76 p.

Magill, Daniel J., D.W. McGill, R.F. Fraser. 2004. Refining Outreach to Woodland Owners in West Virginia-Preferred Topics and Assistance Methods. Journal of Extensions (August). Vol 42 No. 4.

Malhotra, K.C. and Mark Poffenberger. 1989. Forest Regeneration Through Community Participation. West Bengal Forest Department. Calcutta, India

Mater, Catherine. 1993. Minnesota Special Forest Products. Minnesota Department of Natural Resources, Forestry Division.

Mater, Catherine. 1997. Consumer trends, market opportunities, and new approaches to sustain development of special forest products. P. 8-25 in Proc of Seminar. on Special Forest Products: Biodiversity Meets the Marketplace. USDA Forest Service., Washington D.C.

McLain, Rebecca J., and Eric T. Jones. 2002. NonTimber Forest Products in the United States. University Press of Kansas. pp 445.

McGraw, James B. and Mary Furedi. (2005). Deer Browsing and Population Viability of a Forest Understory Plant. Science Vol 307. 11 February 2005. pp 920-922.

Munson, P.J. 1989. "Still More on the Antiquity of Maple Sugar and Syrup in Aboriginal Eastern North America." Journal of Ethnobiology 9: 159-170.

Nature Conservancy. 1977. Preserving Our Natural Heritage. United States Department of the Interior. National Park Service. Washington D.C. 
Nautiyal, J.C. 1988. Forest Economics: Principles and Applications. Hatfaj Publishers. Dehradun, India.

Padoch, Christine. 1992. Marketing of Non-Timber Forest Products in Western Amazonia: general Observations and Research Priorities. Non-Timber Forest Products from Tropical Forests. Nepstad, Daniel C. and Stephen Schwartzman. The New york Botanical Gardens. New York.

Park, H. 2003. The History of Ginseng Cultivation in the Orient. Acta Hort. (ISHS) 620:453-460. Available [Online]<http://www.actahort.org/books/620/620_55.htm>

Pennsylvania Department of Conservation and Natural Resources. 2005. [Online] at $<$ http://www.dcnr.state.pa.us/forestry/sfrmp/nontimber.htm>

Percher, F.P., 1970. Resources of the Southern Fields and Forests. $2^{\text {nd }}$ ed. Amo Press, New York. 601 pp.

Peters, Charles M., Alwyn H. Gentry, and Robert O. Mendlesohn. 1989. Valuation of an Amazonian Rainforest. Nature. June 29, Vol. 339. Pg. 655-656.

Reisenberg, L.D., and Gor, C.O. 1989. Farmers' preferences for methods of receiving information on new or innovative farming practices. Journal of Agricultural Education. 7-13.

Robbins, C., 1999. Medicine from U.S. Wildlands: An assessment of native plant species harvested in the United States for medicinal use and trade and evaluation of the conservation and management implications. A report from TRAFFIC North America for The Nature Conservancy.

Rock, Janet H., Brian Beckage, and Louis J. Gross. 2003. Population recovery following differential harvesting of Allium tricoccum Ait. in the southern Appalachians. Biological Conservation 116 (2004) 227-234.

Rosenberger, Randall S., T.G. Gebremedhin, Y. Hailu. 2004. An Economic Analysis of Urbanization of Agricultural Land in West Virginia. Agricultural and Resources Economics Review. Vol 33 No. 1. Pg 50-60.

Saunders, Kevin, Chad Pierskalla, and Dave McGill. 2006. Forest Landscape Assessment: The Effects of Pre-Experience Education on Public Perception of Scenic Beauty. Unpublished.

Savage, Mark. 1995. Pacific Northwest Special Forest Products: An Industry in Transition. Journal of Forestry. March, Vol.93 No.3. Pg.6-11. 
Schlosser, William E., Keith A. Blatner, Ervin G. Schuster, and Matthew S. Carroll. 1995. Potential for Expansion of the Special Forest Products Industry in the Northern Rockies. Western Journal of Applied Forestry. October, Vol.10 No.4. Pg. 138-143.

Scott, John A., Sam Rogers, and David Cooke. 1995. Woods Grown Ginseng. West Virginia University Extension Service. June 1995. Available [Online] at $<$ http://www.wvu.edu/ agexten/forestry/ginseng.htm>

Shi, Y.J., T.T. Phipps, and D. Colyer. 1997. Agricultural land values under urbanizing influences. Land Economics 73(1):90-100.

Silori, C.S., Mamta Mehar, M.A. Khalid, and V. Paul. 2005. Non-Timber Forest Products: Conservation Status and Management Priorities in the Community Managed Forests of Andhra Pradesh, South India. International Journal of Sustainable Development and World Ecology. Available [Online] $<\mathrm{http}: / /$ www.redorbit.com/news/science $>$

Smith, Vicki. 2005. For Mountain People, Moss is a Cash Crop. Environmental News Network, October 17, 2005. Available [Online] $<$ http://www.enn.com/today.html?id=9039>

Thomas, Margaret G. and David R. Schumann. 1993. Income Opportunities in Special Forest Products: Self-Help Suggestions for Rural Entrepreneurs. United States Department of Agriculture, Forest Service. Agriculture Information Bulletin 666. Washington D.C.

Tompkins, Joshua. 2004. Moss Hunters Roll Away Nature's Carpet, and Some Ecologists Worry. New York Times, November 30, 2004. Available [Online] $<$ http://www.nytimes.com/2004/11/30/science/earth/30moss.html\#>

US Census Bureau web page. Ritchie and Wirt Counties, West Virginia. Available [Online] <http://quickfacts.census.gov/qfd/states $>$

USDA National Agricultural Library. 2005. What is Rural? Available [Online] $<$ http://www.nal.usda.gov/ric/ricpubs/what_is_rural.htm>

USDA Soil Conservation Service. 1961. Soil survey of Jackson and Mason Counties West Virginia. U.S. Department of Agriculture, Soil Conservation Service, Washington D.C.

USDA Soil Conservation Service. 1965. Soil survey of Monroe County West Virginia. U.S. Department of Agriculture, Soil Conservation Service, Washington D.C.

USDA Soil Conservation Service. 1982. Soil survey of Marion and Monongalia Counties West Virginia. U.S. Department of Agriculture, Soil Conservation Service, Washington D.C. 
USDA Soil Conservation Service. 1998. Soil survey of Pocahontas County West Virginia. U.S. Department of Agriculture, Soil Conservation Service, Washington D.C.

Von Hagen, Bettina, James F. Weirgan, Rebecca McLain, Roger Fight, and Harriet H. Christensen. 1996. Conservation and Development of Non-Timber Forest Products in the Pacific Northwest: An annotated Bibliography. Gen. Tech. Rep. PNW-GTR-375. Portland, OR: U.S. Department of Agriculture, Forest Service, Pacific Northwest Research Station. 246 p.

Weinberg, Bill and Laurel Shackelford. 1977. Our Appalachia: An Oral History. The University Press of Kentucky. Lexington.

West Virginia County Data Profiles. 2006. Bureau of Business and Economic Research. College of Business and Economics, West Virginia University. Available [Online] $<$ http://www.be.wvu.edu/bber/2006_data_profiles $>$

West Virginia Trapper Association. 2007. [Online] $<$ http://www.wvtrappers.com/auction.html $>$

Widmann, Richard. 2003. West Virginia's Forest Land Holds its Ground. USDA Forest Service. Northeast Research Station. Available [Online] $<$ http://www.fs.fed.us/ne/newtown_square/news/releases/2003/>

WVDOF. 2007. 2006 Annual Report pp 8-24. Available [Online] $<$ http://www.wvforestry.com/ForestryAnnRep06Web.pdf $>$ 


\section{$\underline{\text { Appendices }}$}

\section{Appendix 1: Six Former WV Division of Forestry Districts}

\section{West Virginia Division of Forestry Districts}

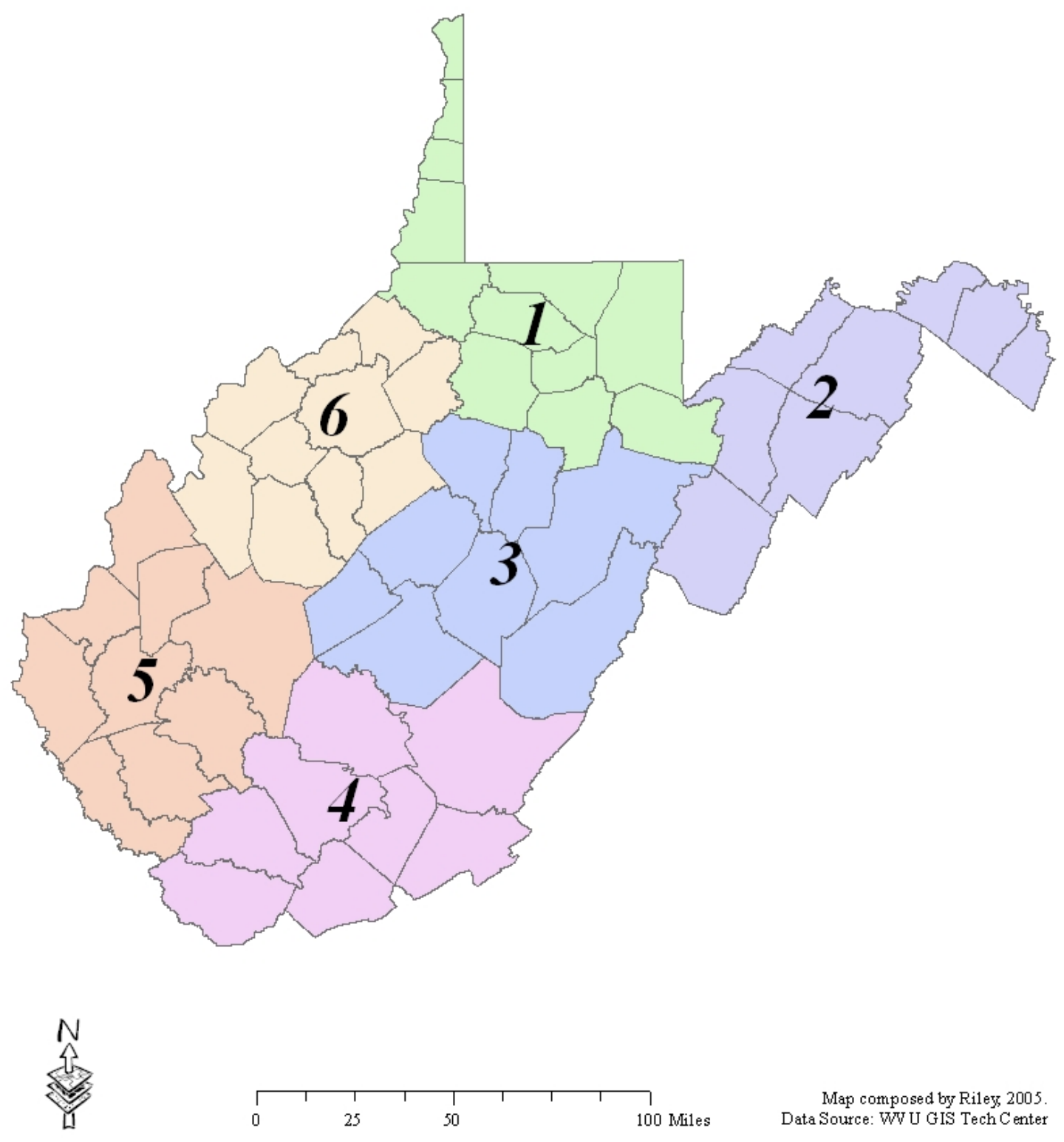




\section{NTFP Demonstration Area Coverage by District Site}

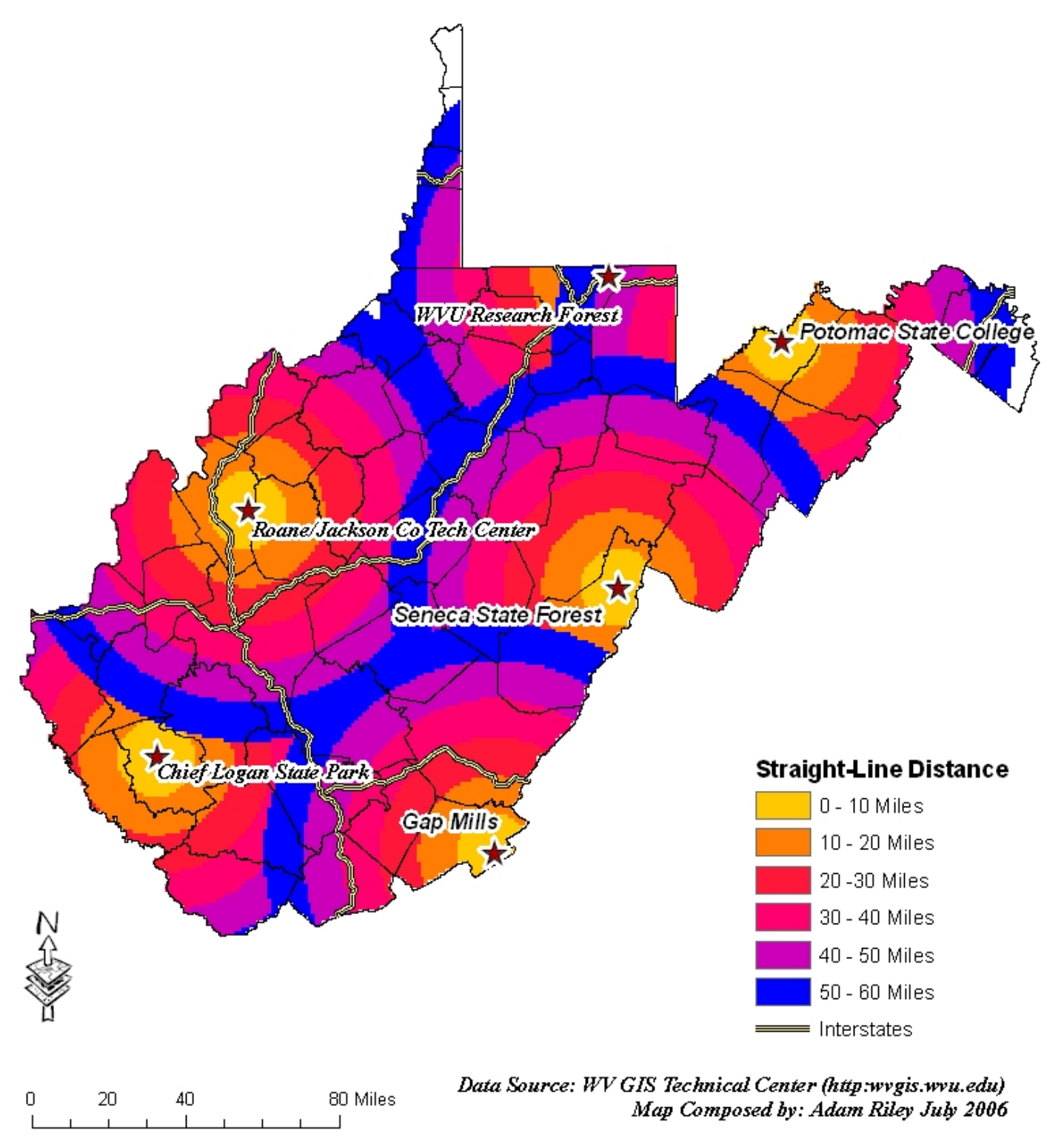




\section{Non-Timber Forest Product Demonstration Area \#1 West Virginia University Research Forest}

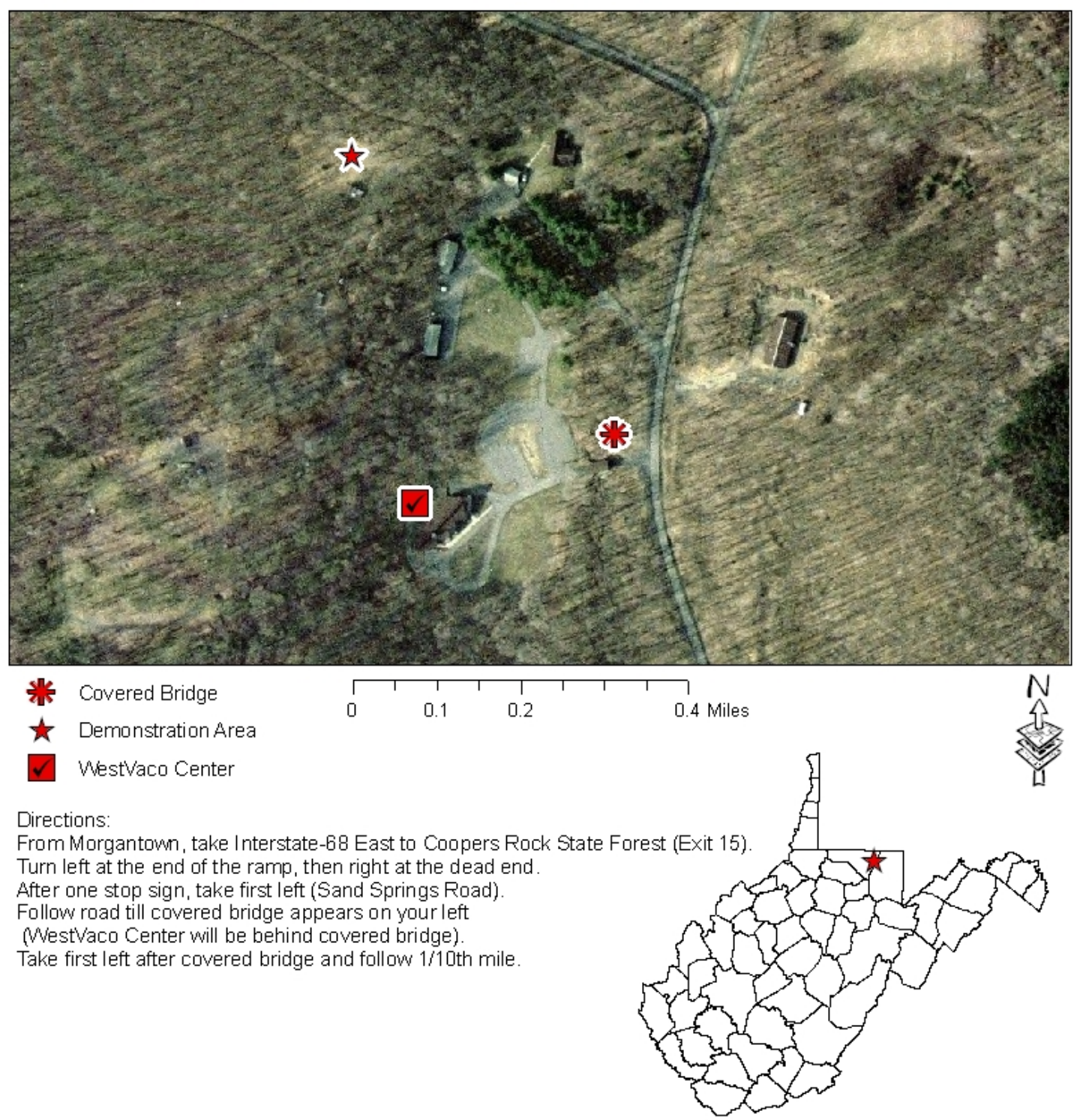

Map composed by Adam Riley; WW; 3/2007 Data source: W GIS Tech Center 


\section{Non-Timber Forest Products Demonstration Area \#2 Potomac State College; Keyser, WW}

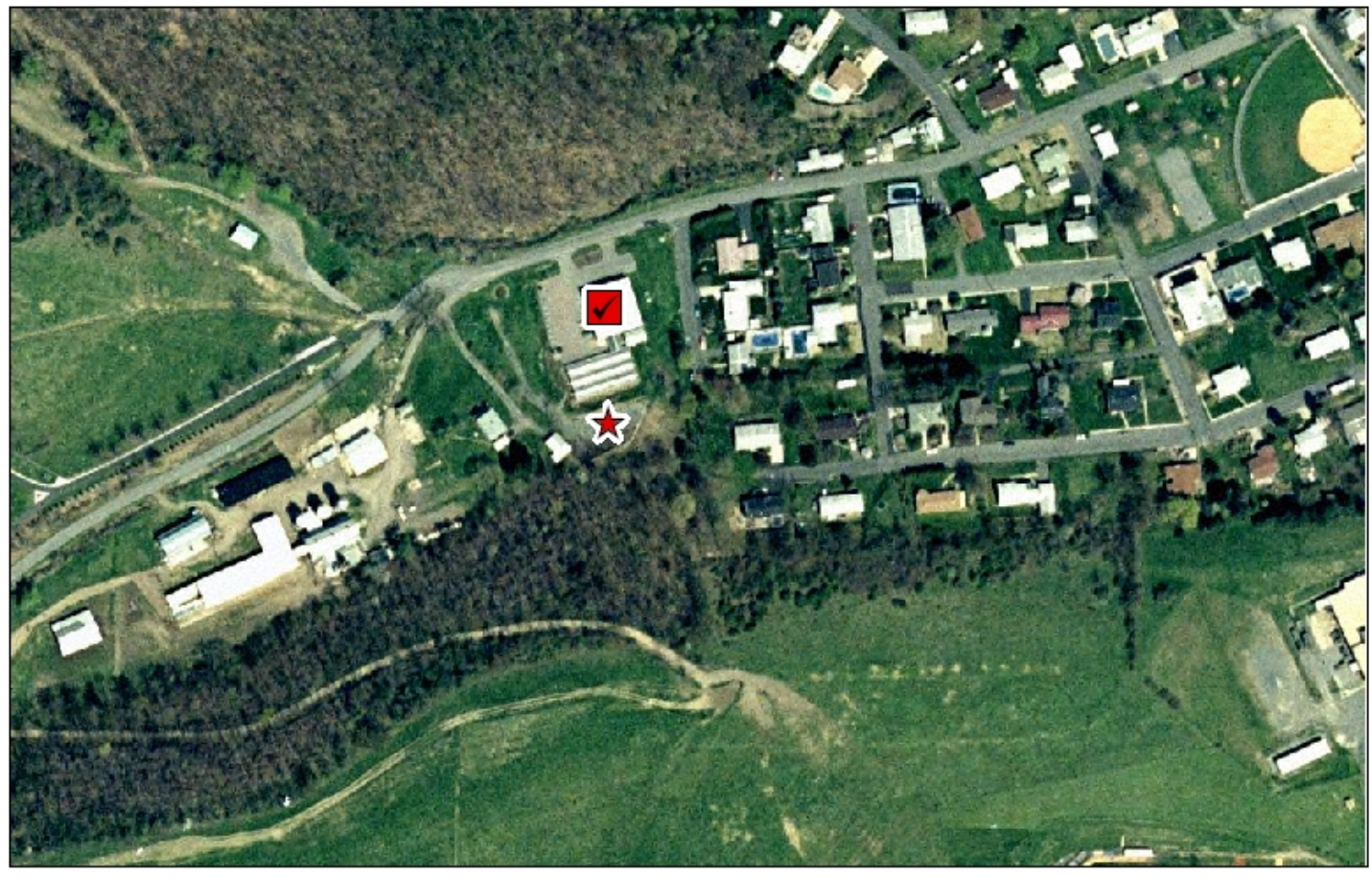

$\star$ Demonstration Area

Agriculture_Technology_Building

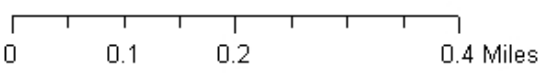

Directions:

Once inside Keyser, follow signs for Potomac State College. pass the main entrance to the collge.

Proceed over and down the hill to a T intersection (pass through one four-way stop).

turn left onto E Street/Parkview Drive.

Continue to the Agriculture Technology Building on the left, just before the Potomac State College Farm.

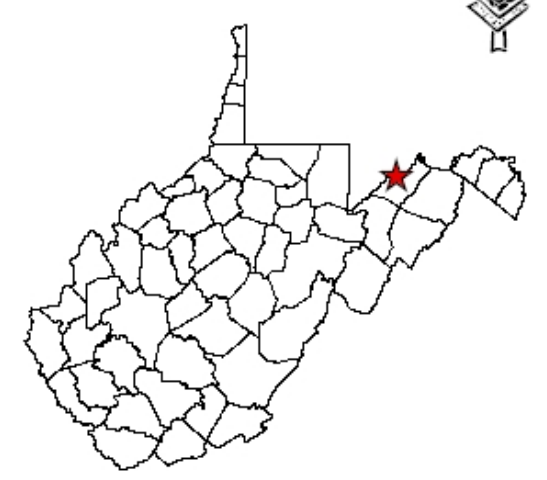

Map composed by Adam Riley; WM; 03/2007 Data Source: W GIS Tech Center 


\section{Non-Timber Forest Product Demonstration Area \#3 Seneca State Forest}

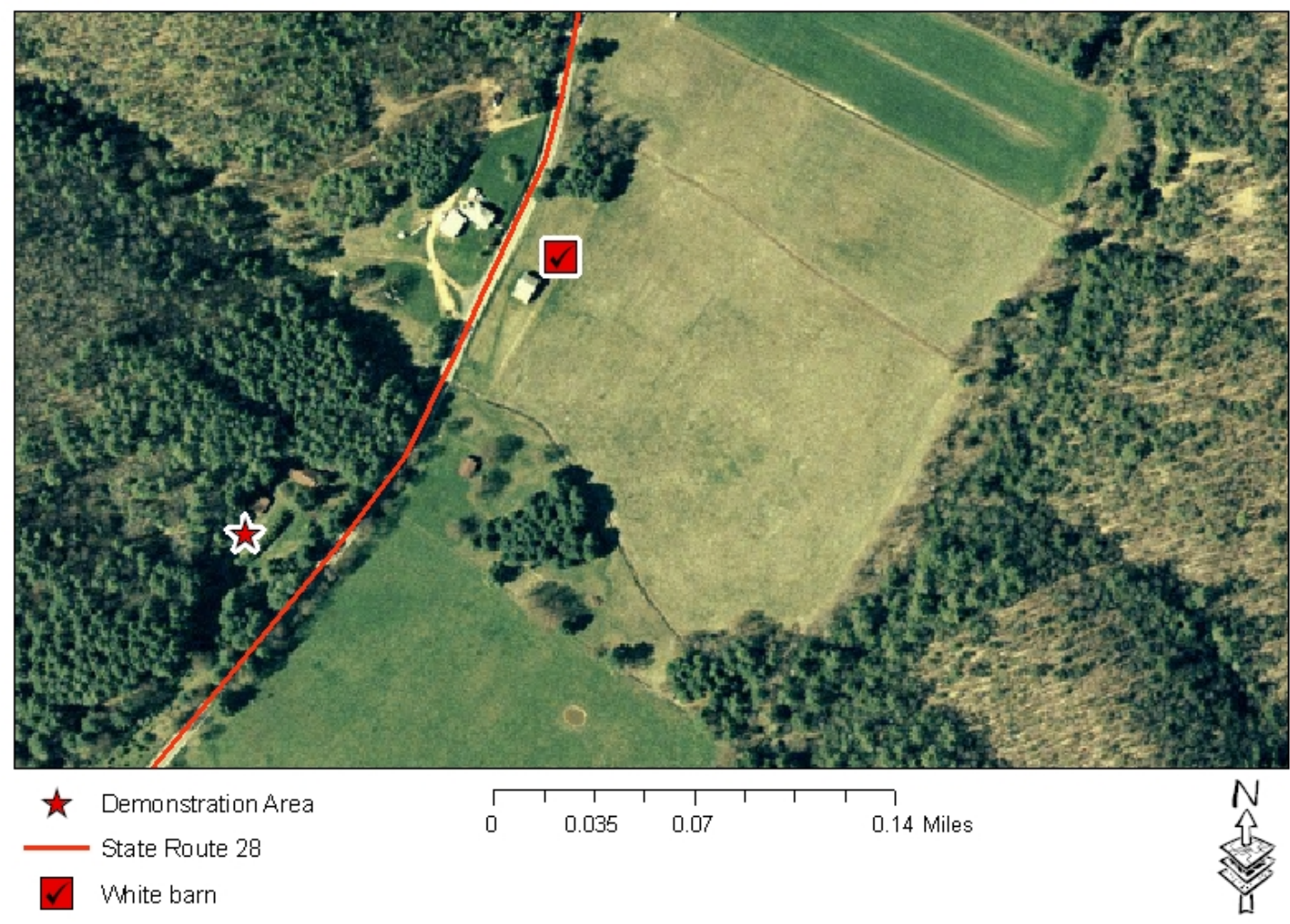

Directions:

From Dunmore, follow State Route 28 South approximately 4.8 miles.

The site has a hidden driveway on the right side of the road,

be sure to locate white barn on left side of the road when approaching site

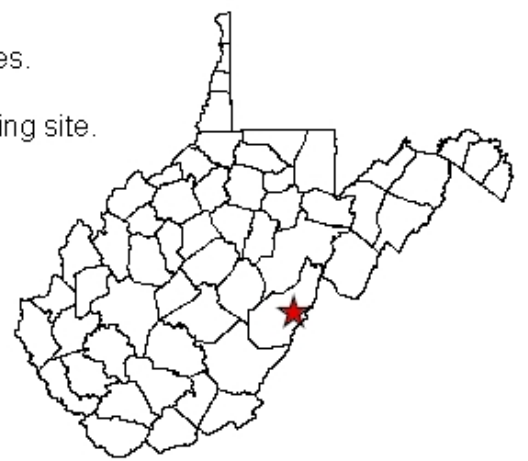

Map composed by Adam Riley; WM; $3 / 2007$ Data source: W GISTech Center 


\section{Non-Timber Forest Product Demostration Area \#4 Gap Mills, WW}

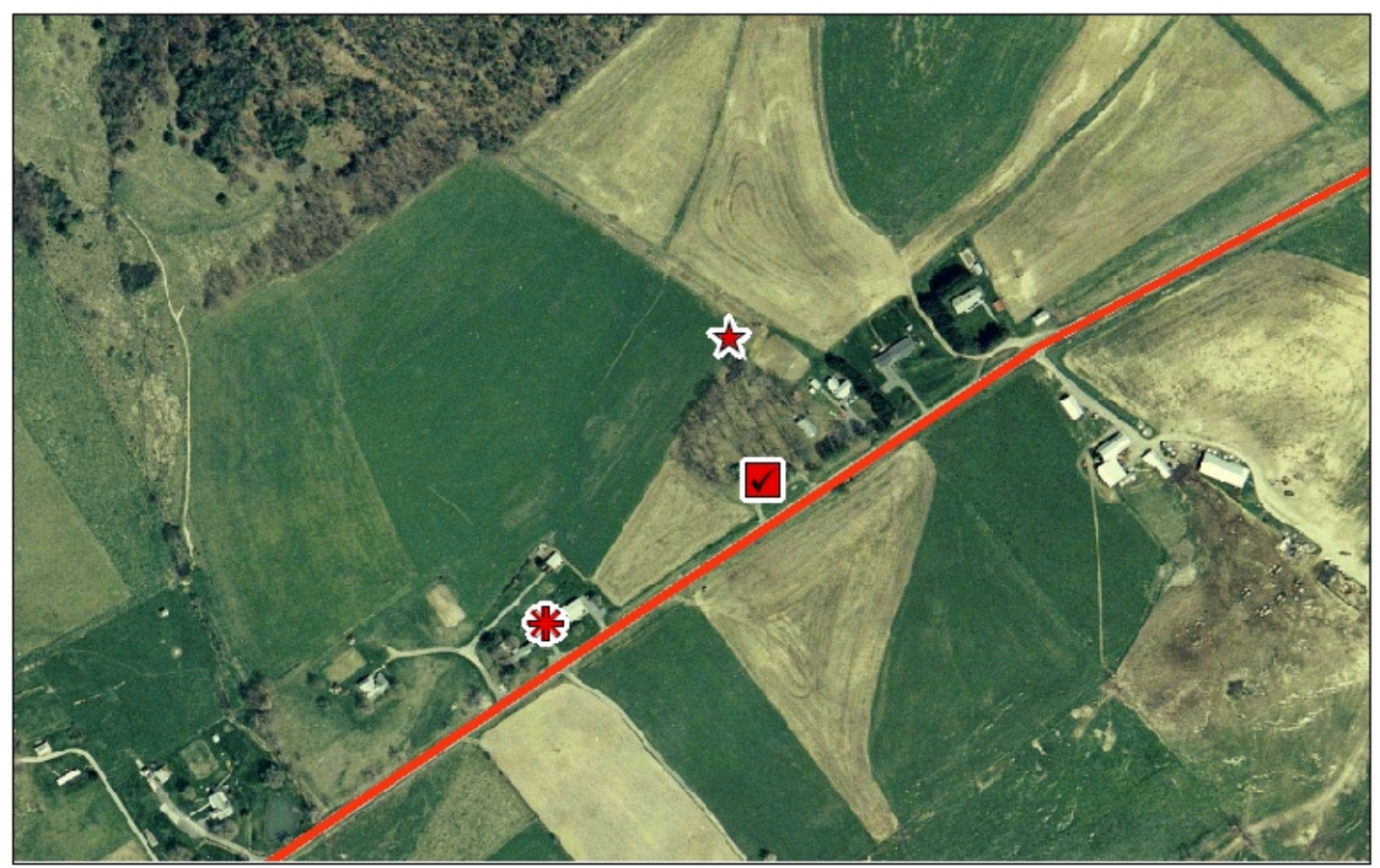

\footnotetext{
$\star$ Demonstration Area

Park Here

State Route 3

she Clarkson Farm (unmarked)
}

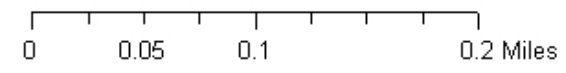

Directions:

From Union, WW take State Route 3 East through Gap Mills approximately 16.8 miles to Clarkson Farm on left.

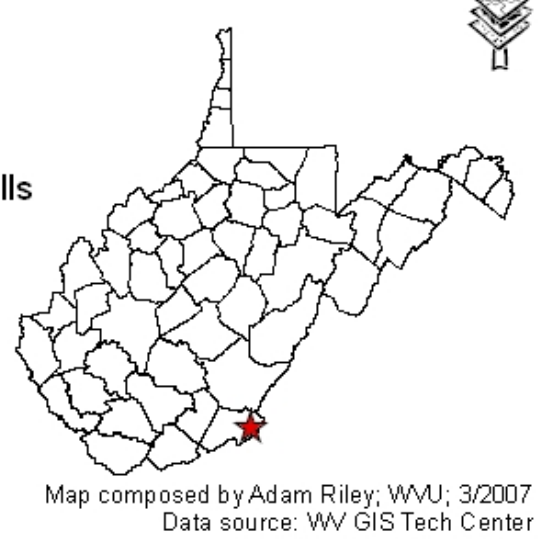




\section{Non-Timber Forest Product Demonstration Area \#5 Chief Logan State Park}

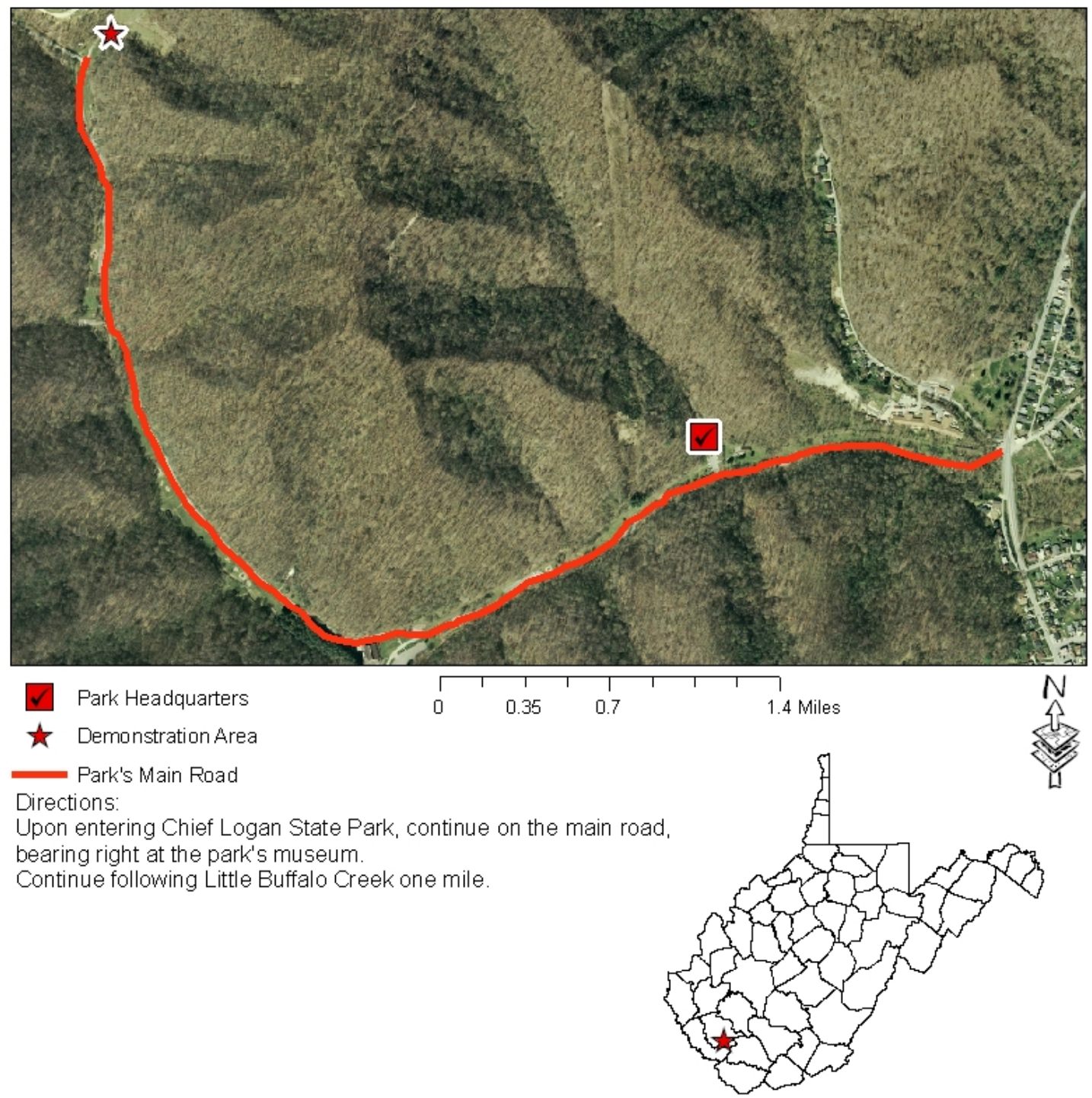

Map composed by Adam Riley; WW; 03/2007 Data source: W GIS Tech Center 


\section{Non-Timber Forest Product Demonstration Area \#6 Roane/Jackson County Technical Center}

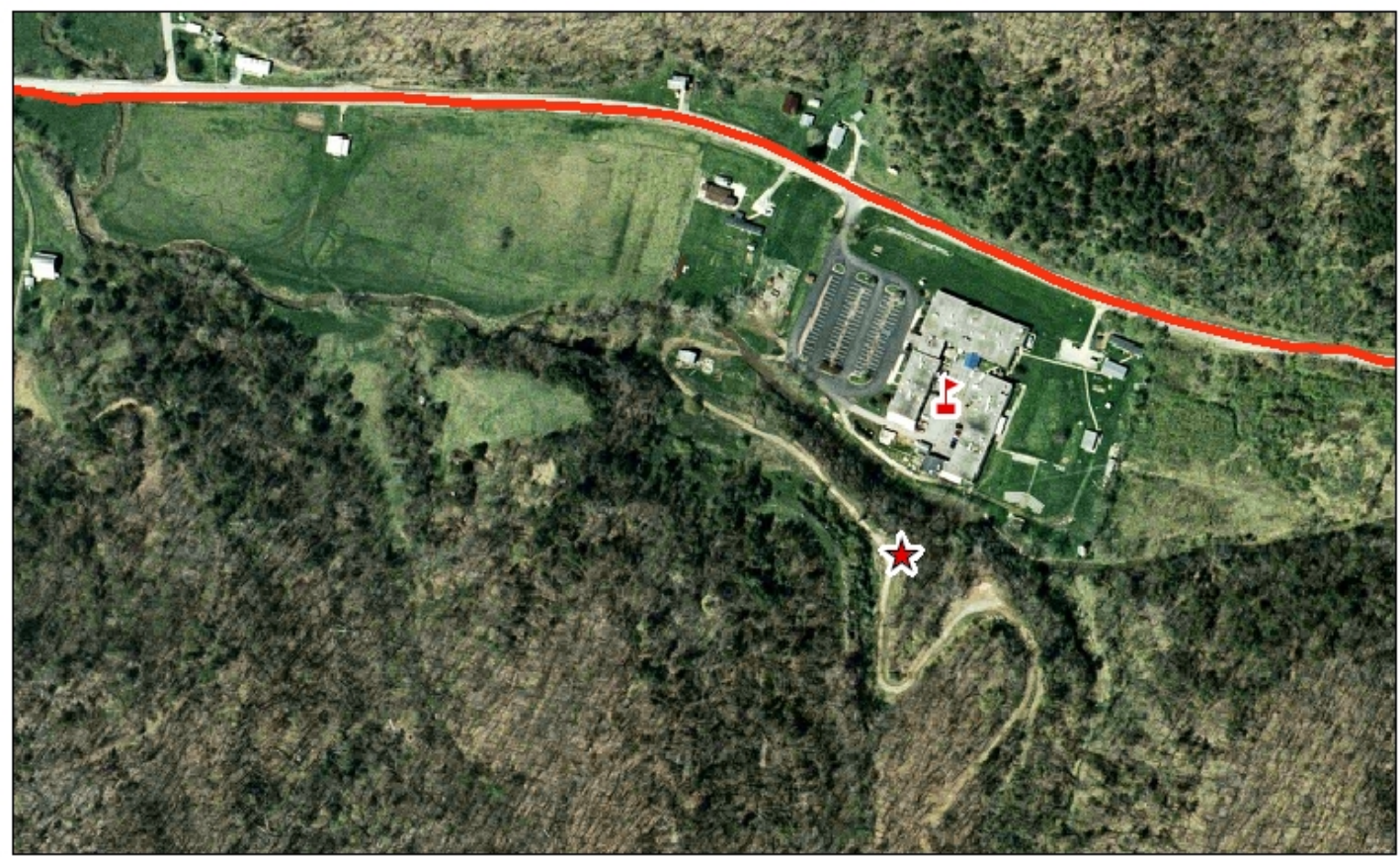

$\star$ Demonstration Site

I Roane/Jackson County Technical Center

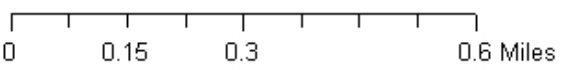

US Route 33

Directions:

From Ripley, take US Route 33 East approximately 18 miles.

Once at Roane/Jackson Technical Center stay to the right in the parking lot, cross stream, head up dirt road 3/10th mile.

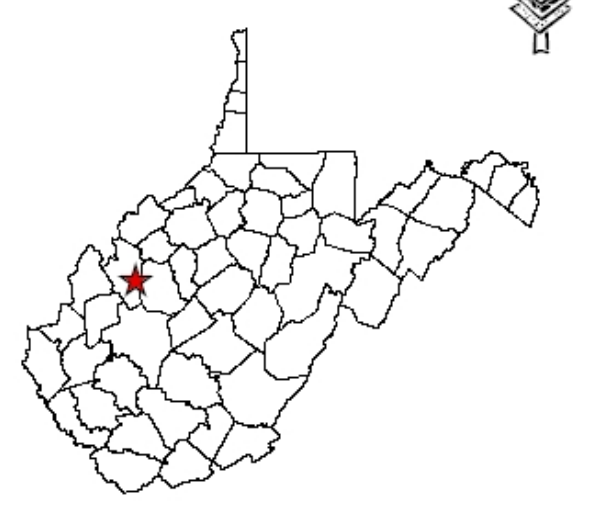

Map created by Adam Riley, WM; 03/2007 Data Source: W GIS Technical Center 


\section{Appendix 9: Case Study Questionnaire}

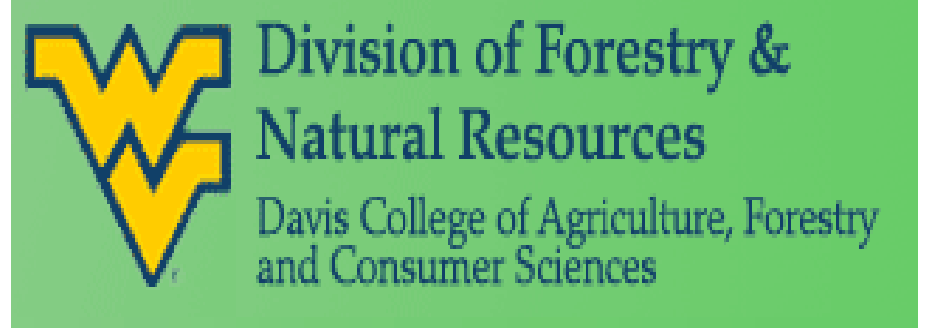

WVU NTFP Questionnaire

Please answer the following questions completely in the spaces provided. If you need additional space, please use the back.

1.) What year did you start your business?

2.) How many acres does your production cover?

2a.) How many acres do you actively manage for production?

3.) How many people does your business employ?

4.) Are any of those employees relatives? Yes No

4a.) If so, how many of your relatives do you employ?

5.) Please provide a brief history of your business. 
5a.) How did your business get started?

5b.) How did you develop an interest in this endeavor?

6.) What type of non-timber forest products does your business produce? 
7.) What are your current production level for each of these products?

8.) Briefly describe some of the problems you have had in running your daily business

9.) What do you market your products for? 
10.) What percentage of your customers are repeat business?

$\%$

10a.) Which of your products is the best seller?

10b.) Which of your products bring the most income?

11.) What types of community members do you interact with to promote your business (woodland owners, ginseng growers, etc) 
12.) Please list some interesting facts about yourself (how long you've been growing/ producing/ selling, published papers, awards, etc)?

12a.) Please list some unique facts about your business.

13.) Is there anything you would like to tell me about yourself that I have not covered? 
14.) Is there anything you would like to tell me about your business that I have not covered?

Thank you very much for your time and effort! 


\section{Non-Timber Forest Product Survey Regions}

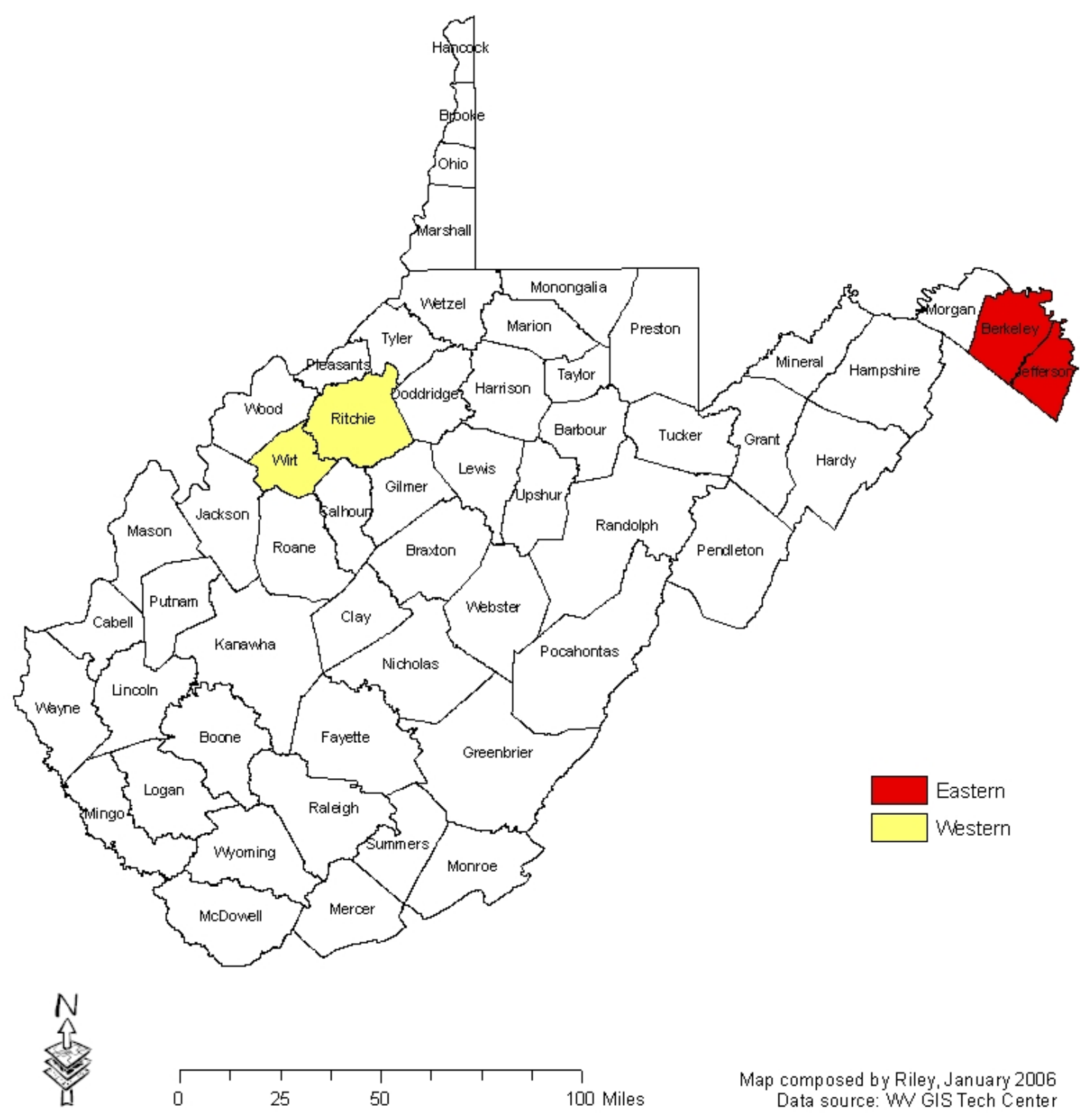




\title{
Appendix 11: Institutional Review Board Approval
}

\section{WestVirginiaUniversity}

Office of Research Compliance

Date: January 9,2007

\author{
MEMORANDUM
}

To: David McGill

DCAFCS/Forestry

From: Lilo A. Ast 4

Sr. Program Coordinator

Re: $\quad$ 17201-E; Promoting Nontimber Forest Products in WV

The Institutional Review Board for the Protection of Human Research Subjects (IRB) finds the above names research project qualifies as an exemption under category $\mathbf{2}$.

This finding will remain in effect only on the condition that the research is carried out exactly as described in the Application. Please submit an amendment to the IRB office if you intend to modify or change your study in any way. Any amendment must be reviewed and acknowledged before initiating any changes or modifications

Best wishes for the success of your research.

$\mathrm{LAA} / \mathrm{clg}$

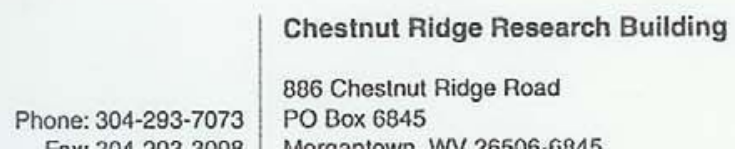

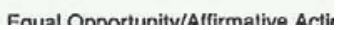




\section{Appendix 12: Pre-Survey Postcard}

W7 Division of Forestry \&

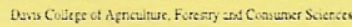

Dave McGill

Forestry Extension Specialist

PO Box 6125

Morgantown, WV 26506

\section{West VirginiaUniversity.}

Dear West Virginia Landowner:

Within the next few weeks you will receive a questionnaire designed to collect information on interest in and production of non-timber forest products (for example ginseng, shiitake mushrooms, and Christmas trees). This survey is aimed at increasing knowledge and awareness of non-timber forest products enterprises for forest landowners like yourself.

This project is sponsored by the WVU Extension

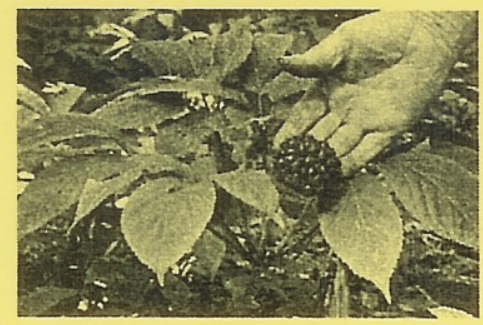
Service/AHC. Your participation is voluntary and if you choose to participate your answers will be kept confidential.

Thank you for your time and cooperation.

Adam C. Riley

Dr. David W. McGill

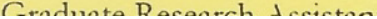

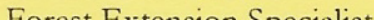




\section{Appendix 13: NTFP Survey Cover Letter WestVurginiaUniversity. \\ Davis College of Agriculture, Forestry and Consumer Sciences \\ Extension Service, Agriculture and Natural Resources}

January 19, 2007

Dear West Virginia Landowner,

We are conducting a survey of landowners from throughout West Virginia of the interest concerning non-timber forest products. These products include anything that can be harvested from your woods that may have monetary value, with the exception of timber. Many private landowners are unaware of the alternate income opportunities that can be obtained from their land. Some of these products are well known, to include medicinal plants such as ginseng and goldenseal, and edible items, such as nuts, berries, and mushrooms.

Our intent in this survey is to find out exactly what people are gathering, as well as if there is any additional interest in non-timber forest products by people who don't currently harvest. It is also our intent to perhaps distribute information about alternative income possibilities to county extension offices through the findings of this survey.

We hope that you will reply to this survey at your earliest convenience. If you do not wish to answer the questionnaire, please let us know by returning the enclosed questionnaire blank or with a note in the self-addressed, stamped envelope.

The information that you provide is strictly confidential and only summarized results describing the product's interest will be made public (for e.g., how many people from what region would be interested in cultivating shiitake mushrooms). If you have any questions regarding the survey, please feel free to contact us. Thank you very much for your help with this important study.

Sincerely,

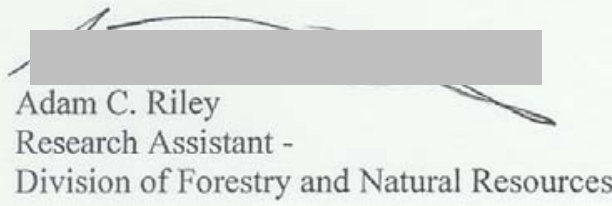

Phone: (304) 293-2941 ext 2310

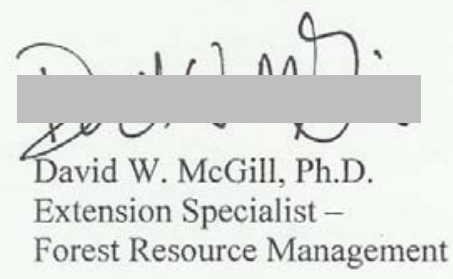

(304) 293-2941 ext 2474 
Appendix 14: Landowner Survey

\section{West Virginia University Division of Forestry and Natural Resources and WVU Extension Service}

\section{Special Forest Products Survey}

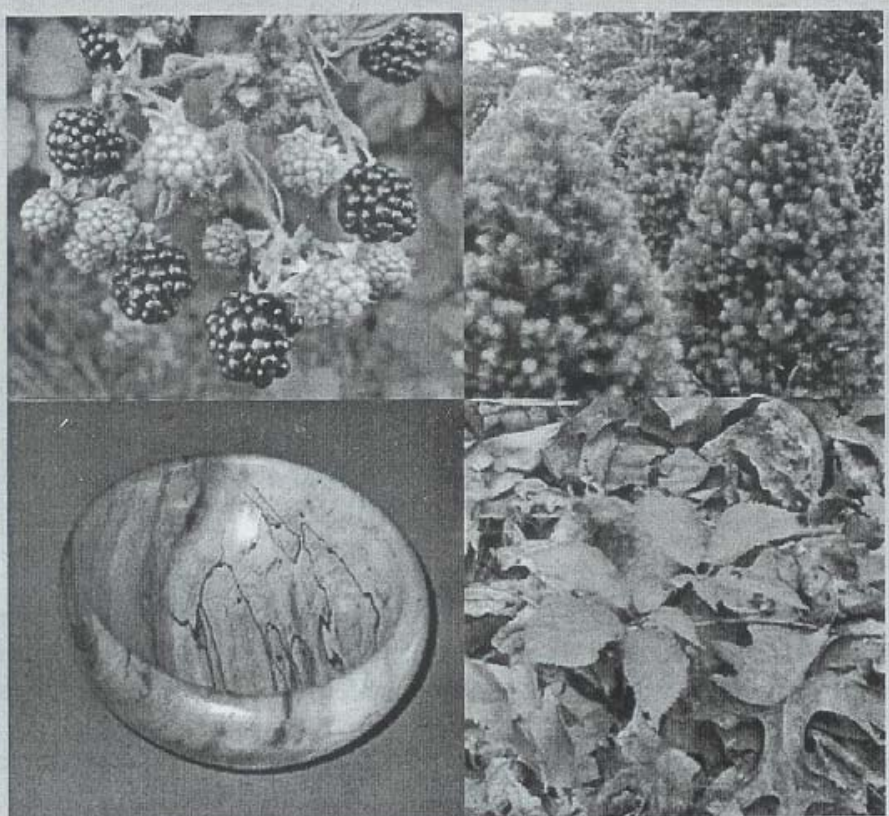

January 2007

Sponsored by:

West Virginia University

Division of Forestry and Natural Resources

Extension Service 
Please return your completed questionnaire

in the envelope provided to:

Adam C. Riley

West Virginia University

Division of Forestry and Natural Resources

PO Box 6125

Morgantown, WV 26506-6125

\section{Instructions:}

- Either a pen or pencil can be used.

- When answering questions that require marking a box, please use an " $\mathrm{X}$ ".

- If you need to change an answer, please make sure that your old answer is either completely erased or clearly crossed out.

- All returned questionnaires will remain confidential at all times.

\section{About this Survey}

'Non-Timber Forest Products' (NTFP) are generally broken down into four categories:

1) Culinary (edible) (berries, fruits, and nuts),

2) Specialty wood-based (baskets, bowls, firewood),

3) Floral and decorative (boughs, cones, Christmas trees), and

4) Medicinal and dietary supplements (ginseng, goldenseal, black cohosh)

These products are often the basis of private family forest-based enterprises that sell to specialty or local markets and are produced for enjoyment or for generating additional revenue. The purpose of this survey is to identify the interest level and educational needs that West Virginia landowners face with respect to these products.

This project is a joint effort of the West Virginia University Division of Forestry and Natural Resources and the WVU Extension Service. You have received the attached survey to provide information to help improve forestry awareness and efficient production of non-timber forest products for forest landowners like yourself.

Your participation is voluntary and you have the right to refrain from answering any questions. You may answer only those questions that you are comfortable answering. If you chose to participate, your answers will be confidential.

Thank vou for vour assistance with this important proiect! 


\section{START HERE:}

\section{1.) Please check any of these that apply:}

$\square$ I no longer own more than 10 acres in West Virginia

$\square$ I would like to receive a summary of the results from this survey.

Here are some questions about the size of and recent activities on your property:

2.) How long have you owned your property? years

3.) How many total acres do you own? acres

4.) How many acres are forested? acres

5.) How many acres are in pasture, fields, or otherwise un-forested? acres

6.) How long ago has it been since your last timber harvest? years

7.) Have you ever owned or operated a forest-based enterprise? $\square$ Yes $\square$ No If so, what type of enterprise?

8.) Have you ever thought about opening a forest based enterprise? $\quad \square$ Yes $\quad \square$ No If so, what type of enterprise?

9.) In the following table, please mark which non-timber forest product have you produced or harvested (and at what levels), or which you may be interested in (for each product type, check the appropriate box).

\begin{tabular}{|l|c|c|c|c|c|}
\hline Non-Timber Forest Product Type & Frequently & Occasionally & Rarely & $\begin{array}{c}\text { Never, but } \\
\text { interested }\end{array}$ & $\begin{array}{c}\text { Never and } \\
\text { NOT interested }\end{array}$ \\
\hline Ginseng & $\square$ & $\square$ & $\square$ & $\square$ & $\square$ \\
\hline Goldenseal & $\square$ & $\square$ & $\square$ & $\square$ & $\square$ \\
\hline Specialty Wood Products (canes, handles, etc) & $\square$ & $\square$ & $\square$ & $\square$ & $\square$ \\
\hline Black Cohosh & $\square$ & $\square$ & $\square$ & $\square$ & $\square$ \\
\hline Vines (grape; camphor, etc.) & $\square$ & $\square$ & $\square$ & $\square$ & $\square$ \\
\hline Ramps & $\square$ & $\square$ & $\square$ & $\square$ & $\square$ \\
\hline Shiitake Mushrooms & $\square$ & $\square$ & $\square$ & $\square$ & $\square$ \\
\hline Morel Mushrooms & $\square$ & $\square$ & $\square$ & $\square$ & $\square$ \\
\hline Maple Syrup & $\square$ & $\square$ & $\square$ & $\square$ & $\square$ \\
\hline Boughs/Cones & $\square$ & $\square$ & $\square$ & $\square$ & $\square$ \\
\hline Fruits/Berries/Nuts & $\square$ & $\square$ & $\square$ & $\square$ & $\square$ \\
\hline Honey & $\square$ & $\square$ & $\square$ & $\square$ & $\square$ \\
\hline Fish & $\square$ & $\square$ & $\square$ & $\square$ & $\square$ \\
\hline Hunting Leases & $\square$ & $\square$ & $\square$ & $\square$ & $\square$ \\
\hline
\end{tabular}

10.) What have been the greatest challenges for producing non-timber forest products?

11.) What has been the greatest success or benefit in producing non-timber forest products? 
Please answer the following questions about yourself:

12.) What is your gender?

13.) What is your birth date? (year) 19

14.) What is your occupation?

15.) What is the highest level of education you have completed?

$\square$ Some High School
$\square$ High School
$\square$ GED
$\square$ Trade or Technical School
$\square$ Some college

$\square$ Associates degree

$\square$ Bachelors degree

$\square$ Masters degree

$\square \mathrm{Ph} . \mathrm{D}$.

16.) What is your average yearly income?

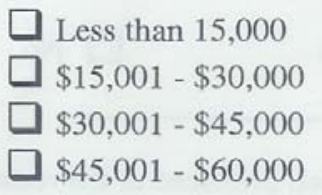

17.) I reside in:

17b.) I live on

18.) Given the opportunity, how much would you be willing to pay for a two (2) hour forest-based enterprise workshop near you? $\$$ for a 2-hr training session or workshop

18a.) How far would you be willing to travel to experience such a workshop? miles

19.) Please use the space provided for additional questions/comments regarding NTFPs or this survey.

Thank you for your help on this important survey! 


\section{Appendix 15: Reminder Postcard}

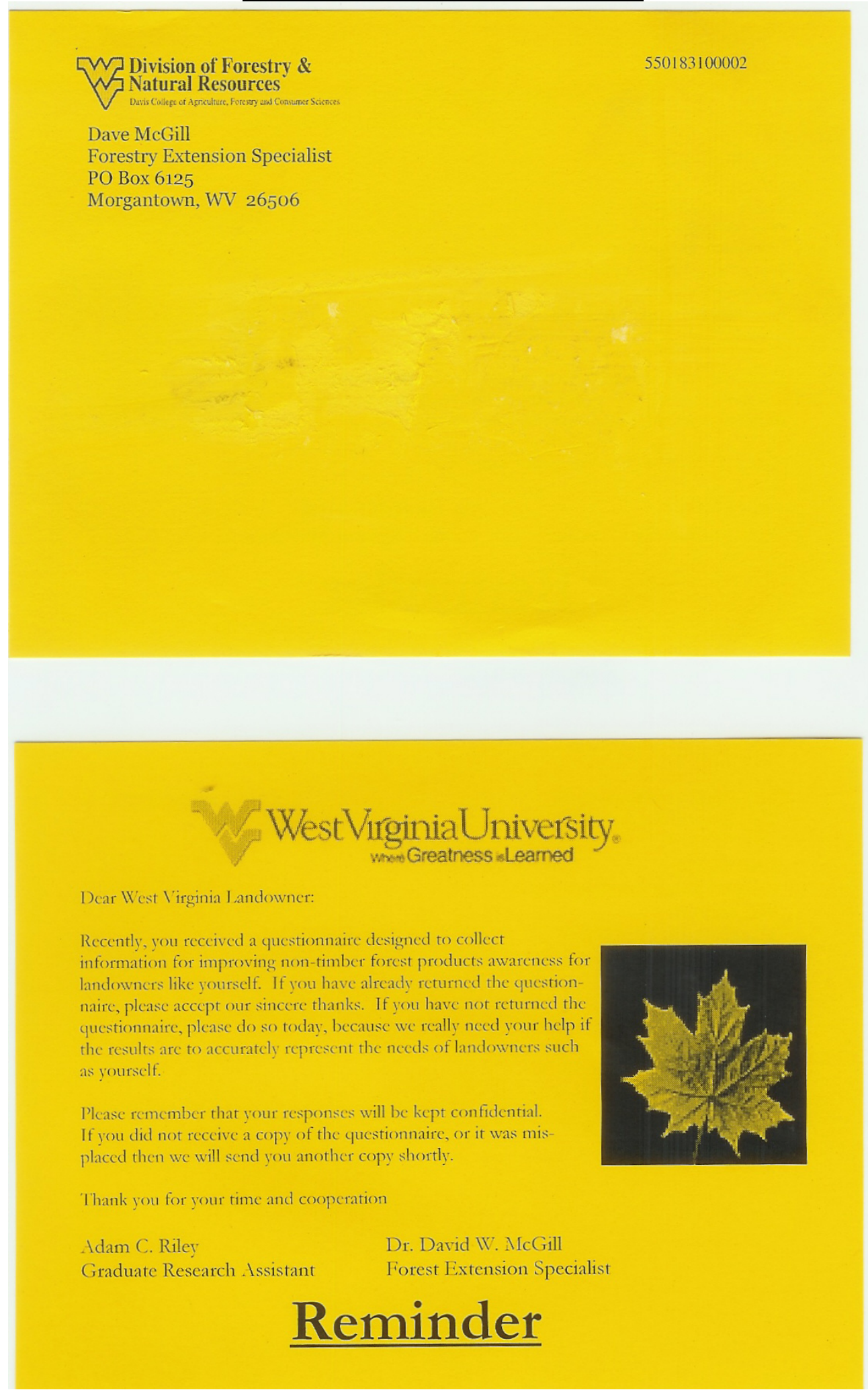




\section{Appendix 16: Cover Letter Follow-up Survey}

\section{WestVırginiaUniversity.}

Davis College of Agriculture, Forestry and Consumer Sciences

Extension Service, Agriculture and Natural Resources

February 27, 2007

Dear West Virginia Landowner,

About a month ago a survey was mailed to you seeking information on non-timber forest products (NTFPs). We have so far received many responses related to the use and production of these products here in West Virginia.

If you have already completed and returned the survey, please accept our sincere thanks. If not, we have enclosed another copy of the survey for you convenience. Again, your participation in this research project is completely voluntary and you do not have to answer all of the questions, but information you provide is vital to the success of the research project. If you do not wish to answer the questionnaire, please let us know by returning the enclosed questionnaire blank or with a note in the self-addressed, stamped envelope.

Again, information you provide is strictly confidential and only summarized results describing the interest in non-timber forest products (for e.g., ginseng and mushrooms). For information regarding your rights as a research subject, you may contact the Office of Research Compliance at 304-293-7073.

If you have any further questions, please feel free to contact us at 304-293-2941 x 2310 . Your contribution to this study is greatly appreciated.

Sincerely,

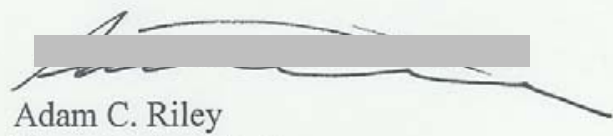

Research Assistant -

Division of Forestry and Natural Resources

Phone: (304) 293-2941 ext 2310

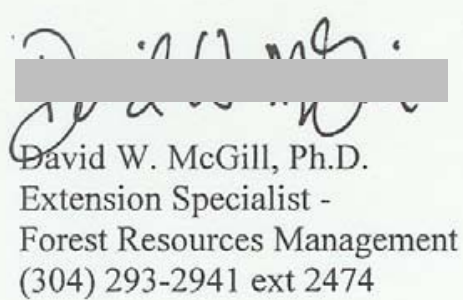

(304) 293-2941 ext 2474 